\title{
Plant stanol esters: focus on intestinal lipoprotein metabolism
}

Citation for published version (APA):

de Smet, E. (2014). Plant stanol esters: focus on intestinal lipoprotein metabolism. [Doctoral Thesis, Maastricht University]. Uitgeverij BOXPress. https://doi.org/10.26481/dis.20140702es

Document status and date:

Published: 01/01/2014

DOI:

10.26481/dis.20140702es

Document Version:

Publisher's PDF, also known as Version of record

\section{Please check the document version of this publication:}

- A submitted manuscript is the version of the article upon submission and before peer-review. There can be important differences between the submitted version and the official published version of record.

People interested in the research are advised to contact the author for the final version of the publication, or visit the DOI to the publisher's website.

- The final author version and the galley proof are versions of the publication after peer review.

- The final published version features the final layout of the paper including the volume, issue and page numbers.

Link to publication

\footnotetext{
General rights rights.

- You may freely distribute the URL identifying the publication in the public portal. please follow below link for the End User Agreement:

www.umlib.nl/taverne-license

Take down policy

If you believe that this document breaches copyright please contact us at:

repository@maastrichtuniversity.nl

providing details and we will investigate your claim.
}

Copyright and moral rights for the publications made accessible in the public portal are retained by the authors and/or other copyright owners and it is a condition of accessing publications that users recognise and abide by the legal requirements associated with these

- Users may download and print one copy of any publication from the public portal for the purpose of private study or research.

- You may not further distribute the material or use it for any profit-making activity or commercial gain

If the publication is distributed under the terms of Article $25 \mathrm{fa}$ of the Dutch Copyright Act, indicated by the "Taverne" license above, 


\section{Plant stanol esters:}

Focus on intestinal lipoprotein metabolism

Els De Smet 


\section{nututim}

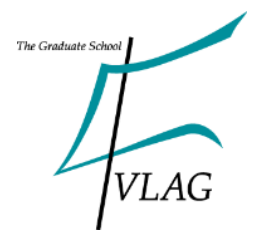

The studies presented in this thesis were performed within NUTRIM, school for Nutrition, Toxicology and Metabolism, which participates in the Graduate School VLAG (Food Technology, Agrobiotechnology, Nutrition and Health Sciences), accredited by the Royal Netherlands Academy of Arts and Sciences.

Cover design: Joris Thys

Cover photo: Nico Kloosterboer

Layout: Els De Smet and Joris Thys

Printed by: Proefschriftmaken.nl || Uitgeverij BOXPress

(C) Copyright Els De Smet, Maastricht 2014

ISBN: 978-90-8891-909-1 


\title{
Plant stanol esters: \\ Focus on intestinal lipoprotein metabolism
}

\author{
PROEFSCHRIFT \\ ter verkrijging van de graad van doctor \\ aan de Universiteit Maastricht \\ op gezag van de Rector Magnificus, \\ Prof. dr. L.L.G. Soete \\ volgens het besluit van het College van Decanen, \\ in het openbaar te verdedigen \\ op woensdag 2 juli 2014 om 10.00 uur
}

door

\section{Els De Smet}

geboren te Bilzen op 16 mei 1986 


\section{Promotores:}

Prof. dr. J. Plat

Prof. dr. ir. R.P. Mensink

\section{Beoordelingscommissie:}

Prof. dr. E.C.M. Mariman (voorzitter)

Prof. dr. E.E. Blaak

Dr. G.M. Dallinga-Thie (Academic Medical Center Amsterdam)

Prof. dr. A.A.M. Masclee

Prof. dr. E.A. Trautwein (Unilever Food and Health Research Institute, Vlaardingen)

Financial support by RAISIO for the publication of this thesis is gratefully acknowledged. 
Contents

$\begin{array}{lll}\text { Chapter } 1 \quad \text { General introduction } & 7\end{array}$

Chapter $2 \quad$ Effects of plant sterols and stanols on intestinal 19 cholesterol metabolism: suggested mechanisms from past to present

Chapter 3 Acute effects of plant stanol esters on hepatic and intestinal lipid and lipoprotein metabolism in mice

Chapter 4 An acute intake of plant stanol esters changes immune related pathways in the jejunum of healthy volunteers

Chapter $5 \quad$ Acute effects of plant stanol esters on postprandial metabolism and its relation with changes in serum lipids after longer-term intake

Chapter 6 The effects of oral amoxicillin on serum lipids and glucose in slightly hypercholesterolemic subjects

Chapter 7 General discussion

Summary

Samenvatting

Appendix Dankwoord

Curriculum Vitae

List of publications

Abbreviations 



\section{CHAPTER 1}

General introduction 


\section{CHAPTER 1}

\section{Introduction}

Cardiovascular diseases (CVD) remain the leading cause of morbidity and mortality worldwide. Important risk factors for the development of CVD are unhealthy dietary habits, tobacco use and physical inactivity. Unhealthy diets may result in dyslipidemia characterized by high serum low-density lipoprotein cholesterol (LDLC) concentrations. Lowering LDL-C concentrations is crucial for the treatment or even the prevention of CVD [1]. A meta-analysis from Baigent et al. [1] showed that there was a risk reduction of non-fatal occlusive vascular events by about one fifth for each $1 \mathrm{mmol} / \mathrm{L}$ reduction in serum LDL-C concentrations 1 year after randomization. More specifically, a decrease in serum LDL-C of 1,2 or $3 \mathrm{mmol} / \mathrm{L}$ lowered the risk by $22 \%, 40 \%$ and $50 \%$, respectively. Relations, however, may depend on genetic background. Ference et al. [2], for example, have demonstrated that persons with the Trp719Arg polymorphism in the kinesin-like protein 6 (KIF6) gene have an even greater increase in the risk of CVD per unit increase in LDL-C, and a correspondingly greater reduction in the risk of CVD per unit decrease in LDL$\mathrm{C}$ as compared to non-carriers. Lowering LDL-C concentrations can be achieved by different means including the consumption of food products enriched with plant sterols or stanols esterified with fatty acids, i.e. plant sterol or stanol esters. These products are called functional foods, which contain one or more functional dietary components, providing positive health effects beyond their traditional nutritional value. A daily intake of $2.5 \mathrm{~g}$ plant sterols/stanols reduces serum LDL-C concentrations up to $10 \%$ [3]. The exact underlying mechanisms of the cholesterollowering activity of plant sterols/stanols are still unknown. However, it is generally accepted that they compete with cholesterol for incorporation into mixed micelles, thereby reducing intestinal cholesterol absorption [4]. Individuals who are characterized as high cholesterol absorbers are more at risk for the development of CVD than individuals who are characterized as high cholesterol synthesizers [5]. In other words, there is an association between high cholesterol absorption and low cholesterol synthesis with an increased severity of CVD [6]. Therefore, it is very interestingly to unravel mechanisms whereby functional foods lower intestinal cholesterol absorption.

\section{Cholesterol metabolism}

Cholesterol is an essential molecule for all vertebrates. It is a structural component of the membrane structure as well as a precursor for the synthesis of steroid hormones, vitamin D and bile acids [7]. Both dietary cholesterol and de novo synthesized cholesterol are transported through the circulation in lipoprotein particles. To maintain whole body cholesterol homeostasis, metabolic adaptations of de novo synthesis and/or catabolism are required in response to fluctuations in dietary intake of cholesterol. The liver plays an important role in cholesterol homeostasis. It is able to synthesize de novo cholesterol and to package lipoproteins with sterols for delivery to peripheral cells. On the other hand, the liver can take up periphery-derived cholesterol from lipoprotein particles followed by excretion via the bile, either after conversion into bile acids or as free cholesterol itself. However, the liver is not the only organ involved in maintaining cholesterol homeostasis. The intestine plays also a crucial role in the synthesis, absorption and removal of cholesterol [8]. Moreover, the gastrointestinal tract is the part of the body containing 
the largest number of microorganisms. It is known from animal studies that gut microbiota affects host metabolism by increased energy extraction and altered lipid metabolism [9]. Thus, the intestine may be a promising target to reduce the risk for CVD. We therefore modified the composition of the gut microbiota using oral amoxicillin to investigate the effects on lipid and glucose metabolism in slightly hypercholesterolemic subjects (chapter 6).

\section{Cholesterol synthesis}

The de novo cholesterol synthesis occurs in many tissues, but the liver and the intestine are considered the major sites of cholesterol synthesis. Cholesterol is synthesized from acetyl-CoA via the mevalonate pathway, which involves a large number of enzymatic steps [10]. The rate-limiting enzyme is 3-hydroxy-3-methylglutaryl-CoA (HMG-CoA) reductase. Expression of this and other enzymes is transcriptionally regulated by the membrane-bound transcription factor sterol regulatory element binding protein (SREBP). SREBPs activate expression of more than 30 genes required for cholesterol, fatty acids, triacylglycerol (TAG) and phospholipid synthesis. In order to reach the nucleus to function as a transcription factor, their $\mathrm{NH}_{2}$-domains must be released. When sterols are scarce, SREBP cleavage-activating protein (SCAP) does not interact with insulin regulated protein (Insig). As a consequence, the SREBP-SCAP complex migrates from the endoplasmatic reticulum to the Golgi apparatus, where it can be cleaved by two proteases. Next, the $\mathrm{NH}_{2}$-domain translocates to the nucleus, where it activates transcription of its target genes. If the cholesterol concentration is high, SREBP is bound to SCAP and Insig, thereby inhibiting translocation and transcription [7]. Three isoforms of SREBP are known. SREBP-1a and SREBP-1c are encoded by a single gene with different transcription start sites. SREBP2 activates cholesterol synthesis and regulates LDLreceptor (LDLr) expression, whereas SREBP-1c is mainly involved in lipogenesis. SREBP-1C is transcriptionally regulated by the liver $X$ receptor (LXR). SREBP-1a is induced in growing cells and acts as a lipid synthetic regulator to cell proliferation. Activation of SREBP-1a depends upon cellular nutritional states and extracellular availability of lipids required for duplication of membranes in cell division [11].

\section{Intestinal cholesterol absorption}

The human intestine deals with relatively large amounts of cholesterol each day. Our normal Western diet provides $400-500 \mathrm{mg}$ of cholesterol per day. $800-1200 \mathrm{mg}$ cholesterol per day enters the intestine via the bile, making biliary cholesterol the most important cholesterol pool for absorption [8]. Biliary cholesterol ends up in the intestine as unesterified cholesterol, whereas $10-15 \%$ of the cholesterol originating from the diet is esterified. It has been suggested that biliary cholesterol is more efficiently absorbed than dietary cholesterol. This can be ascribed to the fact that biliary cholesterol is delivered in mixed micelles, therefore immediately available for absorption, whereas dietary cholesterol must first be transferred into the micellar phase via the oil phase [12] (as reviewed in chapter 2). Intestinal cholesterol absorption is a multistep process that can be controlled at several levels (figure 1). Niemann-Pick C1-like 1 protein (NPC1L1), expressed at the apical membrane of the enterocytes, plays a crucial role in the uptake of cholesterol as well as plant 


\section{CHAPTER 1}

sterols/stanols from the intestinal lumen into the enterocytes [13]. Inside the enterocytes, cholesterol is esterified by Acyl-Coenzyme A cholesterol acyltransferase 2 (ACAT2) [14]. Plant sterols/stanols are poor substrates for ACAT2. After esterification, cholesteryl esters are packaged into chylomicrons and secreted via the lymph thoracic duct into the circulation. The core of a chylomicron consists of TAG and some cholesteryl esters and is surrounded by a phospholipid monolayer, containing unesterified cholesterol and apolipoprotein B48 (apoB48). Cholesterol can also be packaged into nascent high-density lipoprotein (HDL) particles, which are formed by the interaction of apolipoprotein A-I (apoA-I) with the adenosinethriphosphate (ATP)-binding cassette transporter A1 (ABCA1) [15]. Unesterified cholesterol and plant sterols/stanols are excreted from the enterocytes back into the intestinal lumen via ABCG5 and ABCG8 [16]. These three ABC transporters are also highly expressed in the liver. Their expression is regulated via the liver $X$ receptor (LXR), a member of the nuclear receptor family of transcription factors. Two isotypes have been identified in mammals. LXR is predominantly expressed in the liver, intestine and adipose tissue, whereas LXR $\beta$ has a more ubiquitous expression pattern [17]. Endogenous ligands are oxysterols [18], but it has also been suggested that plant stanols can act as a LXR ligand [19], either directly or after conversion into a yet unknown metabolite. Activation of LXRa induces transcription of its target genes, resulting in elevated levels of HDL-C, increased hepatobiliary cholesterol secretion, reduced intestinal cholesterol absorption and increased neutral sterol loss via the faeces. However, systemic stimulation of LXRa leads to increased lipogenesis, hypertriglyceridemia through production of larger very low-density lipoprotein (VLDL) particles and hepatic steatosis [20]. Thus, activating LXRa as anti-atherogenic therapy can only be used as the undesirable effects on lipogenesis can be eliminated.

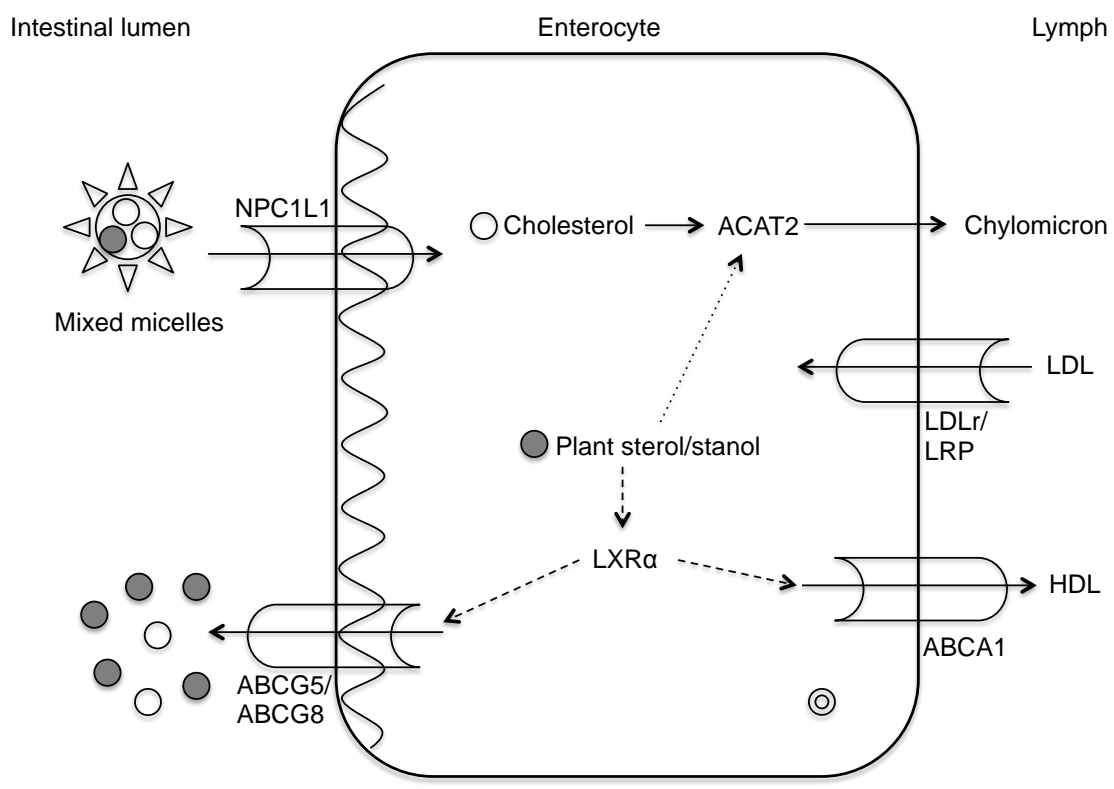

Figure 1: An overview of the transporters involved in intestinal cholesterol absorption. 
We designed two studies to investigate the acute effects of plant stanol esters on the expression profile of genes involved in lipid metabolism. In our first study (chapter 3), we examined the kinetics of plant sterols/stanols in the serum, liver and intestine of $\mathrm{C} 57 \mathrm{BI} / 6 \mathrm{~J}$ mice. Furthermore, we investigated the acute effects of plant stanol esters on the expression profile of genes in the intestine and the liver. Next, the acute effects of plant stanol esters were again examined, but now in intestinal biopsies taken from healthy subjects (chapter 4).

\section{Enterohepatic circulation}

Bile acids are required for the formation of mixed micelles, a necessary step for the solubilisation of dietary lipids. The liver secretes between 12 and $36 \mathrm{~g}$ of bile acids in a day, depending on the number of meals and the amount of fat in these meals. However, the liver's rate of bile acids synthesis from cholesterol is $600 \mathrm{mg} /$ day, sufficient to replace the equivalent losses in the faeces. Therefore, there exists a recycling mechanism for bile acids from the intestine to the liver via the portal vein, which is known as the enterohepatic circulation (figure 2). Several transporter proteins are involved in this process. In the hepatocytes, three $A B C$ transporter proteins; i.e. ABC subfamily B member 4 (ABCB4), ABCB1 and ABCG5/G8 export respectively, phospholipids, bile acids and cholesterol into the bile [21]. On the apical side of the enterocytes from the ileum, the ileal apical bile acid transporter (IBAT) import bile and dietary lipids into the enterocytes. The bile acids are bound to the cytoplasmic intestinal bile acid-binding protein (I-BABP) and are exported into the portal vein. Finally, they are taken up by the hepatocytes via sodium taurocholate cotransporting polypeptide (NTCP), a $\mathrm{Na}^{+}$-linked symporter [22].

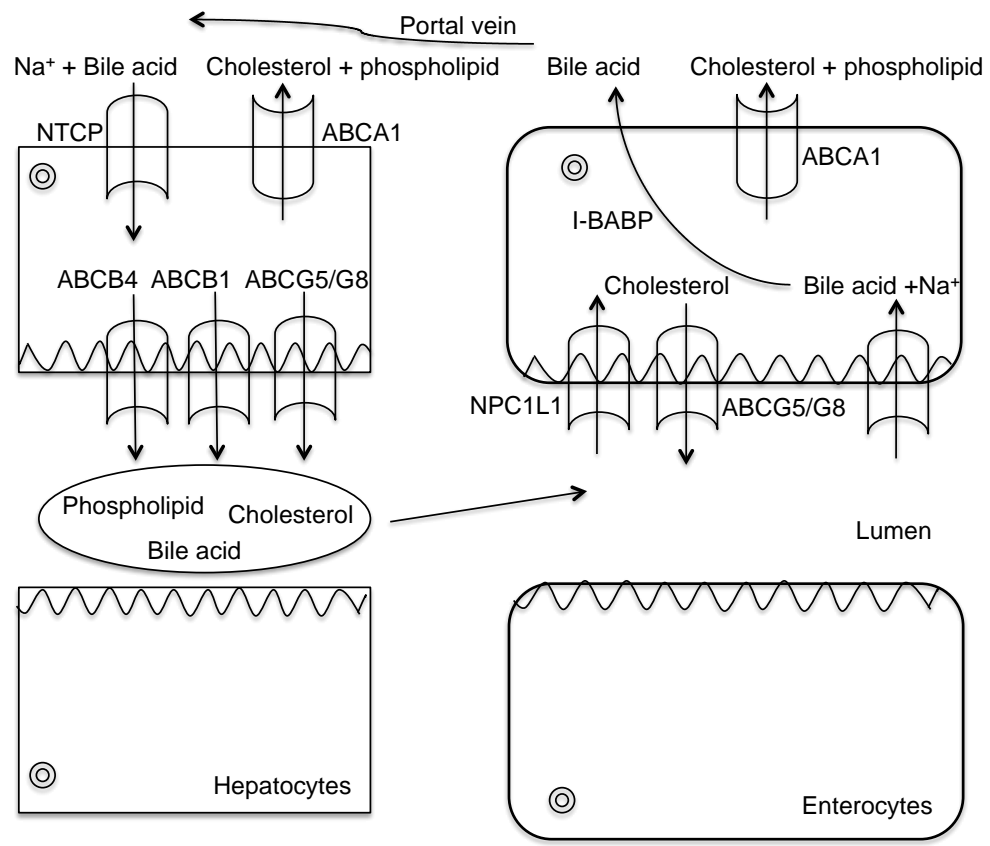

Figure 2: Transporter proteins involved in the enterohepatic circulation. 


\section{CHAPTER 1}

Relation between cholesterol synthesis and cholesterol absorption

Cholesterol synthesis, absorption and efflux are the mechanisms involved in maintaining cholesterol homeostasis (figure 3). Their activation is regulated via the amount of sterols presented in the different tissues. If the intracellular cholesterol concentration is low, the SREBP2 pathway will become activated, resulting in increased cholesterol synthesis, whereas LXRa will be downregulated, leading to a decrease in cholesterol efflux. In case of high intracellular cholesterol concentrations, SREBP2 becomes inactivated and LXRa activated to prevent further accumulation of cellular cholesterol via expression of its target genes. There are natural, such as desmosterol and 24(S), 25-epoxocholesterol, as well as synthetic LXRa agonists. Plasma levels of several non-cholesterol sterols are indicators of changes in cholesterol metabolism and are therefore used as surrogated markers of cholesterol related processes. Serum concentrations of lathosterol and desmosterol, two cholesterol precursors, are positively correlated to endogenous cholesterol synthesis and serum VLDL cholesterol (VLDL-C), and inversely related to dietary cholesterol absorption and serum HDL-C. Serum levels of campesterol and sitosterol, reflecting cholesterol absorption, are positively related to the absorption of cholesterol and serum HDL-C concentrations. These plant sterols are negatively correlated to cholesterol synthesis and serum concentrations of VLDL-C [23]. The surrogate markers for both cholesterol synthesis and absorption are used to investigate cholesterol metabolism in intervention studies. There exists reciprocity between cholesterol synthesis and cholesterol absorption in healthy subjects, but this connection may become dysfunctional in diseased populations [24]. 
Acetyl-CoA

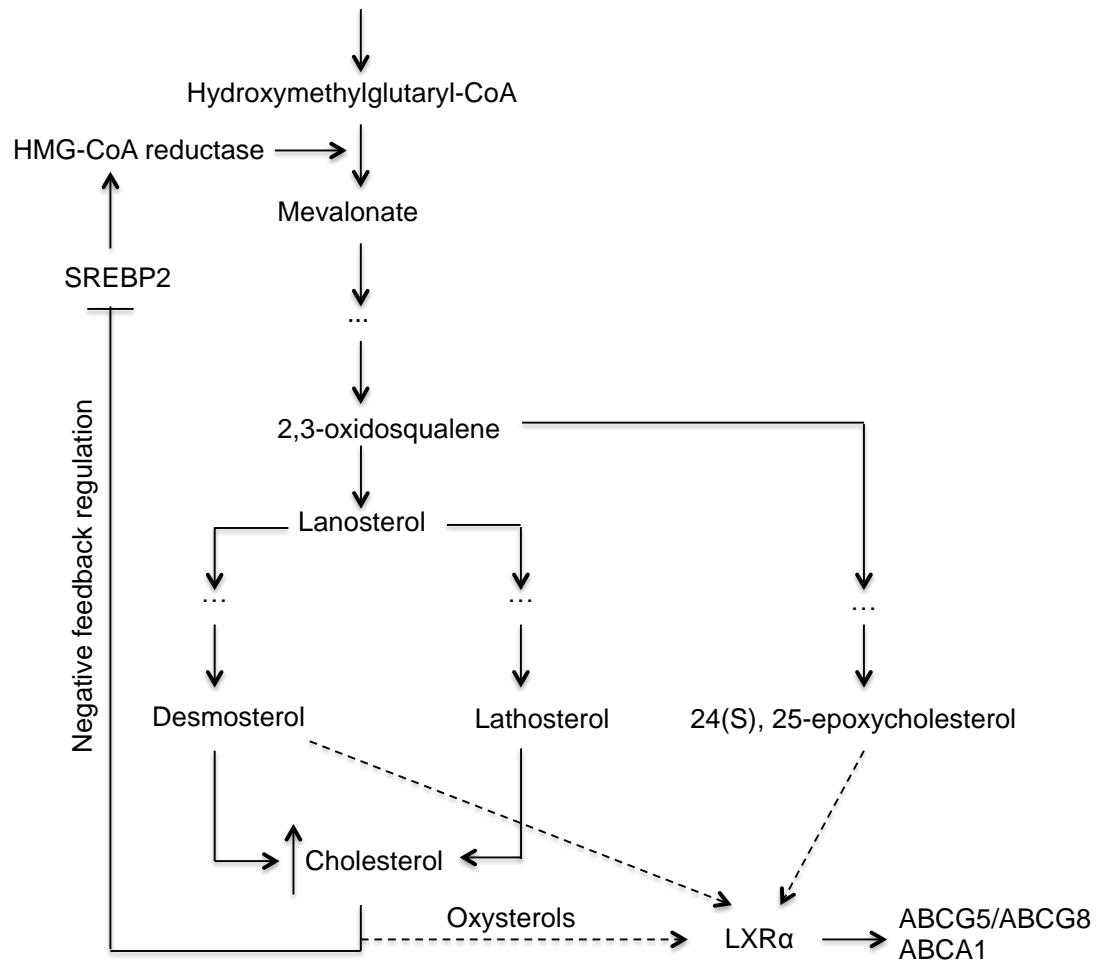

Figure 3: Mechanisms involved in maintaining cholesterol homeostasis.

\section{Lipoproteins involved in cholesterol transport}

The main lipids in lipoproteins are TAG and free and esterified cholesterol. Hydrolysed dietary fat is packaged together with cholesteryl esters and apoB48 into chylomicrons by microsomal triglyceride-transfer protein (MTTP). In the circulation, $\mathrm{HDL}$ particles donate apoC-II and apoE, resulting in a mature chylomicron. Lipoprotein lipase (LPL), an enzyme on endothelial cells lining the blood vessels becomes activated via apoC-II. It catalyses the hydrolysis of TAG in glycerol and free fatty acids, which are absorbed in adipose tissue and muscle for energy and storage, respectively. The smaller, TAG-depleted and relatively cholesteryl esterenriched chylomicron remnants are taken up by the hepatic LDLr via apoB or the LDL receptor-related protein (LRP) via apoE. TAG, free and esterified cholesterol and phospholipids are assembled with apoB100 to form VLDL particles. Again, apoC-II and apoE of VLDL particles are acquired from HDL particles. The VLDLTAG are lipolysed by LPL, thereby decreasing particle size and increasing the density and relative cholesterol concentration. This VLDL remnant is called intermediate-density lipoprotein (IDL) and can be absorbed by the liver or hydrolysed by hepatic lipase $(\mathrm{HL})$, thereby yielding $\mathrm{LDL}$, which transports cholesterol from the liver to the periphery. Both VLDL and LDL particles can be cleared from the circulation via the LDLr/LRP. Part of the LDL that is not rapidly cleared by the liver, 


\section{CHAPTER 1}

may undergo oxidation. These pro-atherogenic particles can be taken up by the macrophages in the vessel wall, resulting in the formation of foam cells, which are involved in the development of atherosclerosis [25, 26]. Proprotein convertase subtilisin/kexin type 9 (PCSK9) can bind to the epidermal growth factor-like repeat A domain of the LDLr, inducing LDLr degradation. Reduced LDLr expression could lead to hypercholesterolemia [27]. Blocking PCSK9, thereby increasing the number of available LDLr seems to be an attractive goal to lower LDL-C concentrations [28, 29]. It could be speculated that a combination of consuming plant stanols and using an antibody against PCSK9 might act additive, resulting in a much higher reduction of LDL-C. Finally, HDL mediates reverse cholesterol transport (RCT) by interacting with $A B C A 1$ and $A B C G 1$ on non-hepatic cells. In peripheral cells, intestine and liver, nascent pre- $\beta$ HDL particles are formed by lipidating lipid-poor apoA-I. After esterification of free cholesterol from the periphery by lecithin:cholesterol acyltransferase (LCAT), mature HDL particles are formed. They enter the hepatocytes via scavenger receptor class $B$ type 1 (SRB1). In mammals, another route for uptake of HDL-C by the liver is via VLDL/LDL. In exchange for TAG, cholesterol esters from HDL can be transferred to apoB-containing lipoproteins by cholesterol ester transfer protein (CETP) [30] (figure 4).

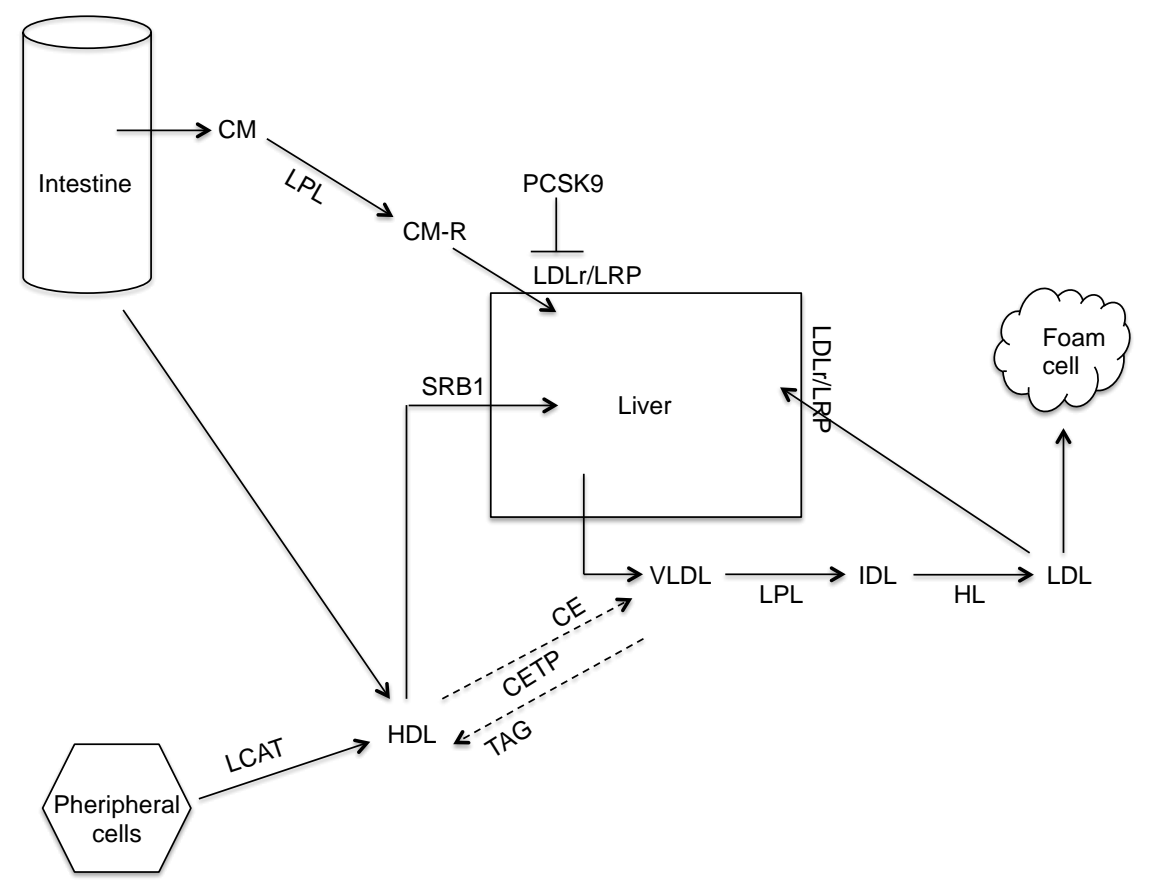

Figure 4: A schematic overview of the lipoprotein metabolism.

In chapter 5, the results are discussed from a randomized, crossover human study in which we investigated the acute as well as semi-long term effects of plant stanol esters on lipid metabolism and the lipoprotein profile. 


\section{Cholesterol excretion}

Hepatobiliary cholesterol secretion or RCT was considered to be the most substantial route for cholesterol excretion from the body. It is the HDL-mediated transport of excess cholesterol from the periphery to the liver, followed by secretion into bile via ABCG5/ABCG8 and subsequent disposal via the faeces. However, RCT cannot be the only route for cholesterol excretion. Low levels of faecal neutral sterol loss could not be observed in ABCG5/ABCG8 double knockout mice, which have very low biliary cholesterol secretion rates [31]. Faecal sterol loss was not affected in mice deficient in ABCB4 (Mdr2), the ABC-transporter involved in biliary phospholipid secretion [32]. Furthermore, faecal sterol loss was not decreased in ABCA $1 \%$ mice [33]. These findings indicated that there must be another pathway for cholesterol excretion, at least in mouse models with disturbed hepatobiliary cholesterol secretion. This direct secretion of plasma cholesterol in the faeces via the intestine is known as transintestinal cholesterol excretion (TICE) [34].

\section{OUTLINE OF THE THESIS}

In this thesis, we will focus on the underlying mechanisms of the cholesterol-lowering activity of plant stanol esters. After a chronological overview of the different paradigms explaining the reduction in intestinal cholesterol absorption by plant sterol and stanol esters in chapter 2, we investigated in chapter 3 the kinetics of plant sterol/stanol distribution in mice. Furthermore, changes in the expression profile of intestinal and hepatic genes involved in sterol metabolism were examined after an acute bolus of plant stanol esters in mice. Chapter 4 was designed to examine the acute effects of plant stanol esters on intestinal mucosal gene expression profiles in healthy, normolipidemic subjects. The acute, postprandial and semi-long term effects of plant stanol esters on glucose, lipid metabolism and lipoprotein profiles are discussed in chapter 5. Finally, changes in lipid and glucose metabolism were investigated in slightly hypercholesterolemic subjects after changing the gut microbiota composition using oral amoxicillin (chapter 6). 


\section{CHAPTER 1}

\section{References}

1. Cholesterol Treatment Trialists, Baigent C., et al., Efficacy and safety of more intensive lowering of LDL cholesterol: a meta-analysis of data from 170,000 participants in 26 randomised trials. Lancet, 2010. 376(9753): p. 1670-81.

2. Ference, B.A., et al., A common KIF6 polymorphism increases vulnerability to low-density lipoprotein cholesterol: two meta-analyses and a meta-regression analysis. PLoS One, 2011. 6(12): p. e28834.

3. Katan, M.B., et al., Efficacy and safety of plant stanols and sterols in the management of blood cholesterol levels. Mayo Clin Proc, 2003. 78(8): p. 965-78.

4. Heinemann, T., et al., Mechanisms of action of plant sterols on inhibition of cholesterol absorption. Comparison of sitosterol and sitostanol. Eur J Clin Pharmacol, 1991. 40 Suppl 1: p. S59-63.

5. Weingartner, O., et al., Relationship between cholesterol synthesis and intestinal absorption is associated with cardiovascular risk. Atherosclerosis, 2010. 210(2): p. 362-5.

6. Silbernagel, G., et al., The relationships of cholesterol metabolism and plasma plant sterols with the severity of coronary artery disease. J Lipid Res, 2009. 50(2): p. 334-41.

7. Maxfield, F.R. and I. Tabas, Role of cholesterol and lipid organization in disease. Nature, 2005. 438(7068): p. 612-21.

8. Grundy, S.M., Absorption and metabolism of dietary cholesterol. Annu Rev Nutr, 1983. 3: p. 71-96.

9. Velagapudi, V.R., et al., The gut microbiota modulates host energy and lipid metabolism in mice. J Lipid Res, 2010. 51(5): p. 1101-12.

10. Goldstein, J.L. and M.S. Brown, Regulation of the mevalonate pathway. Nature, 1990. 343(6257): p. 425-30.

11. Shimomura, I., et al., Differential expression of exons $1 \mathrm{a}$ and 1c in mRNAs for sterol regulatory element binding protein-1 in human and mouse organs and cultured cells. J Clin Invest, 1997. 99(5): p. 838-45.

12. Sklan, D., P. Budowski, and S. Hurwitz, Effect of soy sterols on intestinal absorption and secretion of cholesterol and bile acids in the chick. J Nutr, 1974. 104(8): p. 1086-90.

13. Davis, H.R., Jr. and S.W. Altmann, Niemann-Pick C1 Like 1 (NPC1L1) an intestinal sterol transporter. Biochim Biophys Acta, 2009. 1791(7): p. 679-83.

14. Nguyen, T.M., et al., ACAT2 and ABCG5/G8 are both required for efficient cholesterol absorption in mice: evidence from thoracic lymph duct cannulation. J Lipid Res, 2012. 53(8): p. 1598-609.

15. Ohama, T., et al., Dominant expression of ATP-binding cassette transporter-1 on basolateral surface of Caco-2 cells stimulated by LXR/RXR ligands. Biochem Biophys Res Commun, 2002. 296(3): p. 625-30.

16. Lee, M.H., et al., Identification of a gene, ABCG5, important in the regulation of dietary cholesterol absorption. Nat Genet, 2001. 27(1): p. 79-83.

17. Willy, P.J., et al., $L X R$, a nuclear receptor that defines a distinct retinoid response pathway. Genes Dev, 1995. 9(9): p. 1033-45.

18. Janowski, B.A., et al., An oxysterol signalling pathway mediated by the nuclear receptor $L X R$ alpha. Nature, 1996. 383(6602): p. 728-31.

19. Plat, J., J.A. Nichols, and R.P. Mensink, Plant sterols and stanols: effects on mixed micellar composition and LXR (target gene) activation. J Lipid Res, 2005. 46(11): p. 2468-76.

20. Kannisto, K., et al., LXR Driven Induction of HDL-Cholesterol is Independent of Intestinal Cholesterol Absorption and ABCA1 Protein Expression. Lipids, 2013.

21. Cuperus, F.J., et al., The Role of Canalicular ABC Transporters in Cholestasis. Drug Metab Dispos, 2014. 42(4): p. 546-60.

22. Halilbasic, E., T. Claudel, and M. Trauner, Bile acid transporters and regulatory nuclear receptors in the liver and beyond. J Hepatol, 2013. 58(1): p. 155-68.

23. Miettinen, T.A., R.S. Tilvis, and Y.A. Kesaniemi, Serum plant sterols and cholesterol precursors reflect cholesterol absorption and synthesis in volunteers of a randomly selected male population. Am J Epidemiol, 1990. 131(1): p. 20-31.

24. Miettinen, T.A., H. Gylling, and M.J. Nissinen, The role of serum non-cholesterol sterols as surrogate markers of absolute cholesterol synthesis and absorption. Nutr Metab Cardiovasc Dis, 2011. 21(10): p. 765-9.

25. Brown, M.S. and J.L. Goldstein, A receptor-mediated pathway for cholesterol homeostasis. Science, 1986. 232(4746): p. 34-47. 


\section{GENERAL INTRODUCTION}

26. Shelness, G.S. and J.A. Sellers, Very-low-density lipoprotein assembly and secretion. Curr Opin Lipidol, 2001. 12(2): p. 151-7.

27. Norata, G.D., G. Tibolla, and A.L. Catapano, Targeting PCSK9 for Hypercholesterolemia. Annu Rev Pharmacol Toxicol, 2013.

28. Chan, J.C., et al., A proprotein convertase subtilisin/kexin type 9 neutralizing antibody reduces serum cholesterol in mice and nonhuman primates. Proc Natl Acad Sci U S A, 2009. 106(24): p. $9820-5$.

29. Stein, E.A., et al., Effect of the proprotein convertase subtilisin/kexin 9 monoclonal antibody, AMG 145, in homozygous familial hypercholesterolemia. Circulation, 2013. 128(19): p. 211320.

30. Timmins, J.M., et al., Targeted inactivation of hepatic Abca1 causes profound hypoalphalipoproteinemia and kidney hypercatabolism of apoA-I. J Clin Invest, 2005. 115(5): p. 1333-42.

31. Yu, L., et al., Disruption of Abcg5 and Abcg8 in mice reveals their crucial role in biliary cholesterol secretion. Proc Natl Acad Sci U S A, 2002. 99(25): p. 16237-42.

32. Smit, J.J., et al., Homozygous disruption of the murine mdr2 P-glycoprotein gene leads to a complete absence of phospholipid from bile and to liver disease. Cell, 1993. 75(3): p. 451-62.

33. Groen, A.K., et al., Hepatobiliary cholesterol transport is not impaired in Abca1-null mice lacking HDL. J Clin Invest, 2001. 108(6): p. 843-50.

34. van der Velde, A.E., et al., Regulation of direct transintestinal cholesterol excretion in mice. Am J Physiol Gastrointest Liver Physiol, 2008. 295(1): p. G203-G208. 



\section{CHAPTER 2}

Effects of plant sterols and stanols on intestinal cholesterol metabolism: suggested mechanisms from past to present

Els De Smet, Ronald P. Mensink and Jogchum Plat

Mol Nutr Food Res. 2012;56(7):1058-72 


\section{CHAPTER 2}

\section{Abstract}

Plant sterols and stanols are natural food ingredients found in plants. It was already shown in 1950 that they lower serum low-density lipoprotein cholesterol (LDL-C) concentrations. Meta-analyses have reported that a daily intake of $2.5 \mathrm{~g}$ plant sterols/stanols reduced serum LDL-C concentrations up to $10 \%$. Despite many studies, the underlying mechanism remains to be elucidated. Therefore, the proposed mechanisms that have been presented over the past decades will be described and discussed in the context of the current knowledge. In the early days, it was suggested that plant sterols/stanols compete with intestinal cholesterol for incorporation into mixed micelles as well as into chylomicrons. Next, the focus shifted towards cellular processes. In particular a role for sterol transporters localized in the membranes of enterocytes was suggested. All these processes ultimately lowered intestinal cholesterol absorption. More recently, the existence of a direct secretion of cholesterol from the circulation into the intestinal lumen was described. First results in animal studies suggested that plant sterols/stanols activate this pathway, which also explains the increased faecal neutral sterol content and as such could explain the cholesterol-lowering activity of plant sterols/stanols. 


\section{Introduction}

Cardiovascular diseases (CVD) are the leading cause of morbidity and mortality worldwide. It is well established that lifestyle - and particularly our diet - plays an important role in the prevention and treatment of CVD [1]. A major target for dietary interventions is reducing the increased serum low-density lipoprotein cholesterol (LDL-C) concentrations [2-3]. A meta-analysis, summarizing the results of 26 clinical trials of cholesterol-lowering agents clearly showed a risk reduction of non-fatal occlusive vascular events by about one fifth for each $1 \mathrm{mmol} / \mathrm{L}$ reduction in serum LDL-C concentration 1 year after randomization. More specifically, a serum LDL-C reduction of 1,2 or $3 \mathrm{mmol} / \mathrm{L}$ lowered the risk by $22 \%, 40 \%$ and $50 \%$, respectively [4]. Despite these impressive risk reductions, there is still an ongoing discussion whether these effects are causally related to the reduction in LDL-C concentrations. It is even questioned whether the cardio-protective effects of statins are causally related to their serum LDL-C lowering effects or rather to their pleiotropic effects, such as improving endothelial function, increasing vascular nitric oxide bioavailability, and reducing oxidative stress [5]. In this respect, La Rosa et al. [6] clearly showed that it is not important how LDL-C is lowered. Combining the results of all the currently available intervention studies, showed that lowering serum LDL$\mathrm{C}$ to decrease the risk for a non-fatal myocardial infarct and coronary heart disease death by diet is as valuable as lowering serum LDL-C by for example statins and 3hydroxy-3-methyl-glutaryl-CoA (HMG-CoA) reductase inhibitors. Foods enriched with fatty acid esters of plant sterols or stanols, i.e. plant sterol or stanol esters are well known for their serum LDL-C lowering effect [7, 8], which is not transient, as shown in an 85 weeks intervention study [9]. The effectiveness of these compounds is further supported by the fact that they are nowadays incorporated into national and international guidelines such as the National Cholesterol Education Program guidelines. These guidelines encourage a daily incorporation of $2 \mathrm{~g}$ plant sterols or stanols into a healthy diet low in saturated fatty acids to reduce CVD risk for subjects with elevated LDL-C concentrations. In this case, addition of plant sterols and stanols can lower serum LDL-C concentrations up to 10\% [2]. Plant sterols and stanols are components that are naturally present in plants. Like cholesterol, they exist mainly in a free and an esterified form. When incorporated as functional food ingredient, plant sterols and stanols are frequently esterified with a fatty acid ester to increase the solubility in the food matrix [10]. The rate of absorption of cholesterol and plant sterols/stanols is very different. About $40-60 \%$ of cholesterol is absorbed, whereas plant sterols/stanols are absorbed for $15 \%$ or less, depending on the specific isoform [11-13]. Four meta-analyses have shown significant reductions in LDL-C concentrations after consumption of foods enriched with plant sterol or stanol esters [7, 14-16]. In contrast with these 4 non-linear dose-response curves, Mensink et al. [17] found a clear linear relationship between plant stanol intake and reductions in LDL-C up to $9 \mathrm{~g} / \mathrm{d}$. Compared with the control group, the reductions in serum LDL$\mathrm{C}$ concentrations after a daily consumption of 3,6 and $9 \mathrm{~g}$ were $7.5 \%, 12 \%$ and $17.4 \%$, respectively. Comparable findings were reported by Gylling and colleagues [18], in which a $17.4 \%$ reduction in serum LDL-C was found after a daily consumption of $8.8 \mathrm{~g}$ plant stanols provided as their fatty acid esters for a period of 10 weeks. In this respect, the most recent meta-analysis from Musa-Veloso et al. [8] suggested that consumption of plant stanols above the currently recommended $2 \mathrm{~g} / \mathrm{d}$ is associated with an additional and dose-dependent reduction in serum LDL-C 


\section{CHAPTER 2}

concentrations. They included 113 publications and 1 unpublished study report and found that the maximal reduction in LDL-C was $16.4 \%$ after plant stanol and $8.3 \%$ after plant sterol consumption at daily doses ranging from $0.8-8.8 \mathrm{~g}$ and $0.19-9$ $\mathrm{g}$, respectively. Remarkably, there are no studies comparing the LDL-C lowering activity of high doses ( $>4 \mathrm{~g} / \mathrm{d}$ ) of plant stanols and sterols head-to-head. However, such a clinical trail is needed to further explore the efficacy and possible differences between plant sterols and stanols at higher intakes.

Although the LDL-C lowering effect of food enriched with plant sterol and stanol esters is sustained and widely accepted, the discussion whether the type of food (food matrix) influences its efficacy is still ongoing [7, 16]. Besides the type of food carrier used, the frequency of intake seems to be important as well [7, 19]. Furthermore, Abumweis et al. [16] concluded that the time of intake is also crucial, since consumption before or with breakfast only failed to reduce serum LDL-C, while the expected serum LDL-C lowering effect was observed when plant sterols were consumed together with a main meal being either lunch or dinner.

To better understand all these discrepancies between the individual studies, understanding the effects of plant sterol/stanol esters on (intestinal) cholesterol metabolism is essential. Therefore, the main objective of this review is to focus on past and recent findings, and on assumptions and more or less accepted explanations of the mechanisms underlying the plant sterol/stanol ester induced serum LDL-C-lowering effect. For this, we will provide an historical overview of these compounds, starting in the 1950s until now. Based on these findings we will try to conclude whether we can predict their use to reduce atherosclerotic lesion formation.

\section{Suggested mechanisms over the years}

Inhibition of intestinal cholesterol absorption is an interesting target to lower concentrations of LDL-C and other apoB100 containing lipoprotein fractions. Cholesterol absorption is a multistep process, in which the most important steps are: (1) cleavage of (dietary) sterol/stanol esters into free sterols/stanols in the intestinal lumen, (2) the solubilization of unesterified cholesterol into the emulsified fat phase and the mixed micelles in the lumen, (3) the transport of cholesterol through mucosal barriers such as the unstirred water layer and the brush border membrane. After (4) uptake and (5) (re)esterification by acylcoenzyme A cholesterol acyltransferase 2 (ACAT2) inside the enterocyte, cholesterol is (6) incorporated into chylomicrons by involvement of the microsomal triglyceride transfer protein (MTP) and (7) released into the lymph. Over the years, almost every single step has been discussed for its potential involvement in lowering intestinal cholesterol absorption via plant sterol or stanol ester consumption. We will now recapitulate the chronology of the different paradigms in explaining the reduction in intestinal cholesterol absorption by plant sterol and stanol esters. 


\section{The early days}

The very first studies, mentioning a role for plant sterols in the regulation of serum cholesterol concentrations were published by Peterson et al. [20] in 1951. Chickens were fed a diet containing $0.5-1 \%$ soybean sterols, $0.5-1 \%$ cholesterol or a mixture of both compounds. Significant reductions in hepatic and plasma cholesterol concentrations were found in chickens fed a diet supplemented with the soybean sterols. In the following studies [21], again in chickens, the effects of plant sterols on atherosclerotic lesion formation were evaluated. The extent and severity of the lesions decreased after administration of soybean sterols in cholesterol-fed chickens. The observation that soybean sterols lowered the serum cholesterol concentration was confirmed in other species by Pollak and coworkers. For this, rabbits were fed a diet with cholesterol, sitosterol or a mixture of both in different proportions. Clear inhibition of hypercholesterolemia and prevention of atherosclerosis was achieved by feeding the proper amount of plant sterols. In rabbits, sixfold excess of sitosterol over cholesterol was needed, whereas threefold excess was effective in chickens [21, 22]. Already in these early days, the hypocholesterolemic effect of plant sterols was confirmed in patients [23]. However, the underlying mechanism was completely unknown, but was thought to be related to effects on intestinal cholesterol absorption (table 1, figure 1A) [22, 23]. 
CHAPTER 2

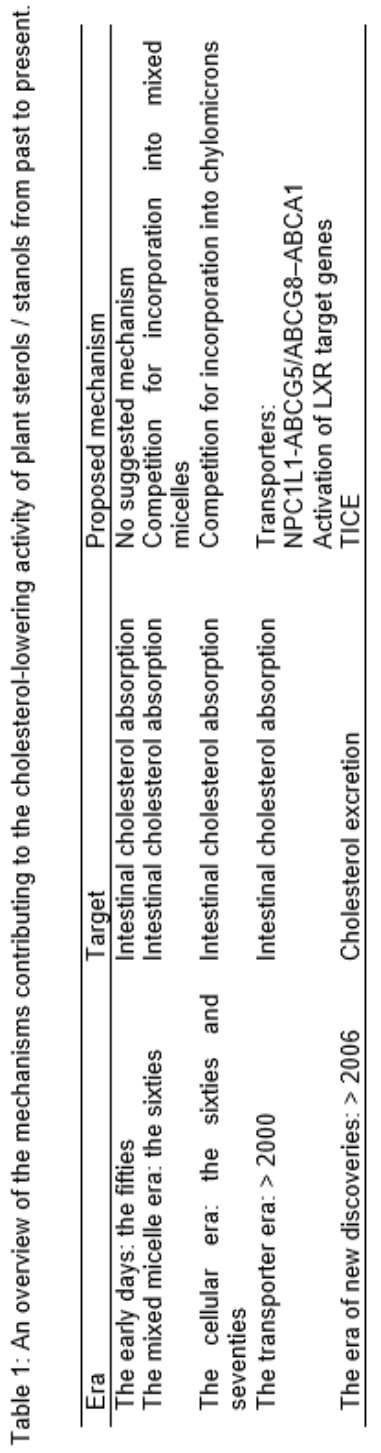




\section{EFFECTS ON INTESTINAL CHOLESTEROL METABOLISM}
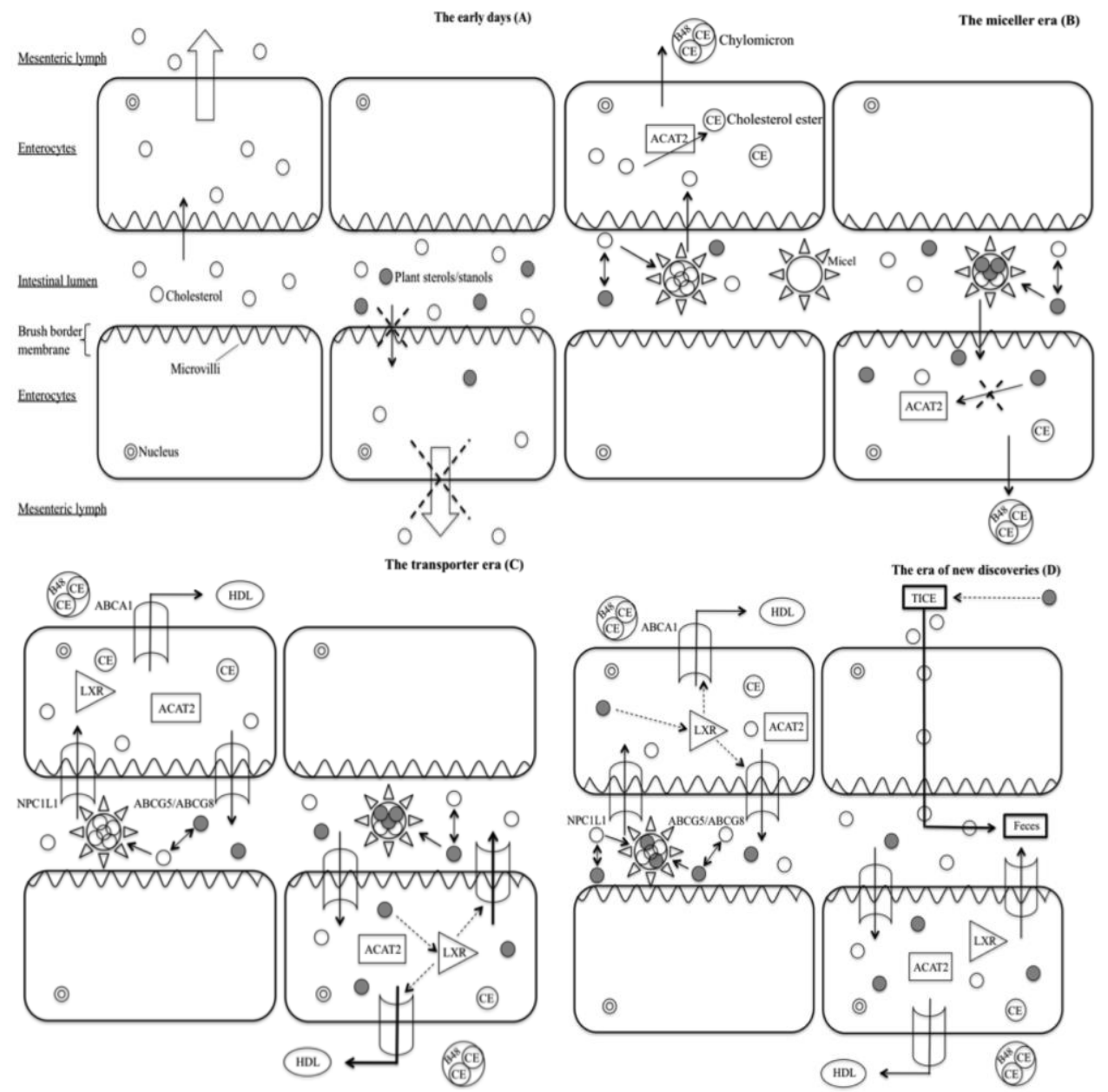

Figure 1: An overview of the paradigms explaining the cholesterol-lowering activity of plant sterols and stanols over the past decades.

(A) The early days: Cholesterol, plant sterols and stanols are taken up into the enterocyte. It was already suggested in 1951 that plant sterols suppress intestinal cholesterol absorption, resulting in decreased serum cholesterol concentrations. (B) The micellar era: There is a competition between cholesterol and plant sterols/stanols for incorporation into mixed micelles, which is a crucial step for cholesterol absorption. If plant sterols/stanols replace micellar cholesterol, less cholesterol will be taken up into the enterocyte. After uptake, cholesterol is normally esterified by intestinal ACAT2. The so-formed cholesteryl esters are incorporated into chylomicrons and secreted into the lymph. In contrast, plant sterols/stanols are poor substrates for ACAT2 and remain in their free form inside the enterocyte. (C) The transporter era: Different sterol transporters like ABCG5/ABCG8 and NPC1L1 and their regulatory mechanisms are discovered. It is questioned whether plant sterols and stanols interact with intracellular cholesterol sensors like LXR, leading to an increased expression of ABCG5/ABCG8 and ABCA1. The latter transports sterols to a nascent HDL particle, whereas ABCG5/ABCG8 promotes the efflux of sterols back into the intestinal lumen, resulting in decreased cholesterol absorption. At the same time, possible regulation of NPC1L1 by plant sterols/stanols is proposed. (D) The era of new discoveries: Recently, transintestinal cholesterol excretion (TICE) has been suggested as a possible target for the plant sterol/stanol mediated cholesterol-lowering effect. Stimulation of TICE increases faecal neutral sterol loss. However, further research is needed to explore the effects of the plant sterols/stanols on the intestinal cholesterol absorption into more detail. For example, the transporters responsible for 


\section{CHAPTER 2}

basolateral and apical cholesterol secretion need to be identified. It is also debated whether TICE alone or possibly together with other mechanisms described in panels $B$ and $C$ explain the full cholesterollowering effect of plant sterols and stanols.

\section{The mixed micelle era}

Intestinal luminal cholesterol consists of two distinct pools derived from respectively endogenous and exogenous cholesterol. The contribution of these two pools to the amounts of cholesterol available for uptake and consequent appearance in serum is not equal. Sklan et al. [24] showed in chickens that endogenous cholesterol is more rapidly and more completely absorbed as compared to exogenous cholesterol. When chickens were fed a cholesterol-free, low fat diet, the duodenum and the upper part of the jejunum are the main sites of cholesterol absorption. Addition of cholesterol into the diet resulted in a distal shift of the predominant site of cholesterol absorption towards the jejunum. Moreover, this shift was accompanied by an increased secretion of endogenous cholesterol as well as bile acids into the duodenum [25]. In contrast to endogenous cholesterol, which is mainly secreted through the bile already in micelles, dietary cholesterol must first be cleaved by specific esterases. Dietary cholesterol is predominantly present in its esterified form and only free cholesterol is incorporated into the mixed micelles to become available for absorption [24]. Altogether, these findings may contribute to the preferential absorption of endogenous over exogenous cholesterol.

The question is how plant sterol and stanol esters interfere with intestinal cholesterol uptake and whether there is a difference between the effects of plant sterols and stanols on endogenous and exogenous cholesterol absorption. As cholesterol and plant sterols/stanols are practically water-insoluble, they have to be solubilied into micelles before absorption can occur. However, the capacity of micelles to solubilise lipophylic water-insoluble molecules is limited. During the sixties of the previous century [26], it became more or less generally accepted that plant sterols and stanols competed with dietary cholesterol for incorporation into mixed micelles (figure 1B). As plant sterols/stanols are more hydrophobic than cholesterol, it was speculated that they displaced cholesterol from the mixed micelles [27] or in other words, plant sterols/stanols lowered the solubility of cholesterol within the mixed micelles $[28,29]$. More into detail, Armstrong ML et al. [30] have suggested that non-cholesterol sterols are less easily dissociated from mixed micelles, thereby limiting the micellar solubilisation of cholesterol. This could be explained by the increased hydrophobicity of plant sterols/stanols compared with cholesterol, resulting in a lower solubility but a higher affinity for micelles. This micelle concept was elegantly shown by lkeda et al. [27]. In that study, rats were fed a diet containing $0.5 \%$ cholesterol alone or $0.5 \%$ cholesterol plus an equal amount of sitosterol or sitostanol for 10 days, directly followed by analysis of the composition of the intestinal aqueous micellar phase. Compared with rats fed cholesterol alone, the solubility of cholesterol in the aqueous micellar phase was $24 \%$ lower for the rats fed cholesterol plus sitosterol and $53 \%$ for those fed cholesterol plus sitostanol. The difference between sitosterol and sitostanol was not statistically significant. There was also no difference between sitosterol and sitostanol in the in vitro experiments.

Following experiments - still focusing on micellar composition - tried to unravel whether plant sterols and stanols were equally effective or not. It was found that the 
recovery of sitostanol in the faeces was almost complete, whereas the recovery of sitosterol ranged between 85-92\% [31]. In agreement, Hassan et al. [32] showed that only $2 \%$ of sitostanol was found in the lymph of Sprague-Dawley rats compared with $36 \%$ for cholesterol, reflecting the poor absorption of sitostanol. They proposed an inverse relationship between the intestinal absorption of plant sterols/stanols and their ability to inhibit cholesterol absorption. To explain the potentially higher efficacy of plant stanols on cholesterol absorption, Heinemann and colleagues [33] suggested that hydrogenation enhanced the hydrophobicity, resulting in a higher affinity for binding to cholic acid micelles, and as a consequence a more effective displacement of cholesterol from the micelles and a more pronounced reduction in the cholesterol absorption. In their in vivo studies, they compared the intestinal cholesterol absorption in humans after infusion of a high dose of sitosterol or sitostanol dissolved in monoleate. Sitosterol significantly reduced the intestinal cholesterol absorption by almost $50 \%$, and sitostanol by almost $85 \%$. Thus, there is a vast majority of evidence showing that plant sterols and stanols lower the incorporation of cholesterol in mixed micelles and as such the amount of cholesterol available for absorption (table 1, figure 2B-E). This proposed mechanism -i.e. interfering with micellar cholesterol incorporation- suggests that plant sterols and stanols have to be consumed simultaneously with dietary cholesterol to achieve a maximal cholesterol-lowering effect. However, in 2000, Plat and colleagues [19] showed that a daily consumption of $2.5 \mathrm{~g}$ plant stanols as their fatty acid esters once per day at lunch was as effective as an equal total dose of $2.5 \mathrm{~g}$ but now divided over three meals. They hypothesized that the plant stanols remained in the intestinal lumen or even within the enterocyte after consumption. It should be realized that this hypothesis was proposed before identification of transporters such as NPC1L1. In agreement, Weststrate et al. [34] found that consumption of plant sterols at lunch and dinner only decreased LDL-C to the same extent as in studies that provided the plant sterols three times daily. Later, many more studies using the 'once a day' protocol indeed found serum LDL-C reductions in line with predicted changes [35, 36]. This finding of 'once a day efficacy' clearly questioned the mechanisms underlying the reduced intestinal cholesterol absorption. Effects could no longer solely be explained by a reduced incorporation of cholesterol into mixed micelles. However, not all studies using the 'once a day' approach were successful. It should be noticed that the oil phase is crucial for the formation of mixed micelles, which subsequently transport the emulsified food components towards the enterocytes via the aqueous micellar phase (figure 2). Therefore, it is of utmost importance that the ingested foods induce bile flow and release of pancreatic lipases. This could explain why Abumweis et al. [16] did not find a reduction in serum LDL-C concentrations after a single consumption of plant sterols/stanols before or with breakfast. However, results of this subgroup analysis should be interpreted with caution since the number of subjects included was small. Doornbos and colleagues [37] included 186 subjects to evaluate the impact of time of intake of plant sterol-enriched $( \pm 3 \mathrm{~g} / \mathrm{d})$ single-dose yoghurt drinks. The drinks, which were different in total fat content $(2.2 \%$ vs. $3.3 \%)$, were consumed at least half an hour before breakfast or after lunch. They concluded that the total cholesterol and LDL-C concentrations were significantly reduced in both conditions, independent of the fat content of the drinks. A significantly larger reduction, however, was observed when the drinks were consumed with or immediately after lunch, suggesting that a fed state is necessary for an optimal cholesterol-lowering activity. As suggested by Doornbos et al. [37], not only the 


\section{CHAPTER 2}

amount of fat, but also the protein content of a meal could be important, since both trigger the release of cholecystokinin after a meal, thereby causing secretion of bile, a necessary step in the formation of mixed micelles.

A crucial factor that has been addressed in only a few studies in the mixed micelle era, is the physical state of the plant sterols and stanols. The physical state may influence the partitioning of plant sterols and cholesterol over the different phases in the intestinal lumen (figure 2). Grundy and colleagues [38] showed that the inhibition of intestinal cholesterol absorption by plant sterols was augmented if the plant sterols were administrated as a micellar solution (as used in perfusion studies) as compared to administration of plant sterols in suspension (as in almost all dietary studies). The importance of the physical state was further substantiated by Lees et al. [28], who fed hypercholesterolemic patients $3 \mathrm{~g} / \mathrm{d}$ of two different sitosterol preparations (either suspension or powder) from tall oil. Serum cholesterol concentrations were reduced in both conditions, but the decrease was more pronounced after administration of the powdered tall oil sterols (12\%) as compared to the tall oil in suspension $(7 \%)$. Ostlund and colleagues [39] agreed that the efficacy of plant sterols/stanols depends on the form in which they are presented. Administration of $1 \mathrm{~g}$ pure sitostanol powder had no significant effect on cholesterol absorption, whereas $700 \mathrm{mg}, 300 \mathrm{mg}$ and even $100 \mathrm{mg}$ sitostanol packaged in lecithin vesicles reduced intestinal cholesterol absorption as compared with a placebo by $37 \%, 35 \%$ and $6 \%$, respectively (figure $2 \mathrm{E})$. These findings can be explained by the fact that sterols form stable crystals, which are solid solutions characterized by an extremely low bio-accessibility. Therefore, a powder forms hardly any micelle making this form almost ineffective.
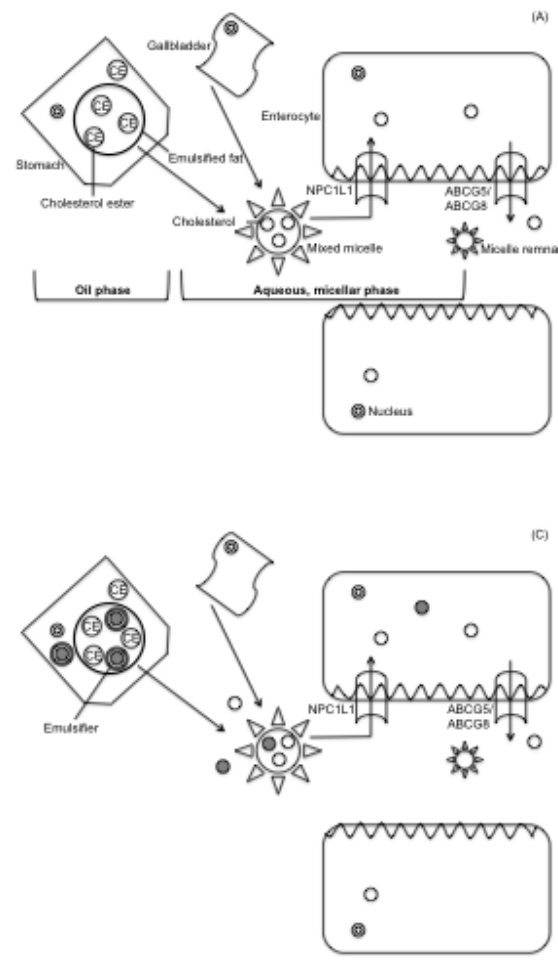
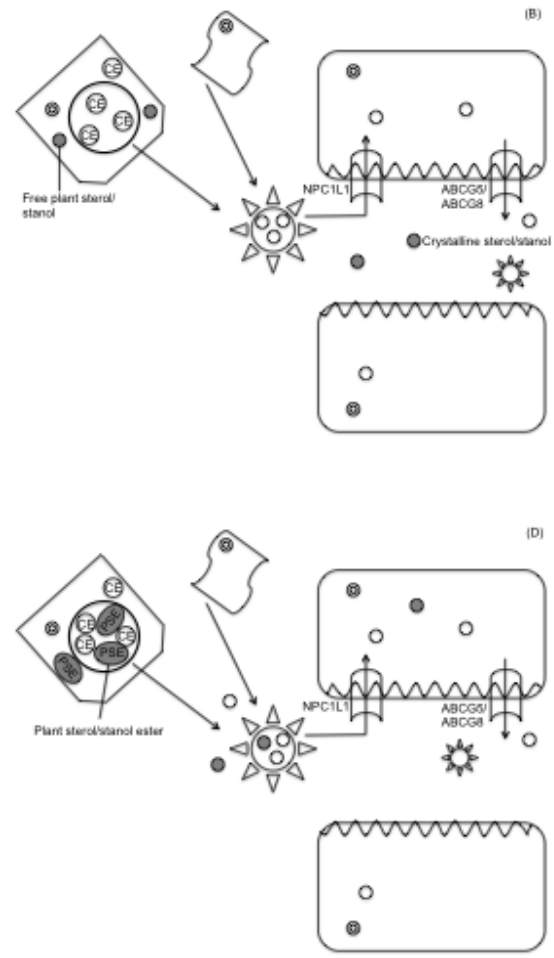


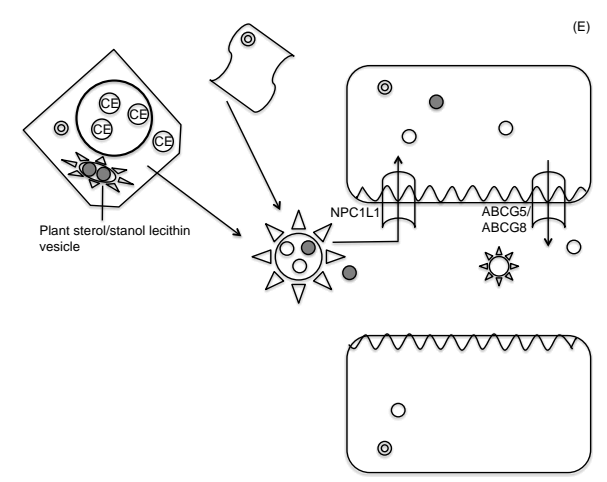

Figure 2: A representation of the crucial role of micelles in the process of cholesterol absorption.

The digestion of food-derived fats is initiated in the stomach by gastric lipase, leading to the formation of crude emulsions, which are further hydrolyzed by pancreatic lipase and cholesterol esterase in the small intestine. Cholesterol as well as plant sterols and stanols have to be incorporated into mixed micelles before absorption can occur.

(A) Mixed micelles are formed on the surface of the emulsified fat droplets as a combined action of bile acids and pancreatic enzymes. They transport free cholesterol through the micellar phase into the enterocyte. (B) Free plant sterols/stanols are not solubilized in the emulsified fat of the food digesta and pass the small intestine as crystalline sterols. In other words, they are unable to compete with cholesterol for incorporation into mixed micelles. (C) Therefore, free plant sterols/stanols need to be made "bioavailable" to the oil phase before competition can occur. This can be realized by the use of an emulsifier. (D) After consumption of plant sterol/stanol esters, the esters are hydrolyzed by pancreatic cholesterol esterase in the small intestine. Again, the free form will compete with cholesterol for incorporation into mixed micelles, thereby reducing intestinal cholesterol absorption. (E) Another possibility to increase the solubility of plant sterols/stanols is the formation of micellar solutions with lecithin. In contrast to the esterified form, which first has to dissolve in dietary fat for entry into the oil phase and next equilibrate with the micellar phase, the use of lecithin micelles allows a direct delivery of plant sterols/stanols into the intestinal micellar phase.

Besides the physical state, it was also considered important whether plant sterols and stanols were provided as free sterols/stanols or as sterol/stanol esters. Mattson et al. [40] reported a 9\% larger reduction in intestinal cholesterol absorption when the subjects ingested plant sterols in the free form as compared with the sterol esters. It was suggested that the ester bond was not completely hydrolyzed by the bile acid-activated pancreatic cholesterol hydrolase in the intestinal lumen. Since plant sterol and stanol esters solubilize poorly into the micellar phase, the major part accumulates in the oil phase. This agrees with the earlier mentioned observations that plant sterol esters, and also cholesterol esters in the oil phase, are less effectively absorbed into the enterocytes [41]. More recently, Kobayashi and coworkers [42] compared the cholesterol-lowering activity of free and esterified plant sterols side-by-side in Sprague-Dawley male rats. After feeding a commercial chow for 1 week, a catheter was placed in the stomach for administration of the test emulsions containing cholesterol without plant sterols, cholesterol with unesterified plant sterols or with plant sterol oleates. The lymphatic $24 \mathrm{~h}$ recovery of radiolabeled cholesterol was significantly lower in rats fed the free plant sterols than in those receiving the control or the plant sterol oleates at $3 \mathrm{hr}$ after administration. However, when it was repeated after incorporating the different sterols into the feed, no 


\section{CHAPTER 2}

significant differences were observed. They suggested that administration of cholesterol and plant sterol oleates as an emulsion into the stomach resulted in a rapid accumulation of plant sterol oleates in the duodenum. The presence of a large amount of the esters in the intestinal lumen might induce a delay in the hydrolysis of the plant sterol oleates, causing a less effective reduction in the cholesterol absorption. Addition of plant sterol oleates to the diet did not lead to an excessive accumulation of the compounds into the duodenum. These studies illustrate the importance of optimal cleavage of the ester bound, thereby releasing free sterols or stanols for the micellar phase.

What do we know about the efficacy of the esterase enzymes in vivo? Miettinen et al. [43] quantified the hydrolysis of $2 \mathrm{~g} / \mathrm{d}$ of plant stanols in 11 colectomized patients fed plant stanol esters for 1 week and observed that $95 \%$ of cholesterol and $90 \%$ of plant sterols/stanols were in the free form. In agreement, Normen and coworkers [44] performed a study in 7 ileostomy subjects receiving $2.5 \mathrm{~g} / \mathrm{d}$ of plant sterol or stanol esters. The proportion of the esterified forms of the plant sterols and stanols were $12.6 \%$ and $15.5 \%$, respectively. This implicates that the major part of the plant sterols/stanols is hydrolyzed in the small intestine. In fact, almost $50 \%$ of the esters are hydrolyzed in the lower duodenum. The findings of Kobayashi and coworkers [42] can also be explained by the activity of lingual lipase, present in the serous (von Ebner) glands of the tongue and by the activity of gastric lipase [45]. It could be that these lipases already hydrolyze a part of the plant sterol esters when added to the diet, an effect that may be less when the test emulsion is given intragastrically.

Although free plant sterols and stanols may at least be as effective as the esterified forms, mainly the plant sterol/stanol esters are used for incorporation into the functional foods due to their higher solubility in oils. However, only the free form of the sterols and the stanols participate into the emulsified fat phase, causing a reduction in the intestinal cholesterol absorption. For this, optimal esterase activity is required (figure 2). Unfortunately, not many human studies have compared the cholesterol-lowering effects of free and esterified plant sterols and stanols. Richelle and colleagues [46] found no significant differences in the reduction of cholesterol absorption $( \pm 60 \%)$ in normocholesterolemic subjects receiving $2.2 \mathrm{~g}$ plant sterols either free or esterified for 7 consecutive days. It should be noted that not solely the sterols were incorporated into the foods, but that sorbitan tristearate was added to the free form as an emulsifier (figure $2 \mathrm{C}$ ). Due to the emulsifier, the free plant sterols/stanols could more easily interact with the emulsified fat phase making them as efficient as the esterified form. Regarding free sitostanol, Ostlund et al. [39] have described another procedure to facilitate partitioning into the emulsified fat phase. Free sitostanol was administered as part of lecithin micelles, which also lowered cholesterol absorption very efficiently (figure $2 \mathrm{E}$ ). They reported that the effective dose of free sitostanol, when incorporated into lecithin micelles, was between 100 and $300 \mathrm{mg}$. In later studies [47], it was found that $1.8-1.9 \mathrm{~g} / \mathrm{d}$ plant stanols in lecithin micelles reduced LDL-C to the same extent as has been reported for plant stanol esters at the same daily intake. In a more recent study, Söderholm et al. [48] showed that free plant sterols incorporated into a rye bread significantly lowered serum LDL-C concentrations. The rye bread was enriched with $2 \mathrm{~g} / \mathrm{d}$ of free plant sterols. Before adding to the dough, the plant sterols were micronized in order to increase the bioavailability in the oil phase. 
In summary, if free sterols or stanols are provided without facilitating its solubilisation into the oil phase, they will be poorly incorporated into the mixed micelles and have limited cholesterol-lowering activity (figure 2B). For the enhancement of free sterols and stanols into the emulsified fat phase several procedures have been presented (figure 2C-E). Ultimately, the free forms - for sterol esters and stanol esters after cleavage by the esterases - will compete with cholesterol for incorporation into mixed micelles, thereby reducing intestinal cholesterol absorption.

\section{The cellular era}

Although displacement of cholesterol from mixed micelles in the intestinal lumen seemed to be an important mechanism of plant sterol- and stanol-induced inhibition of intestinal cholesterol absorption, several other mechanisms involving actively regulated processes have been suggested. Inhibition of cholesterol transport into the brush border membranes is one example, although many of the earlier textbooks mentioned that this uptake was driven by passive diffusion. However, already in 1957, Glover et al. [49] published that the brush border contains a specific binding site for cholesterol, making passive diffusion as the main driver for cholesterol uptake less likely. Similar results were found by lkeda et al. [50], who confirmed the existence of an independent binding site for cholesterol and sitosterol in an isolated brush border at low micellar concentrations. Cholesterol-binding approached saturation at higher concentrations, which could not be observed for sitosterol [51]. Based on these results, it was concluded that competition at the brush border membrane had almost no influence on the plant sterols and stanols-mediated cholesterol-lowering activity. It has also been suggested that plant sterols and stanols interfere with the incorporation of cholesterol into chylomicrons. Before incorporation into a chylomicron, free sterols are (re)esterified by ACAT2. Newly synthesized apoB-48 and triacylglycerol (TAG) accumulate together with cholesterol esters in the smooth endoplasmatic reticulum membrane followed by a MTP proteindependent formation of chylomicrons [52]. In vitro as well as in vivo studies have clearly indicated that mucosal ACAT is a rate-controlling enzyme in the absorption of cholesterol. Kam et al. [53] incubated Caco2 cells, a frequently used in vitro model for absorption studies, for $1 \mathrm{hr}$ with increasing concentrations of 58-035, a specific inhibitor of ACAT. The inhibitor caused a dose-dependent decrease in cholesteryl ester synthesis, reaching a maximal effect at $15 \mu \mathrm{g} / \mathrm{ml}$. After $24 \mathrm{hrs}$, there were no measurable amounts of cholesteryl esters left in the chylomicron and very lowdensity lipoprotein (VLDL) particles isolated from these Caco2 cells. In agreement, Clark and colleagues [54] observed a reduced ACAT activity, if jejunal microsomes were incubated with $0.6 \mu \mathrm{g} / \mathrm{ml}$ of 58-035. In vivo, they investigated also the absorption of cholesterol in mesenteric lymph fistula of Sprague-Dawley rats after ACAT inhibition and observed a reduction in cholesteryl esters in lymph, lymph chylomicrons, and lymph VLDL, whereas the amount of unesterified cholesterol was increased. These results support a major regulatory role for ACAT in cholesterol absorption. It has been suggested that plant sterols interfere with the esterification inside the enterocyte, the first of the final two crucial steps in the process of cholesterol absorption [28]. Since plant sterols and stanols are poor substrates for ACAT2, they could bind the available sites, thereby decreasing its activity by competitive inhibition (figure 1). Field and colleagues [55] indeed observed a decrease in ACAT activity in rabbits after feeding $\beta$-sitosterol. 


\section{CHAPTER 2}

In contrast, if they collected intestinal microsomes from rabbits on chow diet and enriched them with $\beta$-sitosterol, they could not observe any effect on ACAT activity during the $4 \mathrm{hrs}$ of measurement. However, some years later, the same group reported differences in the ACAT activity in $\mathrm{Caco} 2$ cells incubated with micelles containing cholesterol alone or cholesterol plus $\beta$-sitosterol [56]. Addition of cholesterol to the Caco2 cells in a micellar solution increased the basolateral secretion of cholesteryl esters derived from the plasma membrane cholesterol. In other words, micellar cholesterol displaces the cholesterol from the plasma membrane to the endoplasmatic reticulum, which is than used for chylomicron assembly and secretion. If, however, the same amount of $\beta$-sitosterol was added together with cholesterol, the movement of cholesterol from the plasma membrane and the subsequent secretion of cholesteryl esters were significantly reduced. This can be attributed to the displacement of cholesterol from the micelles by $\beta$-sitosterol. The reduced ACAT activity could be explained by the diminished trafficking of cholesterol from the plasma membrane to the endoplasmatic reticulum, as ACAT activity may be regulated by substrate supply [57]. Moreover, it has been shown again in Caco2 cells that HMG-CoA reductase activity is decreased when sitosterol was added despite a reduction in intracellular cholesterol concentration [56]. This indicates that HMG-CoA reductase cannot discriminate between cholesterol and plant sterols, which even further lower intracellular cholesterol pools. Thus, direct effects on ACAT activity are not a likely explanation for the plant sterol/stanol mediated effects on cholesterol absorption. After esterification, the cholesteryl esters are packaged into chylomicrons, a process in which MTP plays a crucial role. It was recently shown in male Golden Syrian hamsters that the cholesterol-lowering activity of sitosterol was associated with a decrease in the mRNA level of MTP [58]. This implies that plant sterols/stanols could also have an effect on MTP expression, which has to be further elucidated. In line with this assumption, Rideout et al. [59] recently showed that plant sterol feeding lowered intestinal fat absorption in C57BL/6J mice, which could also be related to reduced chylomicron formation involving effects on MTP.

\section{The Transporter era}

More recently, Davis et al. [60] have described the crucial role of NPC1L1 in the intestinal uptake and absorption of cholesterol and plant sterols/stanols. NPC1L1deficient mice were characterized by a reduction in cholesterol absorption of almost $90 \%$. Moreover, also serum campesterol and sitosterol concentrations were reduced by $\pm 90 \%$ in these mice as compared with the wild-type mice. These results showed that NPC1L1 plays an important role in the uptake of both cholesterol and plant sterols, indicating that cholesterol and plant sterol absorption was not merely due to passive diffusion (figure 1C). The annexin2/caveolin1 (ANXA2/CAV1) complexes can also play a role in the plant sterol/stanol mediated cholesterol-lowering activity. ANXA2 forms a lipid-protein complex with CAV1 and cholesteryl esters, which may be involved in the internalization/endocytic transport of cholesterol esters from caveolae to internal membranes in lipid rafts of the intestinal brush border [61]. Smart et al. [62] have demonstrated that ANXA2 could be down regulated by plant sterols, thereby reducing cholesterol processing and transport. The significance of this complex for cholesterol absorption however is unclear, since Valasek et al. [63] have shown that the fractional cholesterol absorption and faecal neutral sterol 
excretion are similar in CAV1 knockout mice and their wild-type littermates. Besides cholesterol influx, there is also active secretion of cholesterol and plant sterols from enterocytes back into the intestinal lumen. In this process, ABCG5 and ABCG8, two half-transporters localized on the apical membrane of the enterocytes play a crucial role [64]. They function together as a heterodimer and mediate the efflux of free sterols from the enterocytes [13]. Theoretically, as a consequence of increased ABCG5/ABCG8 activity, less sterols will be available for esterification and incorporation into chylomicrons and as such intestinal sterol absorption will be reduced. The $A B C G 5 / A B C G 8$ transporters are regulated via the liver $X$ receptor $(L X R)$ and numerous attempts have been made to use LXR agonists to influence cholesterol metabolism, i.e. elevate reverse cholesterol transport (RCT) pathways. However, systemic LXR activation causes increased hepatic fatty acid synthesis [65] and steatosis [66]. Therefore, tissue specific approaches have been initiated. Indeed, Lo Sasso et al. [67] recently showed in an elegant series of experiments that intestine specific LXR activation increased RCT and lowered intestinal cholesterol absorption. As expected, intestinal ABCG5/ABCG8 expression was increased and faecal neutral sterol excretion enhanced. The question now is whether plant sterols and stanols influence the expression or activity of these crucial transporter proteins within the enterocytes. Yamanashi et al. [68] studied the role of NPC1L1 using differentiated Caco2 cells as a model for small intestinal epithelial cells. In Caco2 cells overexpressing NPC1L1, the absorption of sitosterol was higher as compared to non-transfected cells. However, sitosterol absorption remained significantly lower as compared to cholesterol absorption. More recently, Zhang et al. [69] showed that cholesterol binds to the luminal N-terminal domain (NTD) of the NPC1L1 protein and that this specific binding is required for the uptake of cholesterol from the intestinal lumen into the enterocyte. Plant sterols cannot bind to NPC1L1-NTD, which may contribute to the selective cholesterol absorption in mammals. So, based on these cell and animal studies, it seems that NPC1L1 is not involved in the decreased cholesterol absorption after plant sterol or stanol intake. It is therefore interesting to know what will happen when ezetimibe will be combined with plant sterols or stanols in the diet. Jakulj and colleagues [70] examined the effects on serum LDL-C concentration in mildly hypercholesterolemic subjects receiving $10 \mathrm{mg} / \mathrm{d}$ of ezetimibe with or without $2 \mathrm{~g} / \mathrm{d}$ of plant sterols for 4 weeks. Combined treatment of plant sterols and ezetimibe did not further reduce the serum LDL-C concentration compared with ezetimibe monotherapy, i.e. serum LDL-C reductions were $25 \%$ and $22 \%$, respectively. One can argue that plant sterols and ezetimibe targeted the same transporter (in this case NPC1L1). Alternatively, it can be hypothesized that ezetimibe blocks NPC1L1, which results in a lower cellular uptake of plant sterols into the enterocytes. As indicated in the following sections, there are indications that plant sterols should be available intracellular to activate cellular processes that contribute to the lowered intestinal cholesterol uptake. Therefore, the lack of an additive effect of the plant sterol-ezetimibe combination could be explained by the reduced intracellular plant sterol concentration due to the ezetimibe-mediated NPC1L1 inhibition. Whatever reason, both are suggestive for the fact that NPC1L1 itself is not involved in the working mechanisms of plant sterols. In contrast to the findings of Jakulj et al. [70], Lin and colleagues [71] very recently showed that adding plant sterols to ezetimibe resulted in a further reduction of cholesterol absorption and a significantly increased faecal cholesterol excretion. This outcome was explained by the authors as an indication that the mechanism by which plant sterols 


\section{CHAPTER 2}

lower intestinal cholesterol absorption is independent of that of ezetimibe. However, more specifically for this purpose designed studies are needed to examine whether NPC1L1 plays a role in the underlying mechanism of plant sterols/stanols.

Also regarding changes in the activity of the $A B C$ transporters and other $L X R$ target genes involved in (intestinal) lipid metabolism several studies can be addressed. The oxysterol-activated receptor LXR regulates the expression of a panel of genes amongst which NPC1L1 [72], ABCA1, ABCG5 and ABCG8 [73]. As mentioned above, LXR activation results in an increase in the faecal neutral sterol loss and a decrease in the intestinal sterol absorption (figure 1C). It has been suggested that LXR - in line with the sterol regulatory element binding protein 2 (SREBP2) -detects changes in intracellular cholesterol concentrations. In case of high intracellular cholesterol concentrations, LXR is activated to prevent via expression of its target genes a further accumulation of cellular cholesterol [74]. It has been suggested that plant sterols and stanols also activate LXR either directly or indirectly after conversion into yet unkown metabolites. Indeed, using a cell-free ligand-sensing assay (LiSA), Plat et al. [75] showed that non-oxidized plant sterols and stanols were potent activators of LXR. Moreover, they showed an increase in ABCA1 mRNA expression if $\mathrm{Caco} 2$ cells were cultured in the presence of mixed micelles enriched with plant sterols and stanols. Unfortunately, it was not possible to measure the expression pattern of $A B C G 5$ and $A B C G 8$, since the mRNA level of both genes was undetectable in these $\mathrm{Caco} 2$ cells. It could however be speculated that plant sterols/stanols can be regarded as local LXR agonists acting only in enterocytes. Physiological intracellular plant sterol concentrations in the enterocytes can indeed reach levels above EC50 concentrations necessary for LXR activation, which seems unlikely in hepatocytes due to the low absorption of plant sterols. The fact that plant sterols and stanols could act as local LXR agonists - and not systemically - also fits with recent observations that plant stanols [76-78] and sterols lower serum TAG concentrations instead of increasing TAG concentrations, as observed for systemic LXR agonists [65]. Systemic LXR agonists induce hepatic lipogenesis, which results in elevated serum TAGs. Plösch and colleagues [64], however, have suggested that plant sterols and stanols lower intestinal cholesterol absorption independently of LXR activation. They fed C57BL/6 mice a diet free of sterols, enriched with cholesterol, or enriched with cholesterol and either plant sterols or stanols for 4 weeks. Addition of plant sterols or stanols to the diet resulted in the expected increase in the faecal neutral sterol excretion. However, gene expression profiles of known LXR target genes were not changed. Moreover, Calpe-Berdiel et al. [79] observed no effects on the intestinal expression of LXR target genes in mice fed a western-type diet enriched with or without plant sterols. Finally, plant sterols were still effective in lowering intestinal cholesterol absorption in ABCG5 knockout mice, illustrating that these transporters are not obligatory to show effects [80]. Despite these inconsistent results regarding the role of the $A B C$ transporters, we still cannot exclude a possible role for plant sterols and stanols on the activation of yet unknown LXR target genes. Therefore, it is too early to exclude LXR as a mediator of the plant sterol/stanol induced effects on intestinal cholesterol absorption. 


\section{The era of new discoveries}

The most recent and probably most provocative explanation for the effects of plant sterols/stanols on intestinal cholesterol metabolism is related to the process called transintestinal cholesterol excretion (TICE). Until recently, the RCT route, which is hepatobiliary cholesterol secretion mediated by hepatic ABCG5/ABCG8, was thought to be the most important route responsible for the disposal of cholesterol. However, disruption of biliary cholesterol secretion in mice had no effect on the faecal neutral sterol excretion [81, 82]. This finding suggested that the hepatobiliary cholesterol secretion might not be the only route for cholesterol excretion into the intestinal lumen. In this respect, van der Velde et al. [83] have demonstrated that cholesterol is secreted throughout the entire length of the small intestine, but most actively in the proximal part. They performed intestinal perfusion studies in mice under bile-diverted conditions and reported that intravenously injected radiolabeled cholesterol ends up in the intestinal perfusate. The direct cholesterol flow from blood into the intestinal lumen is further supported by the results of Brown et al. [84]. They observed in mice with a targeted deletion of hepatic ACAT2 a 2-fold increase in the faecal neutral sterol excretion. However, this increased faecal sterol loss occurred without an increase in biliary cholesterol secretion. In contrast, a trend towards a reduction in the cholesterol concentration in the gallbladder bile was observed as compared with the controls. In addition, in line with the observations of van der Velde and colleagues [83], they also showed that intestinal cholesterol secretion was most pronounced in the proximal part of the small intestine. Altogether, these findings indicate that there must be a direct transport of cholesterol from the circulation into the intestinal lumen. This so-called TICE pathway could in theory also be an explanation for the cholesterol-lowering activity of the plant sterols and stanols (figure 1D). It should be noted that plant sterols/stanols may also compete with TICEderived cholesterol for incorporation into mixed micelles, thereby decreasing cholesterol absorption. However, the magnitude of this effect may depend on the place where TICE-derived cholesterol enters the intestinal lumen. Based on the mechanisms described in the mixed micelle era, it is expected that the effects diminished the more distal TICE-derived cholesterol enters the intestinal lumen.

Recently, Brufau et al. [85] shows a role of plant sterols and stanols in the stimulation of cholesterol excretion via this non-biliary route. Feeding wild-type mice a plant sterol-enriched diet resulted as expected in an increased faecal neutral sterol excretion, whereas a more moderate increase was observed in ABCG5 knockout mice. Furthermore, the non-biliary cholesterol excretion was 6 -fold elevated in the plant sterol group and 3.5-fold in the ABCG5 knockout mice fed plant sterols. It should be mentioned that the transporter protein responsible for cholesterol efflux out of the enterocyte into the lumen - and as such part of the TICE route- is currently unknown. Although it is tempting to speculate that this process is at least partly mediated by ABCG5/ABCG8, Brufau et al. [85] found an unexpected decrease in both the mRNA level and the protein expression of this transporter, while TICE was activated. Although the evidence for a role of ABCG5/ABCG8 in TICE is not strong, LXR is thought to be one of the key players involved in the regulation of TICE. Treating C57BL/6J mice with T0901317, a LXR agonist, caused a significant increase in TICE [86]. Although the evidence for plant sterols and stanols to act as a ligand for LXR is contradictory (see transporter era), this novel pathway does suggest that intestinal LXR activation is needed to explain effects on intestinal 


\section{CHAPTER 2}

cholesterol metabolism. Therefore, intestinal LXR activation in response to plant sterol/stanol consumption needs to be studied into far more detail and especially the search for currently unknown and therefore not yet analyzed LXR target genes needs attention. In this respect, Sehayek et al. [87] reported already in 2002 that specific loci on chromosomes 2 and 14 distinct from ABCG5/ABCG8 regulate plasma plant sterol concentrations in mice.

A remarkable observation that also needs attention was the absence of a doseresponse effect of plant sterol consumption on the non-biliary cholesterol excretion in mice. The lowest supplementation of the plant sterol $(1 \%)$ resulted already in a maximal stimulation of TICE [85]. This can only be explained by acknowledging that plant sterols and stanols not only activate TICE and as such increase faecal neutral sterol excretion but at the same time must also lower absorption of intestinal cholesterol. The combination of both processes is the observed net effect. Therefore, in future studies, it is a challenge to quantify the postprandial appearance of cholesterol in the chylomicron fraction and at the same time quantify the changes in TICE, to ensure which part of the increase in the faecal neutral sterol loss is due to an increased TICE and to a decreased incorporation of cholesterol into chylomicrons. Up till now, the contribution of TICE in humans has not been described. A better understanding of the process of TICE itself as well as exploring possibilities to activate TICE seems, however, an attractive approach for the prevention and even the treatment of CVD.

Given the above overview, we conclude that impaired micellar solubilisation of intestinal cholesterol is the only unequivocally established effect of the plant sterols/stanols. The so-called cellular and transporter eras have provided many interesting observations, but results are not consistent. However, the fact that both the mixed micelle era, nor the cellular or the transporter eras can fully explain all observations, the exact molecular mechanisms behind the cholesterol-lowering activity of plant sterols/stanols is likely a complex interplay of multiple processes. 


\section{Clinical benefit}

Independent from the mechanism underlying the serum LDL-C-lowering effects, an important issue often raised is the question 'what is the evidence that we benefit from plant sterol or stanol consumption in terms of cardiovascular risk'. Several observations suggest that plant sterols and stanols not only lower serum LDL-C concentrations, but also ultimately improve endothelial dysfunction [88, 89]. Up till now, it is unknown whether plant sterols and stanols exert these effects by a direct or an indirect effect. Direct effects assume a functional effect of the plant sterols/stanols themselves on the vessel wall. For this route, there is hardly any evidence. Indirect effects mean that the reduced CVD risk is explained through effects on LDL-C.

In animals it is easy to evaluate whether dietary interventions affect lesion development, which is of course in humans more difficult. However, endothelial dysfunction is a reflection of an early, but reversible stage in the development of atherosclerosis, and the presence of endothelial dysfunction is considered to be a preclinical marker of CVD [90]. Here, we will provide a short overview of controlled intervention studies evaluating effects of plant sterols/stanols on endothelial function and/or possible atherosclerotic lesion characteristics in suitable animal models and humans. Ntanios et al. [91] fed twenty-four male New Zealand White rabbits a diet rich in cholesterol or in cholesterol with one of the three $1 \%(\mathrm{w} / \mathrm{w})$ plant sterol mixtures derived from soybean containing $0.01 \%(\mathrm{w} / \mathrm{w})$ plant stanols, tall oil containing $0.2 \%(\mathrm{w} / \mathrm{w})$ plant stanols, or tall oil containing $0.8 \%(\mathrm{w} / \mathrm{w})$ plant stanols. In rabbits fed the $0.8 \%(\mathrm{w} / \mathrm{w})$ plant stanols, serum total cholesterol, LDL-C and very low-density lipoprotein-cholesterol (VLDL-C) concentrations were reduced by 49,37 and $63 \%$, respectively as compared to the control group. Moreover, lesion developments in the ascending aorta and coronary arteries were substantially reduced as compared to the control group. There was no significant difference in plaque formation between the $0.01,0.2 \%(\mathrm{w} / \mathrm{w})$ plant stanol and the control group. The observation that plant stanols can indeed lower lesion formation agreed with a study by Plat et al. [92], who demonstrated that plant sterol or stanol consumption lowered atherosclerotic lesion development in heterozygous LDL receptor + - mice to the same extent despite opposite changes in serum plant sterol and stanol concentrations. These findings suggest that changes in serum plant sterols or stanols themselves do not directly contribute to plaque development in these mice. Volger and colleagues [93] also evaluated the association between the reduction in serum cholesterol concentration and atherosclerotic lesions. They fed apoE ${ }^{\star} 3$ Leiden transgenic mice a control diet or the same diet enriched with plant stanol esters for 38 weeks. The cholesterol-lowering activity of the plant stanol esters was more pronounced in the VLDL and IDL fractions than in the LDL fraction $(70 \%, 77 \%$ and $20 \%$ reductions, respectively). As compared to the control group, plant stanol ester feeding significantly reduced the atherosclerotic lesion area and severity. The control mice showed type 2-3 lesions, characterized by regular intimal fatty streaks/mild plaques, whereas the mice receiving plant stanol esters predominantly had type 1 lesions, which consist of individual foam cells. In contrast, Weingärtner et al. [94] suggested that administration of plant sterol esters caused a negative vascular effect, independent of the plasma cholesterol concentrations. They fed C57BL/6J wild-type mice a normal chow enriched with $2 \%(\mathrm{w} / \mathrm{w})$ plant sterol esters for 4 weeks. These mice developed an impaired endothelium-dependent 


\section{CHAPTER 2}

vasorelaxation compared with the wild-type mice on normal chow. A significant larger lesion size after cerebral ischemia was observed in wild-type SV/129 mice treated for 4 weeks with normal chow and $2 \%(\mathrm{w} / \mathrm{w})$ plant sterol esters compared with the control group. Finally, Weingartner et al. also used ApoE-/- mice as a model of lipid-driven atherogenesis. Mice were fed a Western-type diet or normal chow for 6 months, enriched with $2 \%(\mathrm{w} / \mathrm{w})$ plant sterol esters, $0.005 \%(\mathrm{w} / \mathrm{w})$ ezetimibe, a combination of both or without any supplementation. The reduction in atherosclerotic plaque formation was most pronounced in mice treated with ezetimibe and significantly larger than in mice fed the plant sterol esters. The mice treated with ezetimibe and plant sterol esters showed a trend towards greater lesion formation as compared to mice treated with ezetimibe alone. Despite the equal reduction in serum cholesterol concentration, plant sterol ester consumption was associated with twice the amount of plaque formation compared with ezetimibe. However, further studies are needed to confirm the potentially negative effect of plant sterols on atherogenesis in mice. It should also be noticed that the amount of plant sterol ester supplementation in the animal studies, calculated as $\mathrm{mg} / \mathrm{d}^{*} \mathrm{~kg}$ body weight, was approximately 100 times higher as the amount incorporated into margarine used in human studies.

One of the most frequently used surrogate markers for measuring endothelium function in humans is flow-mediated vasodilatation (FMD) [90]. Celermayer et al. [95] have clearly shown that FMD is a valuable predictor for future cardiovascular risk. There are only a few studies investigating the effects of plant sterol or stanol consumption on endothelial function. De Jongh et al. [96] evaluated the short-term effect of plant sterols on endothelial dysfunction in heterozygous familial hypercholesterolemic children. Forty-one children between 5 and 12 years of age received $2.3 \mathrm{~g}$ plant sterols per day for 4 weeks. As expected, administration of plant sterols resulted in a $14 \%$ decrease in serum LDL-C concentrations. However, this was not associated with an improvement of the impaired FMD. Hallikainen and colleagues [97] also showed that a daily intake of $2 \mathrm{~g}$ plant sterol or stanol esters for ten weeks had no effect on the endothelial function as measured by FMD in 76 hypercholesterolemic adults, although serum LDL-C concentrations were reduced by $9-12 \%$ as compared to the controls. Also Jakulj et al. [98] evaluated the effect of plant stanols ( $2 \mathrm{~g} / \mathrm{d}$ for four weeks) on FMD in 42 heterozygous FH children between 7-12 years. Serum total cholesterol and LDL-C concentrations were reduced by $7.5 \%$ and $9.2 \%$, respectively and again, improvement on the endothelial function was not observed. Finally, Raitakari et al. [99] evaluated the effect of plant stanol esters on endothelial function and arterial elasticity. The 150 hypercholesterolemic adults received $2 \mathrm{~g} / \mathrm{d}$ of plant stanol esters for three months. Despite the significant $9.3 \%$ reduction in the LDL-C concentration between the treated and the control group, they observed again no significant change in FMD or carotid artery compliance. However, a subgroup analysis demonstrated that arterial elasticity and endothelial function improved in subjects with below average baseline values for these parameters. This is in line with the observation of De Jong et al. [100] who evaluated the long-term effect (eighty-five weeks) of plant sterol or stanol esters on vascular function in patients on statin treatment. No effect in the whole population was observed, but endothelial dysfunction and arterial stiffness were improved in a subgroup of patients at risk for cardiovascular events [99]. This implies that plant sterols and stanols might improve vascular function in subjects with a suboptimal vessel condition [100] and probably more important that a long follow-up period is 


\section{EFFECTS ON INTESTINAL CHOLESTEROL METABOLISM}

needed to see protective effects. Although these observations are of great relevance, it does not prove that cardiovascular events are actually reduced. For this, future studies especially designed for this purpose are needed.

\section{Mechanisms in relation to the clinical benefit}

Reducing intestinal cholesterol absorption and/or stimulating TICE, two processes which both result in elevated faecal neutral sterol excretion, are currently the two paradigms explaining the LDL-C-lowering activity of plant sterols and stanols. Based on all observations described, it seems most likely that - at least in animals - both mechanisms are effective.

In this respect, a relevant question that remains is whether the long-term clinical benefit will depend on the pathways underlying the well-established LDL-C- lowering effects. If the target of the plant sterol/stanol treatment is to lower intestinal cholesterol absorption, the cholesterol concentration inside the body will decrease, while more cholesterol is excreted in the faeces as faecal neutral sterols. If, on the other hand, the main mechanism is to stimulate TICE, which also results in an increased faecal neutral sterol excretion, possibly more cholesterol will be secreted directly from the vessel wall to the intestinal lumen and the faeces. It can be speculated that this latter route of cholesterol reshuffling throughout the body might be preferable in terms of the most promising long-term clinical outcome. However, one can also argue that reducing intestinal cholesterol absorption lowers the amount of available cholesterol reaching the vessel wall. Activation of the process that has the largest net effect on inhibiting lesion formation remains to be evaluated. This conclusion illustrates that it is of utmost importance to better understand the underlying mechanisms of the cholesterol-lowering activity of plant sterols/stanols and of other food components as well - to be able to predict the long-term clinical benefits. 


\section{CHAPTER 2}

\section{References}

1. Krauss, R. M., Eckel, R. H., Howard, B., Appel, L. J., et al., AHA Dietary Guidelines: revision 2000: A statement for healthcare professionals from the Nutrition Committee of the American Heart Association. Stroke, 2000. 31 : p. 2751-2766.

2. Lauer, M. S., Fontanarosa, P. B., Updated guidelines for cholesterol management. JAMA, 2001. 285: p. 2508-2509.

3. Brown, M. S., Goldstein, J. L., Lipoprotein metabolism in the macrophage: implications for cholesterol deposition in atherosclerosis. Annu Rev Biochem, 1983. 52: p. 223-261.

4. Baigent, C., Blackwell, L., Emberson, J., Holland, L. E., et al., Efficacy and safety of more intensive lowering of LDL cholesterol: a meta-analysis of data from 170,000 participants in 26 randomised trials. Lancet, 2010. 376: p. 1670-1681.

5. Landmesser, U., Bahlmann, F., Mueller, M., Spiekermann, S., et al., Simvastatin versus ezetimibe: pleiotropic and lipid-lowering effects on endothelial function in humans. Circulation, 2005. 111: p. 2356-2363.

6. LaRosa, J. C., Low-density lipoprotein cholesterol reduction: the end is more important than the means. Am J Cardiol, 2007. 100: p. 240-242.

7. Demonty, I., Ras, R. T., van der Knaap, H. C., Duchateau, G. S., et al., Continuous doseresponse relationship of the LDL-cholesterol-lowering effect of phytosterol intake. J Nutr, 2009. 139: p. 271-284.

8. Musa-Veloso, K., Poon, T. H., Elliot, J. A., Chung, C., A comparison of the LDL-cholesterol lowering efficacy of plant stanols and plant sterols over a continuous dose range: results of a meta-analysis of randomized, placebo-controlled trials. Prostaglandins Leukot Essent Fatty Acids, 2011. 85: p. 9-28.

9. de Jong, A., Plat, J., Lutjohann, D., Mensink, R. P., Effects of long-term plant sterol or stanol ester consumption on lipid and lipoprotein metabolism in subjects on statin treatment. Br J Nutr, 2008. 100: p. 937-941.

10. Devaraj, S., Jialal, I., The role of dietary supplementation with plant sterols and stanols in the prevention of cardiovascular disease. Nutr Rev, 2006. 64: p. 348-354.

11. Sudhop, T., Sahin, Y., Lindenthal, B., Hahn, C., et al., Comparison of the hepatic clearances of campesterol, sitosterol, and cholesterol in healthy subjects suggests that efflux transporters controlling intestinal sterol absorption also regulate biliary secretion. Gut, 2002. 51: p. 860-863. Ling, W. H., Jones, P. J., Dietary phytosterols: a review of metabolism, benefits and side effects. Life Sci, 1995. 57: p. 195-206.

13. Klett, E. L., Lu, K., Kosters, A., Vink, E., et al., A mouse model of sitosterolemia: absence of Abcg8/sterolin-2 results in failure to secrete biliary cholesterol. BMC Med, 2004. 2: p. 5.

14. Law, M., Plant sterol and stanol margarines and health. BMJ, 2000. 320: p. 861-864.

15. Katan, M. B., Grundy, S. M., Jones, P., Law, M., et al., Efficacy and safety of plant stanols and sterols in the management of blood cholesterol levels. Mayo Clin Proc, 2003. 78: p. 965-978.

16.

17. Mensink, R. P., de Jong, A., Lutjohann, D., Haenen, G. R., Plat, J., Plant stanols dosedependently decrease $L D L$-cholesterol concentrations, but not cholesterol-standardized fatsoluble antioxidant concentrations, at intakes up to $9 \mathrm{~g} / \mathrm{d}$. Am J Clin Nutr, 2010. 92: p. 24-33.

18. Gylling, H., Hallikainen, M., Nissinen, M. J., Simonen, P., Miettinen, T. A., Very high plant stanol intake and serum plant stanols and non-cholesterol sterols. Eur J Nutr, 2009. 49: p. 111117.

19. Plat, J., van Onselen, E. N., van Heugten, M. M., Mensink, R. P., Effects on serum lipids, lipoproteins and fat soluble antioxidant concentrations of consumption frequency of margarines and shortenings enriched with plant stanol esters. Eur J Clin Nutr, 2000. 54: p. 671-677.

20. Peterson, D. W., Effect of soybean sterols in the diet on plasma and liver cholesterol in chicks. Proc Soc Exp Biol Med, 1951. 78: p. 143-147.

21. Peterson, D. W., Nichols, C. W., Jr., Shneour, E. A., Some relationships among dietary sterols, plasma and liver cholesterol levels, and atherosclerosis in chicks. J Nutr, 1952. 47: p. 57-65.

22. Pollak, O. J., Successive prevention of experimental hypercholesteremia and cholesterol atherosclerosis in the rabbit. Circulation, 1953. 7: p. 696-701.

23. Pollak, O. J., Reduction of blood cholesterol in man. Circulation, 1953. 7: p. 702-706.

24. Sklan, D., Dahan, M., Budowski, P., Hurwitz, S., Differential absorption of endogenous and exogenous cholesterol in the chick as affected by dietary oil level and phytosterols. J Nutr, 1977. 107: p. 1996-2001. 


\section{EFFECTS ON INTESTINAL CHOLESTEROL METABOLISM}

25. Sklan, D., Budowski, P., Hurwitz, S., Effect of soy sterols on intestinal absorption and secretion of cholesterol and bile acids in the chick. J Nutr, 1974. 104: p. 1086-1090.

26. Borgstrom, B., Partition of lipids between emulsified oil and micellar phases of glyceride-bile salt dispersions. J Lipid Res, 1967. 8: p. 598-608.

27. Ikeda, I., Tanabe, Y., Sugano, M., Effects of sitosterol and sitostanol on micellar solubility of cholesterol. J Nutr Sci Vitaminol, 1989. 35: p. 361-369.

28. Lees, A. M., Mok, H. Y., Lees, R. S., McCluskey, M. A., Grundy, S. M., Plant sterols as cholesterol-lowering agents: clinical trials in patients with hypercholesterolemia and studies of sterol balance. Atherosclerosis, 1977. 28: p. 325-338.

29. Brown, A. W., Hang, J., Dussault, P. H., Carr, T. P., Phytosterol ester constituents affect micellar cholesterol solubility in model bile. Lipids, 2010. 45: p. 855-862.

30. Armstrong, M. J., Carey, M. C., Thermodynamic and molecular determinants of sterol solubilities in bile salt micelles. J Lipid Res, 1987. 28: p. 1144-1155.

31. Sugano, M., Morioka, H., Ikeda, I., A comparison of hypocholesterolemic activity of betasitosterol and beta-sitostanol in rats. J Nutr, 1977. 107: p. 2011-2019.

32. Hassan, A. S., Rampone, A. J., Intestinal absorption and lymphatic transport of cholesterol and beta-sitostanol in the rat. J Lipid Res, 1979. 20: p. 646-653.

33. Heinemann, T., Kullak-Ublick, G. A., Pietruck, B., von Bergmann, K., Mechanisms of action of plant sterols on inhibition of cholesterol absorption. Comparison of sitosterol and sitostanol. Eur J Clin Pharmacol, 1991. 40: Suppl 1, S59-63.

34. Weststrate, J. A., Meijer, G. W., Plant sterol-enriched margarines and reduction of plasma total- and LDL-cholesterol concentrations in normocholesterolaemic and mildly hypercholesterolaemic subjects. Eur J Clin Nutr, 1998. 52: p. 334-343.

35. Matvienko, O. A., Lewis, D. S., Swanson, M., Arndt, B., et al., A single daily dose of soybean phytosterols in ground beef decreases serum total cholesterol and LDL cholesterol in young, mildly hypercholesterolemic men. Am J Clin Nutr, 2002. 76: p. 57-64.

36. Rudkowska, I., AbuMweis, S. S., Nicolle, C., Jones, P. J., Cholesterol-lowering efficacy of plant sterols in low-fat yogurt consumed as a snack or with a meal. J Am Coll Nutr, 2008. 27: p. 588595.

37. Doornbos, A. M., Meynen, E. M., Duchateau, G. S., van der Knaap, H. C., Trautwein, E. A., Intake occasion affects the serum cholesterol lowering of a plant sterol-enriched single-dose yoghurt drink in mildly hypercholesterolaemic subjects. Eur J Clin Nutr, 2006. 60: p. 325-333.

38. Grundy, S. M., Mok, H. Y., Determination of cholesterol absorption in man by intestinal perfusion. J Lipid Res, 1977. 18: p. 263-271.

39. Ostlund, R. E., Jr., Spilburg, C. A., Stenson, W. F., Sitostanol administered in lecithin micelles potently reduces cholesterol absorption in humans. Am J Clin Nutr, 1999. 70: p. 826-831.

40. Mattson, F. H., Grundy, S. M., Crouse, J. R., Optimizing the effect of plant sterols on cholesterol absorption in man. Am J Clin Nutr, 1982. 35: p. 697-700.

41. Nissinen, M., Gylling, H., Vuoristo, M., Miettinen, T. A., Micellar distribution of cholesterol and phytosterols after duodenal plant stanol ester infusion. Am J Physiol Gastrointest Liver Physiol, 2002. 282: p. G1009-1015.

42. Kobayashi, M., Hamada, T., Goto, H., Imaizumi, K., Ikeda, I., Comparison of effects of dietary unesterified and esterified plant sterols on cholesterol absorption in rats. J Nutr Sci Vitaminol (Tokyo), 2008. 54: p. 210-214.

43. Miettinen, T. A., Vuoristo, M., Nissinen, M., Jarvinen, H. J., Gylling, H., Serum, biliary, and fecal cholesterol and plant sterols in colectomized patients before and during consumption of stanol ester margarine. Am J Clin Nutr, 2000. 71: p. 1095-1102.

44. Normen, L., Ellegard, L., Janssen, H. G., Steenbergen, H., et al., Phytosterol and phytostanol esters are effectively hydrolysed in the gut and do not affect fat digestion in ileostomy subjects. Eur J Nutr, 2006. 45: p. 165-170.

45. Carey, M. C., Small, D. M., Bliss, C. M., Lipid digestion and absorption. Annu Rev Physiol, 1983. 45: p. 651-677.

46. Richelle, M., Enslen, M., Hager, C., Groux, M., et al., Both free and esterified plant sterols reduce cholesterol absorption and the bioavailability of beta-carotene and alpha-tocopherol in normocholesterolemic humans. Am J Clin Nutr, 2004. 80: p. 171-177.

47. Spilburg, C. A., Goldberg, A. C., McGill, J. B., Stenson, W. F., et al., Fat-free foods supplemented with soy stanol-lecithin powder reduce cholesterol absorption and LDL cholesterol. J Am Diet Assoc, 2003. 103: p. 577-581.

48. Soderholm, P. P., Alfthan, G., Koskela, A. H., Adlercreutz, H., Tikkanen, M. J., The effect of high-fiber rye bread enriched with nonesterified plant sterols on major serum lipids and 


\section{CHAPTER 2}

apolipoproteins in normocholesterolemic individuals. Nutr Metab Cardiovasc Dis, 2012. 22: p. 575-82.

49. Glover, J., Green, C., Sterol metabolism 3. The distribution and transport of sterols across the intestinal mucosa of the guinea pig. Biochem J, 1957. 67: p. 308-316.

50. Ikeda, I., Tanaka, K., Sugano, M., Vahouny, G. V., Gallo, L. L., Inhibition of cholesterol absorption in rats by plant sterols. J Lipid Res, 1988. 29: p. 1573-1582.

51. Ikeda, I., Tanaka, K., Sugano, M., Vahouny, G. V., Gallo, L. L., Discrimination between cholesterol and sitosterol for absorption in rats. J Lipid Res, 1988. 29: p. 1583-1591.

52. Liu, Y., Manchekar, M., Sun, Z., Richardson, P. E., Dashti, N., Apolipoprotein B-containing lipoprotein assembly in microsomal triglyceride transfer protein-deficient McA-RH7777 cells. J Lipid Res, 2010. 51: p. 2253-2264.

53. Kam, N. T., Albright, E., Mathur, S. N., Field, F. J., Inhibition of acylcoenzyme A:cholesterol acyltransferase activity in CaCo-2 cells results in intracellular triglyceride accumulation. J Lipid Res, 1989. 30: p. 371-377.

54. Clark, S. B., Tercyak, A. M., Reduced cholesterol transmucosal transport in rats with inhibited mucosal acyl CoA:cholesterol acyltransferase and normal pancreatic function. J Lipid Res, 1984. 25: p. 148-159.

55. Field, F. J., Mathur, S. N., beta-sitosterol: esterification by intestinal acylcoenzyme A: cholesterol acyltransferase (ACAT) and its effect on cholesterol esterification. J Lipid Res, 1983. 24: p. 409-417.

56. Field, F. J., Born, E., Mathur, S. N., Effect of micellar beta-sitosterol on cholesterol metabolism in CaCo-2 cells. J Lipid Res, 1997. 38: p. 348-360.

57. Chang, C. C., Chen, J., Thomas, M. A., Cheng, D., et al., Regulation and immunolocalization of acyl-coenzyme A: cholesterol acyltransferase in mammalian cells as studied with specific antibodies. J Biol Chem, 1995. 270: p. 29532-29540.

58. Liang, Y. T., Wong, W. T., Guan, L., Tian, X. Y., et al., Effect of phytosterols and their oxidation products on lipoprotein profiles and vascular function in hamster fed a high cholesterol diet. Atherosclerosis, 2011. 219: p. 124-33.

59. Rideout, T. C., Harding, S. V., Jones, P. J., Consumption of plant sterols reduces plasma and hepatic triglycerides and modulates the expression of lipid regulatory genes and de novo lipogenesis in C57BL/6J mice. Mol Nutr Food Res, 2010. 54: p. Suppl 1, S7-13.

60. Davis, H. R., Jr., Zhu, L. J., Hoos, L. M., Tetzloff, G., et al., Niemann-Pick C1 Like 1 (NPC1L1) is the intestinal phytosterol and cholesterol transporter and a key modulator of whole-body cholesterol homeostasis. J Biol Chem, 2004. 279: p. 33586-33592.

61. Calpe-Berdiel, L., Escola-Gil, J. C., Julve, J., Zapico-Muniz, E., et al., Differential intestinal mucosal protein expression in hypercholesterolemic mice fed a phytosterol-enriched diet. Proteomics, 2007. 7: p. 2659-2666.

62. Smart, E. J., De Rose, R. A., Farber, S. A., Annexin 2-caveolin 1 complex is a target of ezetimibe and regulates intestinal cholesterol transport. Proc Natl Acad Sci U S A, 2004. 101: p. 3450-3455.

63. Valasek, M. A., Weng, J., Shaul, P. W., Anderson, R. G., Repa, J. J., Caveolin-1 is not required for murine intestinal cholesterol transport. J Biol Chem, 2005. 280: p. 28103-28109.

64. Plosch, T., Kruit, J. K., Bloks, V. W., Huijkman, N. C., et al., Reduction of cholesterol absorption by dietary plant sterols and stanols in mice is independent of the Abcg5/8 transporter. J Nutr, 2006. 136: p. 2135-2140.

65. Schultz, J. R., Tu, H., Luk, A., Repa, J. J., et al., Role of LXRs in control of lipogenesis. Genes Dev, 2000. 14: p. 2831-2838.

66. Grefhorst, A., Elzinga, B. M., Voshol, P. J., Plosch, T., et al., Stimulation of lipogenesis by pharmacological activation of the liver $X$ receptor leads to production of large, triglyceride-rich very low density lipoprotein particles. J Biol Chem, 2002. 277: p. 34182-34190.

67. Lo Sasso, G., Murzilli, S., Salvatore, L., D'Errico, I., et al., Intestinal specific LXR activation stimulates reverse cholesterol transport and protects from atherosclerosis. Cell Metab, 2010. 12: p. 187-193.

68. Yamanashi, Y., Takada, T., Suzuki, H., Niemann-Pick C1-like 1 overexpression facilitates ezetimibe-sensitive cholesterol and beta-sitosterol uptake in CaCo-2 cells. J Pharmacol Exp Ther, 2007. 320: p. 559-564.

69. Zhang, J. H., Ge, L., Qi, W., Zhang, L., et al., The N-terminal domain of NPC1L1 protein binds cholesterol and plays essential roles in cholesterol uptake. J Biol Chem, 2011. 286: p. 2508825097. 


\section{EFFECTS ON INTESTINAL CHOLESTEROL METABOLISM}

70. Jakulj, L., Trip, M. D., Sudhop, T., von Bergmann, K., et al., Inhibition of cholesterol absorption by the combination of dietary plant sterols and ezetimibe: effects on plasma lipid levels. J Lipid Res, 2005. 46: p. 2692-2698.

71. Lin, X., Racette, S. B., Lefevre, M., Ma, L., et al., Combined effects of ezetimibe and phytosterols on cholesterol metabolism: a randomized, controlled feeding study in humans. Circulation, 2011. 124: p. 596-601.

72. Duval, C., Touche, V., Tailleux, A., Fruchart, J. C., et al., Niemann-Pick C1 like 1 gene expression is down-regulated by LXR activators in the intestine. Biochem Biophys Res Commun, 2006. 340: p. 1259-1263.

73. Calpe-Berdiel, L., Escola-Gil, J. C., Blanco-Vaca, F., New insights into the molecular actions of plant sterols and stanols in cholesterol metabolism. Atherosclerosis, 2009. 203: p. 18-31.

74. Dang, H., Liu, Y., Pang, W., Li, C., et al., Suppression of 2,3-oxidosqualene cyclase by high fat diet contributes to liver $X$ receptor-alpha-mediated improvement of hepatic lipid profile. $\mathrm{J}$ Biol Chem, 2009. 284: p. 6218-6226.

75. Plat, J., Nichols, J. A., Mensink, R. P., Plant sterols and stanols: effects on mixed micellar $C$ omposition and LXR (target gene) activation. J Lipid Res, 2005. 46: p. 2468-2476.

76. Plat, J., Brufau, G., Dallinga-Thie, G. M., Dasselaar, M., Mensink, R. P., A plant stanol yogurt drink alone or combined with a low-dose statin lowers serum triacylglycerol and non-HDL cholesterol in metabolic syndrome patients. J Nutr, 2009. 139: p. 1143-1149.

77. Plat, J., Mensink, R. P., Plant stanol esters lower serum triacylglycerol concentrations via a reduced hepatic VLDL-1 production. Lipids, 2009. 44: p. 1149-1153.

78. Theuwissen, E., Plat, J., van der Kallen, C. J., van Greevenbroek, M. M., Mensink, R. P., Plant stanol supplementation decreases serum triacylglycerols in subjects with overt hypertriglyceridemia. Lipids, 2009. 44: p. 1131-1140.

79. Calpe-Berdiel, L., Escola-Gil, J. C., Ribas, V., Navarro-Sastre, A., et al., Changes in intestinal and liver global gene expression in response to a phytosterol-enriched diet. Atherosclerosis, 2005. 181: p. 75-85.

80. Plosch, T., van der Veen, J. N., Havinga, R., Huijkman, N. C., et al., Abcg5/Abcg8-independent pathways contribute to hepatobiliary cholesterol secretion in mice. Am J Physiol Gastrointest Liver Physiol, 2006. 291: p. G414-423.

81. Kruit, J. K., Plosch, T., Havinga, R., Boverhof, R., et al., Increased fecal neutral sterol loss upon liver $X$ receptor activation is independent of biliary sterol secretion in mice. Gastroenterology, 2005. 128: p. 147-156.

82. Temel, R. E., Sawyer, J. K., Yu, L., Lord, C., et al., Biliary sterol secretion is not required for macrophage reverse cholesterol transport. Cell Metab, 2010. 12: p. 96-102.

83. van der Velde, A. E., Vrins, C. L., van den Oever, K., Kunne, C., et al., Direct intestinal cholesterol secretion contributes significantly to total fecal neutral sterol excretion in mice. Gastroenterology, 2007. 133: p. 967-975.

84. Brown, J. M., Bell, T. A., 3rd, Alger, H. M., Sawyer, J. K., et al., Targeted depletion of hepatic ACAT2-driven cholesterol esterification reveals a non-biliary route for fecal neutral sterol loss. J Biol Chem, 2008. 283: p. 10522-10534.

85. Brufau, G., Kuipers, F., Lin, Y., Trautwein, E. A., Groen, A. K., A reappraisal of the mechanism by which plant sterols promote neutral sterol loss in mice. PLoS One, 2011. 6: p. e21576.

86. van der Veen, J. N., van Dijk, T. H., Vrins, C. L., van Meer, H., et al., Activation of the liver X receptor stimulates trans-intestinal excretion of plasma cholesterol. J Biol Chem, 2009. 284: $\mathrm{p}$. 19211-19219.

87. Sehayek, E., Duncan, E. M., Lutjohann, D., Von Bergmann, K., et al., Loci on chromosomes 14 and 2, distinct from $A B C G 5 / A B C G 8$, regulate plasma plant sterol levels in a C57BL/6J $x$ CASA/Rk intercross. Proc Natl Acad Sci U S A, 2002. 99: p 16215-16219.

88. Russell, J. C., Ewart, H. S., Kelly, S. E., Kralovec, J., et al., Improvement of vascular dysfunction and blood lipids of insulin-resistant rats by a marine oil-based phytosterol compound. Lipids, 2002. 37: p. 147-152.

89. Vaskonen, T., Mervaala, E., Krogerus, L., Karppanen, H., Supplementation of plant sterols and minerals benefits obese Zucker rats fed an atherogenic diet. J Nutr, 2002. 132: p. 231-237.

90. Corretti, M. C., Anderson, T. J., Benjamin, E. J., Celermajer, D., et al., Guidelines for the ultrasound assessment of endothelial-dependent flow-mediated vasodilation of the brachial artery: a report of the International Brachial Artery Reactivity Task Force. J Am Coll Cardiol, 2002. 39: p. 257-265.

91. Ntanios, F. Y., Jones, P. J., Frohlich, J. J., Dietary sitostanol reduces plaque formation but not lecithin cholesterol acyl transferase activity in rabbits. Atherosclerosis, 1998. 138: p. 101-110. 


\section{CHAPTER 2}

92. Plat, J., Beugels, I., Gijbels, M. J., de Winther, M. P., Mensink, R. P., Plant sterol or stanol esters retard lesion formation in $L D L$ receptor-deficient mice independent of changes in serum plant sterols. J Lipid Res, 2006. 47: p. 2762-2771.

93. Volger, O. L., Mensink, R. P., Plat, J., Hornstra, G., et al., Dietary vegetable oil and wood derived plant stanol esters reduce atherosclerotic lesion size and severity in apoE*3-Leiden transgenic mice. Atherosclerosis, 2001. 157: p. 375-381.

94. Weingartner, O., Lutjohann, D., Ji, S., Weisshoff, N., et al., Vascular effects of diet supplementation with plant sterols. J Am Coll Cardiol, 2008. 51: p. 1553-1561.

95. Celermajer, D. S., Sorensen, K. E., Bull, C., Robinson, J., Deanfield, J. E., Endotheliumdependent dilation in the systemic arteries of asymptomatic subjects relates to coronary risk factors and their interaction. J Am Coll Cardiol, 1994. 24: p. 1468-1474.

96. de Jongh, S., Vissers, M. N., Rol, P., Bakker, H. D., et al., Plant sterols lower LDL cholesterol without improving endothelial function in prepubertal children with familial hypercholesterolaemia. J Inherit Metab Dis. 2003, 26: p. 343-351.

97. Hallikainen, M., Lyyra-Laitinen, T., Laitinen, T., Agren, J. J., et al., Endothelial function in hypercholesterolemic subjects: Effects of plant stanol and sterol esters. Atherosclerosis, 2006. 188: p. 425-432.

98. Jakulj, L., Vissers, M. N., Rodenburg, J., Wiegman, A., et al., Plant stanols do not restore endothelial function in pre-pubertal children with familial hypercholesterolemia despite reduction of low-density lipoprotein cholesterol levels. J Pediatr, 2006. 148: p. 495-500.

99. Raitakari, O. T., Salo, P., Gylling, H., Miettinen, T. A., Plant stanol ester consumption and arterial elasticity and endothelial function. Br J Nutr, 2008. 100: p. 603-608.

100. De Jong, A., Plat, J., Bast, A., Godschalk, R. W., et al., Effects of plant sterol and stanol ester consumption on lipid metabolism, antioxidant status and markers of oxidative stress, endothelial function and low-grade inflammation in patients on current statin treatment. Eur $\mathrm{J}$ Clin Nutr, 2008. 62: p. 263-273. 


\section{CHAPTER 3}

Acute effects of plant stanol esters on hepatic and intestinal lipid and lipoprotein metabolism in mice

Els De Smet, Ronald P. Mensink, Maurice Konings, Gemma Brufau, Albert K. Groen, Rick Havinga, Marleen Schonewille, Anja Kerksiek, Dieter Lütjohann and Jogchum Plat

Submitted 


\section{CHAPTER 3}

\section{Abstract}

Aim: To gain more insight into the kinetics of plant stanol uptake and routing in C57BL/6J mice, after a plant stanol ester gavage. In addition, acute changes in intestinal and hepatic gene expression profiles were investigated.

Methods: At the age of 8 weeks, mice - fed a plant sterol/stanol poor diet from weaning - received an oral gavage consisting of $0.25 \mathrm{mg}$ cholesterol $+50 \mathrm{mg}$ plant stanol esters dissolved in olive oil. Animals were euthanized at different time points. In a $2^{\text {nd }}$ comparable set-up, mesenteric lymph-canulated versus sham-operated mice received the same oral gavage, which was now deuterium labeled.

Results and conclusion: Intestinal and hepatic sitostanol concentrations increased already within 15 minutes post-gavage. This rapid hepatic appearance was absent in lymph-canulated mice suggesting a very fast lymph-mediated uptake. Hepatic mRNA expression of SREBP2 and its target genes was rapidly decreased, whereas expression of LXR target genes was increased. The intestinal SREBP2 pathway was increased, whereas the expression of LXR target genes hardly changed. The 5-and 6-fold increased intestinal LDLr and PCSK9 expression is suggestive for TICE activation. We conclude that in C57BL/6J mice plant stanol kinetics are fast, and affect intestinal and hepatic gene expression within 15 minutes postprandial after lymph-mediated uptake. 


\section{Introduction}

In humans, plant sterols and stanols lower intestinal cholesterol absorption, thereby reducing serum low-density lipoprotein cholesterol (LDL-C) concentrations up to $10 \%$ at daily intakes of $2-2.5 \mathrm{~g}$ [1]. The exact mechanisms underlying this effect are unknown. Besides competition with cholesterol for incorporation into mixed micelles, which is necessary for intestinal cholesterol absorption [2], other mechanisms extending towards whole body sterol metabolism have been suggested as well [3]. Within the enterocytes and hepatocytes, there are numerous proteins involved in the transport and metabolism of cholesterol and plant sterols/stanols. For example, overexpression of the human gene encoding ATP-binding cassette transporter G5 and G8 (ABCG5, ABCG8) in the liver and the small intestine of C57BL/6J x SJL F 2 mice reduced intestinal cholesterol absorption and promoted biliary cholesterol secretion [4]. Although these cholesterol transporter genes are under control of the liver $X$ receptor (LXR), plant sterol and stanol ester feeding increased faecal neutral sterol excretion without changing intestinal LXR expression [5]. Furthermore, intestinal expression of LXR target genes such as Niemann-Pick C1-Like protein 1 (NPC1L1), ABCA1, ABCG5, ABCG8 was not influenced after plant sterol or stanol intake [6]. Consumption of plant sterols or stanols might also interfere with intracellular sterol handling, i.e. the incorporation of cholesterol into chylomicrons. In this respect, Liang et al. [7] showed decreased mRNA expression of acetylcoenzyme $A$ acetyltransferase (ACAT2) and microsomal triglyceride transfer protein (MTTP) after sitosterol feeding in Golden Syrian hamsters. Also, basolateral apolipoprotein B (apoB) secretion by HepG2 and Caco2 cells was decreased after incubation with plant sterols, suggesting a reduced production of lipoproteins by these liver and intestinal cell lines [8]. Although not conclusive, these studies show that plant sterols and stanols affect intestinal and hepatic sterol metabolism in vitro and in various animal models. For the animal data, the absence of consistent effects may relate to the various amounts of plant sterols in the diets, resulting in different tissue and serum concentrations, which may affect pathways underlying the cholesterol-lowering effects of the added plant sterols/stanols. Besides the potentially confounding effect of the background diet, it should also be acknowledged that metabolism in rodents is extremely fast in comparison to man. In this context, Igel and coworkers [9] earlier showed that intestinal uptake of dietary plant sterols was an extremely fast process, i.e. free plant sterols administered into the stomach were already present in enterocytes 15 minutes later. In other words, to study in vivo effects of plant sterols and stanols in mice, sampling must occur at short intervals immediately after administration. To gain more insight in the kinetics of plant sterol and stanol distribution, we used C56BL/6J mice, which were fed a plant sterol and stanol poor diet from weaning. For this we were particularly interested to see whether the fast appearance of plant sterols in the enterocytes was also visible in the liver. In addition, the acute effects of plant stanol esters on intestinal and hepatic expression of genes involved in lipid and lipoprotein metabolism were monitored from 0 minutes to 240 minutes post-gavage. In addition, post-gavage changes in plant sterol and deuterated plant stanol concentrations were examined as well. We here show that an acute bolus of dietary deuterium labeled sitostanol provided as sitostanol oleate appeared already after 15 minutes in the liver. This rapid hepatic appearance was absent in lymph-canulated mice suggesting a very fast lymph-mediated uptake possible via pre-formed available chylomicrons. 


\section{CHAPTER 3}

Also, the expression profiles of genes involved in hepatic and intestinal lipid and lipoprotein metabolism changed rapidly after the gavage. Interestingly, effects on gene expression in liver and intestine were in opposite direction.

\section{Materials and methods}

\section{Study 1: Animals, diet and experimental design}

Female C57BL/6J pups (F0) were fed a plant sterol and stanol poor diet from weaning and used for breeding at the age of 8 weeks. The newborn pups (F1) were fed the same plant sterol and stanol poor diet and housed in a light- and temperaturecontrolled facility with free access to water. At the age of 8 weeks, the mice (10 male/11 female) were given an oral gavage, which consisted of unesterified cholesterol $(0.25 \mathrm{mg})$ (Sigma, St.Louis, Mo) and plant stanols $(50 \mathrm{mg})$, which were provided as their fatty acid esters, dissolved in $500 \mu \mathrm{l}$ refined plant sterol poor olive oil. Their regular plant sterol poor food was removed from the cages two hours before the start of the gavage to bring the mice in "fasting" condition. The stanol ester mixture used was prepared by RAISIO Nutrition Ltd and composed of $70 \%$ sitostanol and 30\% campestanol (Benecol Liquid, Raisio, Finland). Plant stanols were esterified with a fatty acid blend containing $80 \%$ linoleic acid, $15 \%$ oleic acid and $5 \%$ stearic and palmitic acids to produce fat-soluble plant stanol esters. All mice were injected with Temgesic $(0.1 \mathrm{mg} / \mathrm{kg}$ ) (Schering-Plough, Reckitt Benkiser Healthcare (UK) Limited) subcutaneously 30 minutes before the gavage for painrelieve. At 7 different time points post-gavage $(T=0,15,30,60,120,180$ and 240 minutes), mice were anesthetized with isoflurane (1-2\%) directly followed by blood and tissue collection. The experiment was approved by the Ethical Committee for animal testing of Maastricht University, the Netherlands (project number 2009-129).

\section{Study 2: Animals, diet and experimental design}

For this experiment, 35 male C57BL/6J mice were fed a plant sterol and stanol poor diet from weaning, as described for study 1 . At the age of 8 weeks, mice were anesthetized and the ductus lymphaticus thoracicus was canulated proximal from the cisternae magnum via an abdominal approach. The mice in the control group were subjected to a sham operation, leaving the lymph circulation intact. Immediately after surgery, they received the same gavages as used in study 1 . The only difference was that we now used d4-plant stanols $(50 \mathrm{mg})$, which were esterified with oleic acid and d6-cholesterol $(0.25 \mathrm{mg})$. A hydrogenation reaction was used to reduce stigmasterol to d4-plant stanols [10]. The esterification of d4-plant stanols was performed by RAISIO Nutrition Ltd, Finland. The plant stanol blend contained $90 \%$ d4-sitostanol, $8 \%$ d4-campestanol and $2 \%$ non-labeled stigmasterol and brassicasterol. Using the deuterated plant stanols and cholesterol enabled us to specifically follow the plant stanols and cholesterol from the gavage into the circulation and the tissues over time. The mice remained under anesthesia until sacrificed at 6 different time points post-gavage. This experiment was approved by the Ethical Committee on animal testing of Groningen University, the Netherlands (project number 5356D). 


\section{Sample collection}

In both studies, fasting blood was collected by cardiac puncture into EDTA tubes. Plasma was separated from whole blood by centrifugation at $1000 \mathrm{xg}$ and stored at $-80^{\circ} \mathrm{C}$. After sacrificing, the liver was removed, rinsed with phosphate buffered saline (PBS), and stored for mRNA expression analysis and measurement of plant sterol and stanol concentrations. The intestines were removed, carefully rinsed after a midline incision and divided into 4 segments: the duodenum, jejunum, ileum and colon. Next, each segment was further divided into smaller parts. The first part of the three small intestinal segments was used for mRNA analysis. These samples were immediately frozen in liquid nitrogen. In contrast, the second part of the intestinal segments, which was used to determine the sterol and stanol concentrations, was scraped before freezing in order to obtain an enterocyte-rich sample. All samples were stored at $-80^{\circ} \mathrm{C}$.

\section{Serum and tissue concentration of sterols and stanols}

Hepatic, intestinal and plasma plant sterol (sitosterol and campesterol), plant stanol (sitostanol and campestanol), and cholesterol precursor (lathosterol and desmosterol) concentrations were analyzed by gas-liquid chromatography-mass spectrometry (GC-MS), as described previously [11]. D4-plant stanols and d6cholesterol were measured as described by Lütjohann et al. [9] and Sudhop et al. [12]. All samples from the same animal were always analyzed in the same run.

\section{RNA preparation and real-time RT-PCR}

Total RNA was isolated from the livers, the duodenum, the jejunum and the ileum. After grinding, the lysate was homogenized in RLT buffer. RNA purification was conducted using the RNeasy mini kit (Qiagen, The Netherlands). Reverse transcription was performed with $350 \mathrm{ng}$ total RNA as described [13]. To $2 \mu \mathrm{l}$ cDNA, $1 \mu \mathrm{l}$ primer of the gene of interest and $1 \mu \mathrm{l}$ primer of the household gene were added (supplemental table 1). The PCR mixture also consisted of $6 \mu \mathrm{l}$ water and $10 \mu \mathrm{l}$ mastermix (Applied Biosystems). The probes from the genes of interest were FAM labeled at the 5' end. All data was normalized to hypoxanthine phosphoribosyltransferase 1 (HPRT1) (VIC labeled/MGB Probe, Primer Limited; Gibco, Life Technologies). The cDNA was amplified for 40 cycles.

\section{Results}

\section{Intestinal cholesterol and plant stanol concentrations}

During the 240 minutes post-gavage period in study 1 , there was a clear response in transit time of plant stanols within the scraped enterocytes from proximal to distal along the gastrointestinal tract. As expected, the increase in sitostanol became apparent first in the duodenum, followed by the jejunum, ileum and finally in the colon. Results for absolute $(\mu \mathrm{g} / \mathrm{mg}$ wet tissue; figure $1+$ supplemental fig 1 , panels A) as well as cholesterol-standardized (figure $1+$ supplemental fig 1 , panels $A^{\prime}$ ) levels were comparable. The same patterns were observed for campestanol, but 


\section{CHAPTER 3}

less pronounced which could be explained by the composition of the gavage (figure 1 , panel $B$ and $\left.B^{\prime}\right)$. There was a remarkable strong increase in both sitostanol as well as campestanol concentrations in the ileum after 2 hours. As expected, the uptake at the apical side between the lymph-canulated and the sham-operated mice (supplemental figure 2, panels A and B) was comparable. Also, the pattern of d4sitostanol/d6-cholesterol was comparable as that of $\mathrm{d} 4$-campestanol/d6-cholesterol, which was again less pronounced. Although the gavage also contained a small amount of cholesterol, the total cellular cholesterol concentrations in the scraped enterocytes decreased slightly over time (figure 1, panel C). However, concentrations of the gavage-derived d6-cholesterol within enterocytes increased over time (study 2; supplemental figure 1, panels $\mathrm{C}+\mathrm{D}$ ).
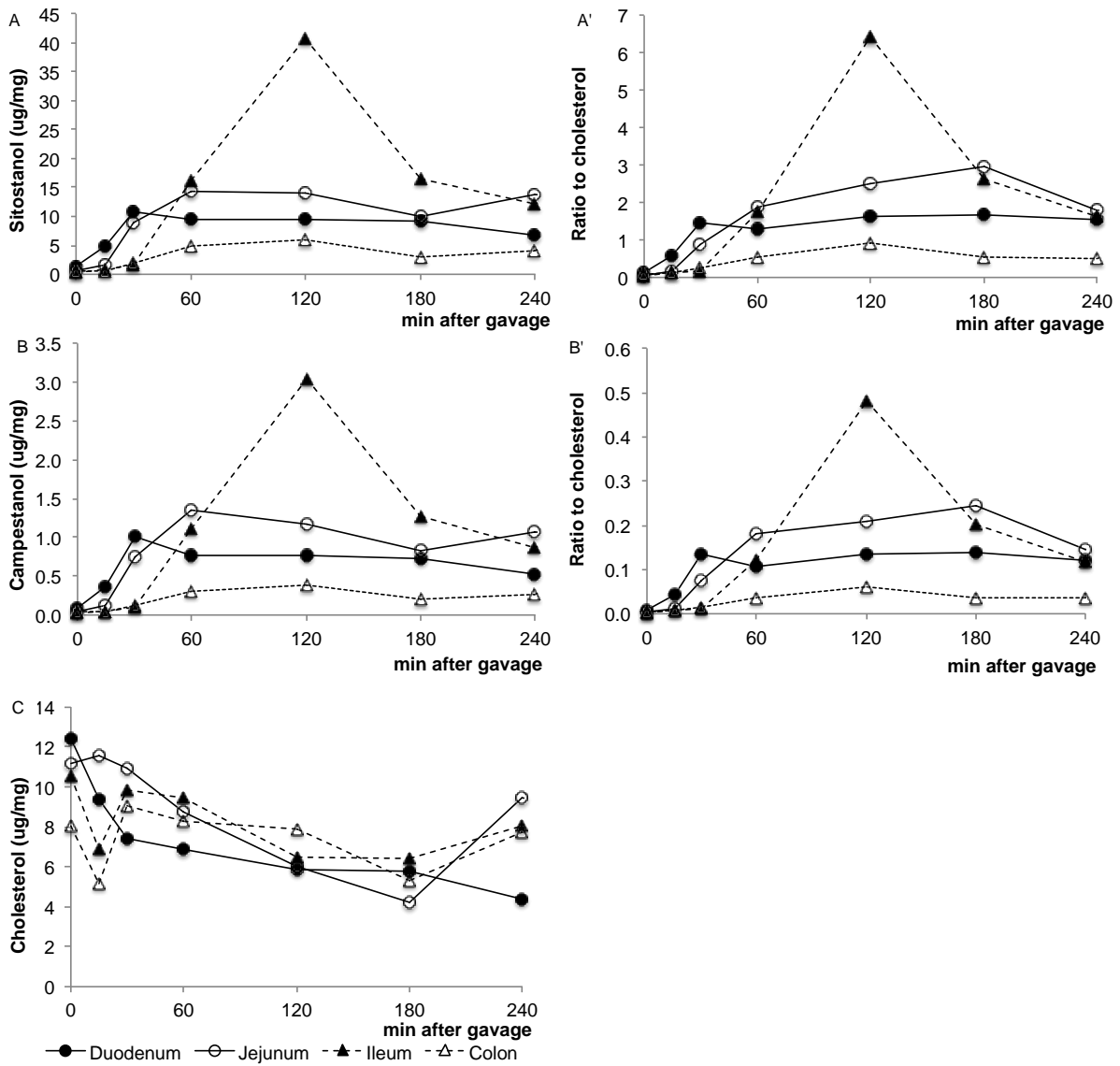

Figure 1: Study I: Time kinetics of sitostanol $\left(A+A^{\prime}\right)$, campestanol $\left(B+B^{\prime}\right)$ and cholesterol $(C)$ levels in the intestinal tissue at different time points expressed as absolute value and as a ratio to cholesterol. Values are expressed as means ( $\mathrm{n}=2$ or 3 each). 
The intestinal mRNA expression of sterol regulatory element binding protein 2 (SREBP2) and its target genes; 3-hydroxy-3-methyl-glutaryl-CoA reductase (HMGCoA reductase), the low-density lipoprotein receptor (LDLr) and proprotein convertase subtilisin/kexin type 9 (PCSK9) were clearly upregulated (figure 2, panel A) during the post-gavage period. However, the increase in mRNA expression of HMG-CoA reductase did not result in an increase in lathosterol and desmosterol concentrations (supplemental figure 3, panel A). There was no clear consistent change in the duodenal expression profiles of LXR $\alpha$ and its target genes ABCG5, ABCG8 and ABCA1 throughout the post-gavage period (figure 2, panel B). Finally, both intestinal apoB and MTTP expression slightly, but gradually increased over time for three hours following the gavage (figure 2, panel C).

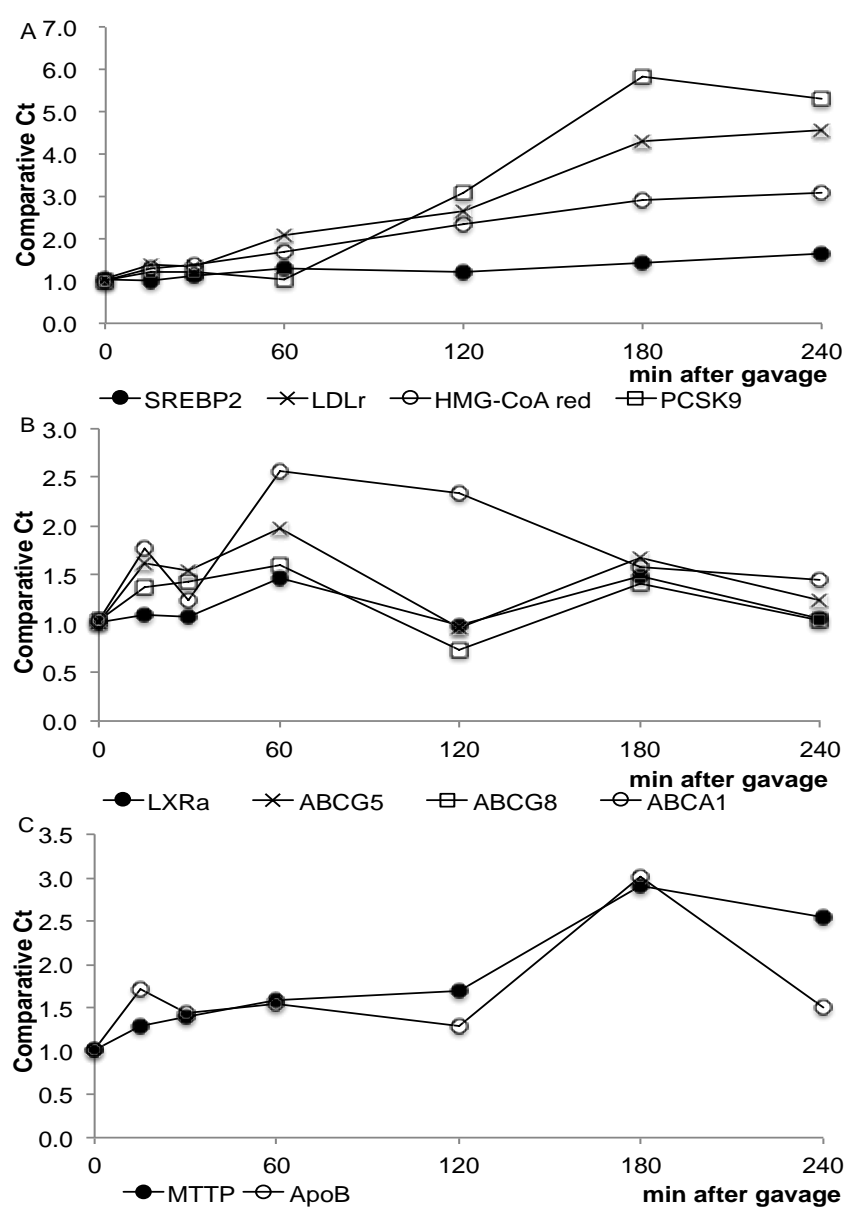

Figure 2: Study I: Changes in the expression profile of genes involved in the sterol metabolism in the duodenum. Values are expressed as means ( $n=2$ or 3 each). 


\section{CHAPTER 3}

Serum and hepatic cholesterol and plant stanol concentrations over time

In study 1, serum sitostanol and campestanol concentrations clearly increased during the hours following the oral gavage. This increase in serum concentrations started from 30-60 minutes post-gavage (figure 3) and continued over the following hours.
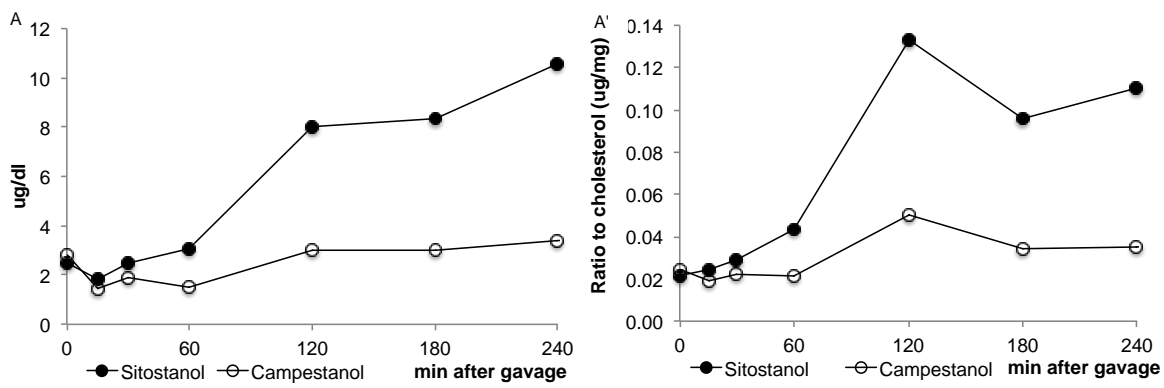

Figure 3: Study I: Time kinetics of sitostanol and campestanol levels in the serum at different time points expressed as an absolute value and as a ratio to cholesterol. Values are expressed as means $(n=2$ or 3 each).

Surprisingly, hepatic sitostanol concentrations were already increased after 15 minutes (figure 4, panel A), i.e. even before the increase in serum sitostanol concentrations became evident. After this first rapid appearance, sitostanol concentrations decreased and increased again after 120 minutes. Hepatic campestanol concentrations followed the same pattern, but like for the enterocytes, changes were less pronounced.

The intriguing question is now via which route the plant stanols reached the liver already after 15 minutes. Interestingly, this very rapid hepatic appearance of the plant stanols was absent in the lymph-canulated mice in study 2 (figure 4, panel B), whereas it was again clearly visible in the sham-operated mice (figure 4, panel C). From the data in study 2, it is evident that the hepatic plant stanols were derived from the gavage, since the gavage contained d4-plant stanols that could be detected in the liver. All changes in serum and hepatic plant stanol concentrations occurred without changing hepatic and serum cholesterol concentrations (supplemental figure 4 , panels A and B). Finally, we were not able to detect d6-cholesterol in the liver in the post-gavage period. 

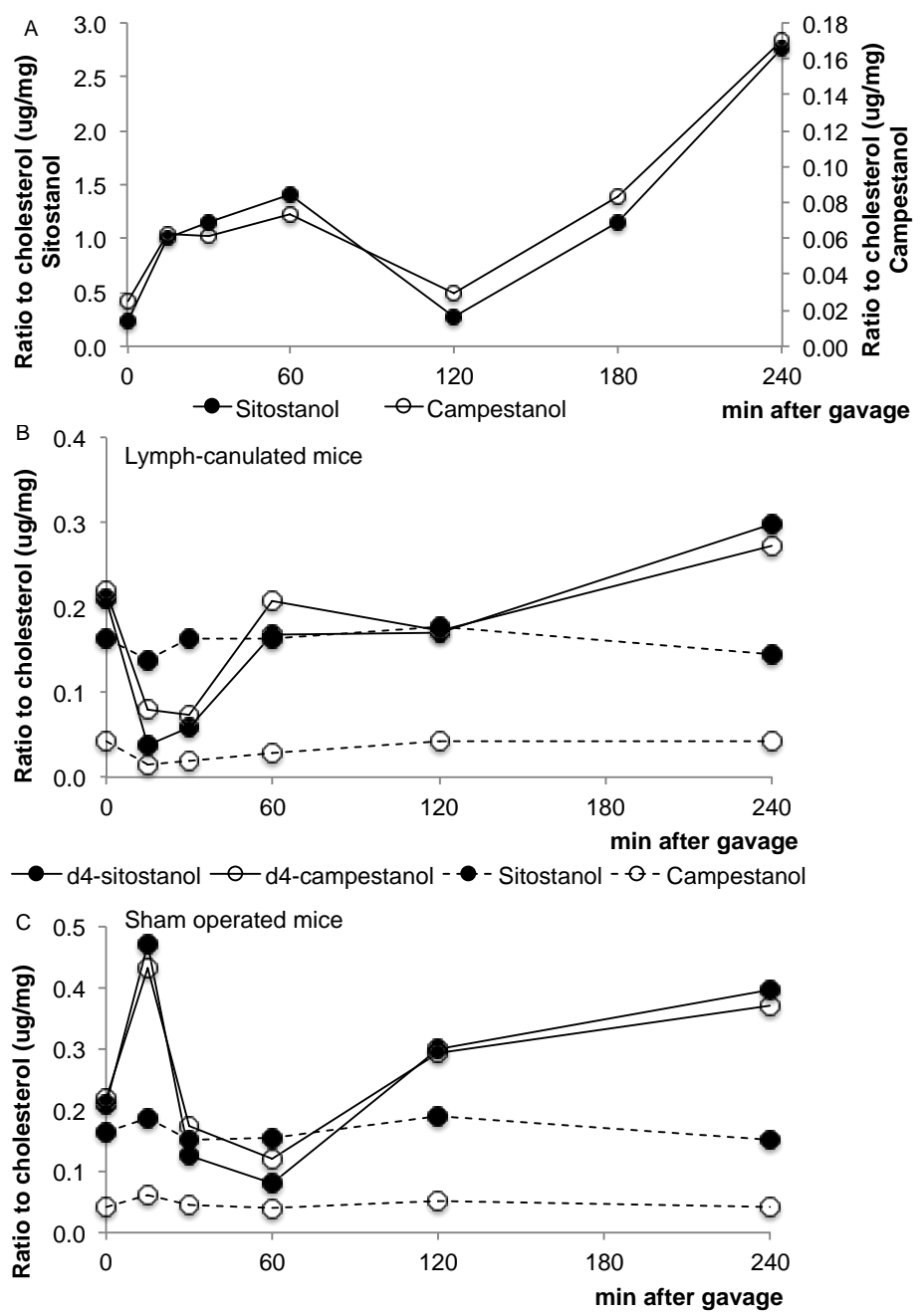

d4-sitostanol - - d4-campestanol -

- Sitostanol - $\diamond$ - Campestanol

Figure 4: Study I: Time kinetics of sitostanol and campestanol levels in the liver at different time points expressed as $\mu \mathrm{g} / \mathrm{mg}$ cholesterol (A). Study II: Time kinetics of d4-sitostanol, sitostanol, d4-campestanol and campestanol levels in the liver of lymph-canulated mice (B) and in the liver of sham operated mice (C) at different time points. Values are expressed as means ( $\mathrm{n}=2$ or 3 each). 


\section{CHAPTER 3}

Hepatic expression profile of genes involved in sterol metabolism

In the liver, mRNA expression levels of SREBP2 and its target genes HMG-CoA reductase, the LDLr and PCSK9 were all very rapidly downregulated, already after 15 minutes (figure 5, panel A). The hepatic concentration of lathosterol and desmosterol remained practically stable (supplemental figure 3, panel B). In contrast to the down regulation of the SREBP2 pathway, hepatic expression profiles of $L X R \alpha$ and its target genes $A B C G 5$ and $A B C G 8$ were upregulated, again already starting after 15 minutes (figure 5, panel B). Finally, mRNA levels of apoB and MTTP were immediately down-regulated post-gavage (figure 5 , panel C).
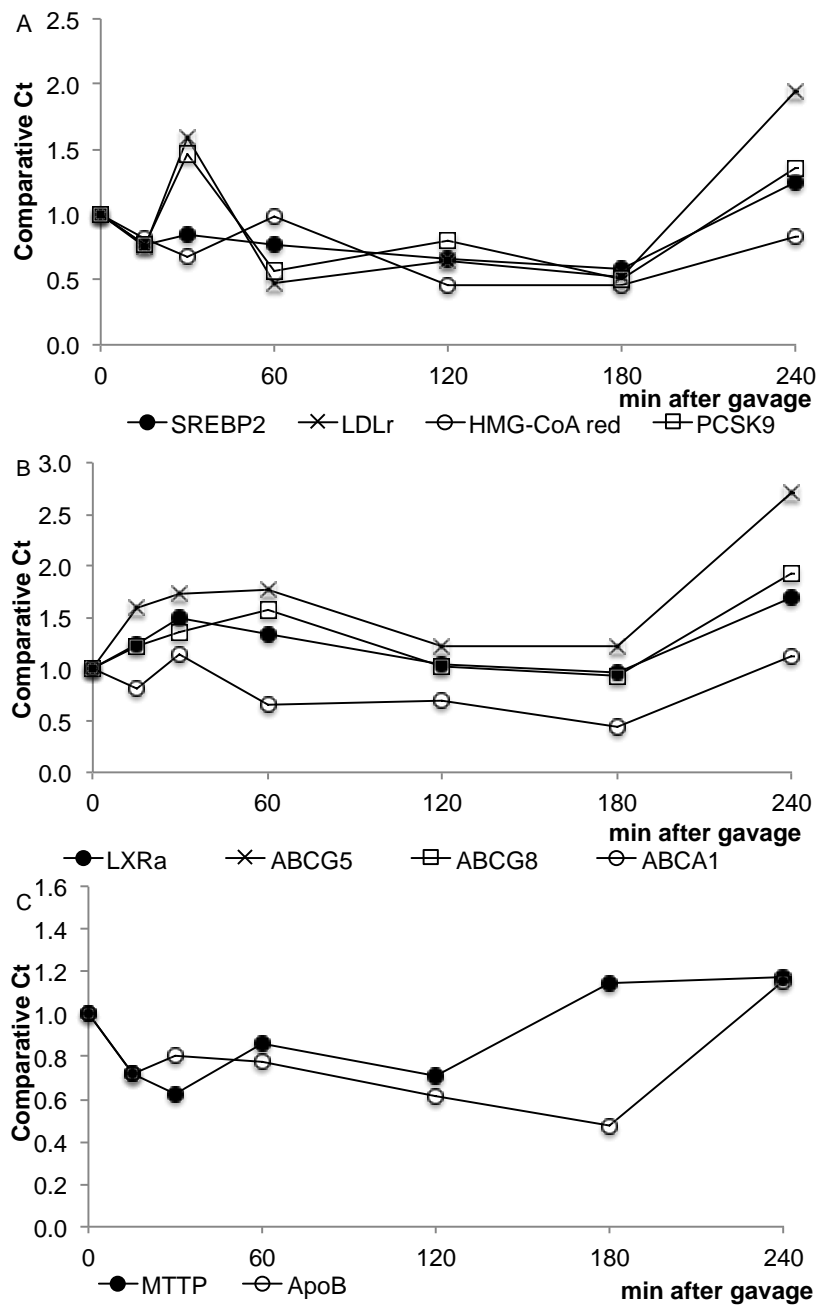

Figure 5: Study I: Changes in the hepatic expression profile of genes involved in the sterol metabolism. Values are expressed as means ( $\mathrm{n}=2$ or 3 each). 


\section{Discussion}

In this study we show that in C57BL/6J wild-type mice hepatic sitostanol and campestanol concentrations increased already after 15 minutes following an oral gavage with (deuterated) plant stanol esters and cholesterol. This rapid hepatic appearance was absent in lymph-canulated mice. Therefore, our data suggests that plant stanols can be taken up via a very fast lymph-mediated route, possibly via preformed intestinal available chylomicrons. Interestingly, changes in serum plant stanols lagged behind and became evident after 30-60 minutes. In the intestine, the SREBP2 pathway was activated, whereas expression of LXR and its target genes remained practically unchanged during the post-gavage period. Especially, the increase in intestinal LDLr and PCSK9 expression was pronounced. Surprisingly, changes in hepatic gene expression were opposite to those in the intestine. It should be noticed that these acute effects after a one-time single dose of plant stanol esters are different from those observed after longer-term intake of plant stanol esters [14]. Moreover, also in humans we have earlier shown an increased LDLr expression in peripheral blood mononuclear cells - which correlate positively to that in the liver [15] - after 8 weeks plant stanol ester consumption [16]. Questions that are not answered by our studies are (1) how do plant stanols reach the liver so rapidly after intake in a lymph-dependent way without a clear increase in serum concentrations, (2) do the plant stanols reach the liver in free or esterified form, and (3) does the acute change in hepatic plant stanol concentrations affect liver function.

As expected, there was a clear response in transit time of plant stanols within the enterocytes from proximal to distal along the gastrointestinal tract. This pattern was highly consistent and might relate to the fact that we fed the mice plant sterol poor diets from weaning to start the oral gavage with very low background plant sterol concentrations in serum as-well-as in tissues. In table 1, we compared serum and tissue plant sterol concentrations in three different studies using diets containing different plant sterol contents. It is evident that lower plant sterol contents result in lower concentrations in various tissues. Therefore, it could be argued that differences in dietary plant sterol content might be a main reason for the large inconsistency between these studies.

Table 1: Comparison of serum and liver concentration of plant sterols after administration of diets different in plant sterol content.

\begin{tabular}{|c|c|c|c|}
\hline & Standard chow ${ }^{[30]}$ & Unpublished data $^{1}$ & Our study (F1) \\
\hline \multicolumn{4}{|l|}{ Diet } \\
\hline Campesterol (ng/ml) & 199 & 63.8 & 9.85 \\
\hline Sitosterol (ng/ml) & 582 & 219 & 54.5 \\
\hline \multicolumn{4}{|l|}{ Serum } \\
\hline Campesterol (mg/dL) & $3.60 \pm 0.76$ & $1.22 \pm 0.17$ & $0.70 \pm 0.26$ \\
\hline $\begin{array}{l}\text { Sitosterol (mg/dL) } \\
\text { Liver }\end{array}$ & $1.00 \pm 0.20$ & $0.52 \pm 0.07$ & $0.35 \pm 0.14$ \\
\hline Campesterol (ng/mg) & $247 \pm 40$ & $102 \pm 17$ & $72 \pm 15$ \\
\hline Sitosterol $(\mathrm{ng} / \mathrm{mg})$ & $52.8 \pm 8.0$ & $28 \pm 4.1$ & $18 \pm 3.3$ \\
\hline
\end{tabular}

${ }_{1}^{1}$ unpublished data. C57BL/6J mice were fed a plant sterol poor chow, a plant sterol enriched or a plant stanol enriched diet for 1 week. After sacrificing, blood and tissues were collected and analyzed. Mice in this study received a plant sterol poor chow. 


\section{CHAPTER 3}

As shown in figure 1, in our hands using the plant sterol poor diets preceding the experimental day, 15 minutes after the oral gavage, the sitostanol concentration started to increase in the proximal parts of the small intestine. This is in agreement with observations from Igel and colleagues [9], who also detected the deuterated sterols and stanols in the small intestinal wall 15 minutes after administration via a stomach tube, indicating that the uptake in the enterocytes is a rapid process in mice. Unexpected, plant stanol concentrations strongly increased in the ileum 2 hours post-gavage. This can be explained by the fact that the proximal part of the small intestine is the major site of chylomicron formation and secretion, resulting in a fast disappearance of plant stanols within the enterocyte of the duodenum and jejunum. In the more distal parts, chylomicron synthesis is less, resulting in a transient accumulation of plant stanols [17] that fades away when ABCG5/ABCG8 activity increases [18].

In this study, we have shown that within the same time frame, plant stanol concentrations were also strongly elevated in the liver suggesting that plant stanol uptake and distribution is even faster than indicated by lgel et al. [9]. This extremely rapid hepatic appearance of sitostanol was unexpected, since it suggests that it only takes 15 minutes for the plant stanol esters to be digested and absorbed into the enterocytes, incorporated into chylomicrons, secreted into the lymph, and removed by the liver after entering the circulation. We therefore propose that this very fast lymph-mediated uptake should be facilitated via pre-formed available intestinal chylomicrons. Coppack et al. [19] described earlier the possibility of releasing such chylomicrons following ingestion of carbohydrates as well as mixed meals. Surprisingly, there was no clear change in serum plant stanol or cholesterol concentrations preceding the hepatic appearance at this early time point. It cannot be excluded that the enrichment of plant stanols in serum was too low to be detected at this stage due to a strong dilution. If true, this dilution must have been lower in the liver making detection possible. The second, larger increase in hepatic plant stanol concentrations after 120 minutes might be explained by the uptake of chylomicron remnants by the liver. Theoretically, it is possible to explain this early increase in hepatic concentrations by postulating that plant stanols not only reach the liver via the "normal" chylomicron route, i.e. via secretion into lymph, but also through the portal vein, independent of chylomicron incorporation. Therefore, a second study was performed to specifically address the route of entrance into the liver. In that study, we found that the rapid appearance of d4-plant stanols in the liver was absent in the lymph-canulated mice. However, the uptake into the enterocytes was comparable between the lymph-canulated and the sham-operated mice. Therefore, we must conclude that the rapid appearance of plant stanol esters in the liver is lymph-dependent. Interestingly, we were not able to detect d6-cholesterol in the liver within this short time frame, suggesting that the hepatic appearance was specific for plant stanols. However, it could also be possible that the detection limit for d6cholesterol was too low due to a strong dilution. In line with the observed reduced post-gavage cholesterol content of the scraped enterocytes in the duodenum, the expression of SREBP2 [20] and its target genes increased. Remarkably, the hepatic SREBP2 pathway was down regulated. Whether this will affect metabolism is not known, as changes in mRNA expression are not always translated into changes in protein expression and activity. Therefore, we can only speculate why gene expression in these two tissues differed. In the intestine, intracellular cholesterol concentrations post-gavage decreased, which might have activated the SREBP2 
pathway. In the liver, the expression of LXR target genes ABCG5 and ABCG8, both involved in sterol efflux, was increased. The question remains whether the increased hepatic LXR expression can be explained by an effect of changes in intracellular cholesterol concentrations or maybe via a direct effect of sitostanol. In this respect, both intestine and liver showed a rapid increase in sitostanol concentrations. Therefore, it is not likely that sitostanol itself will be responsible for the changes in gene expression. There might, however, be an alternative explanation. Spann et al. [21] recently showed that desmosterol was an important regulator in LXR activation in macrophages. We observed that desmosterol concentrations in the intestines were severely reduced already 15 minutes post-gavage, whereas those in the liver remained stable. In this respect, the large difference in absolute desmosterol concentrations between liver and intestine was remarkable. Therefore, it could be speculated that the differences in desmosterol concentrations might have influenced tissue specific LXR expression. However, It should be noticed that there was a time delay of several hours between the decrease in intestinal desmosterol concentrations and the changes in the expression profile of LXR. Finally, we found a decrease in the hepatic expression profile of MTTP and apoB, suggesting a reduced hepatic lipoprotein production, which is in line with earlier cell [8] and human studies [22]. The 5-fold increased intestinal LDLr expression is suggestive for an enhanced clearance of cholesterol via the enterocytes. Le May et al. [23] showed that LDL provides cholesterol to the intestine for transintestinal cholesterol excretion (TICE), which contributes up to $33 \%$ of total faecal sterol loss in mice. Recently, Davidson and colleagues [24] demonstrated also a role for LDL particles in the delivery of cholesterol for TICE. Moreover, Brufau et al. [25] earlier showed an increase in TICE activity after plant sterol intake. Therefore, it may be possible that the increased intestinal LDLr expression, observed in our study, contributes to plant stanol-induced TICE activation. Recently, not only a role for intestinal LDLr expression, but also for PCSK9 was suggested in TICE [23]. Interestingly, PCSK9 was the strongest upregulated gene we evaluated in our study. Preclinical [26] as well as clinical studies [27] indicate that blocking PCSK9, thereby increasing the number of available LDr, is an attractive route to lower LDL-C levels. More research is however needed to unravel the role of PCSK9 after consumption of plant stanols, especially in humans. Finally, if activation of TICE by plant stanols, thereby increasing the clearance of cholesterol through intestinal LDLr upregulation and neutral sterol secretion into the intestinal lumen, contributes to the mechanism behind the LDL-C reductions, this may also explain why no clear reductions on chylomicron formation in humans are observed after plant stanol ester consumption $[28,29]$. In other words, it is possible that increased secretion and reduced intestinal cholesterol absorption explain the cholesterol-lowering activity of plant stanols. The suggested mechanism via TICE however needs to be further elucidated. In this respect, it should be mentioned that despite the strong increase in intestinal LDLr expression, the cholesterol concentrations in the serum and within the enterocyte did not change. Also, how these results compare to the human situation, warrants further study. 


\section{CHAPTER 3}

In summary, we have demonstrated that orally applied plant stanols had a fast appearance within the enterocytes and in addition were rapidly taken up into the liver. This rapid hepatic appearance could not be observed in the lymph-canulated mice, suggesting a lymph dependent route of entrance. Post-gavage changes in hepatic gene expression patterns of genes involved in sterol metabolism were opposite as those of the intestines, indicating that acute effects of plant stanols are tissue specific. Finally, in the acute condition intestinal LDLr and PCSK9 expression were strongly increased for which we do not yet oversee the role in the changes in cholesterol metabolism towards longer term interventions, but this certainly demands further attention in future studies.

\section{Acknowledgement}

We thank Rik Tinnemans and Rick Havinga for expert technical assistance. We are grateful to Anja Kerksiek for the analysis of the plant sterols, stanols and cholesterol precursors. All authors read and approved the final manuscript. Authors have no conflict of interest. The study was sponsored by RAISIO Nutrition Ltd, Finland.

\section{Supplemental data}

Supplemental table 1: Genes of interest and their specific assay on demand.

\begin{tabular}{ll}
\hline Gene & $\begin{array}{l}\text { Specific assay } \\
\text { (Applied Biosystems, Life Technologies) }\end{array}$ \\
\hline ABCA1 & Mm00442646_m1 \\
ABCG5 & Mm00446241_m1 \\
ABCG8 & Mm00445970_m1 \\
ACAT2 & Mm00782408_s1 \\
ApoB & Mm01545156_m1 \\
HMG-CoA reductase & Mm01282499_m1 \\
HPRT1 & Mm00446968_m1 \\
LXRa & Mm00443451_m1 \\
MTTP & Mm00435015_m1 \\
NPC1L1 & Mm01191972_m1 \\
PCSK9 & Mm01263610_m1 \\
SREBP2 & Mm01306292_m1 \\
\hline
\end{tabular}




\section{ACUTE EFFECTS ON INTESTINAL AND HEPATIC LIPID METABOLISM}
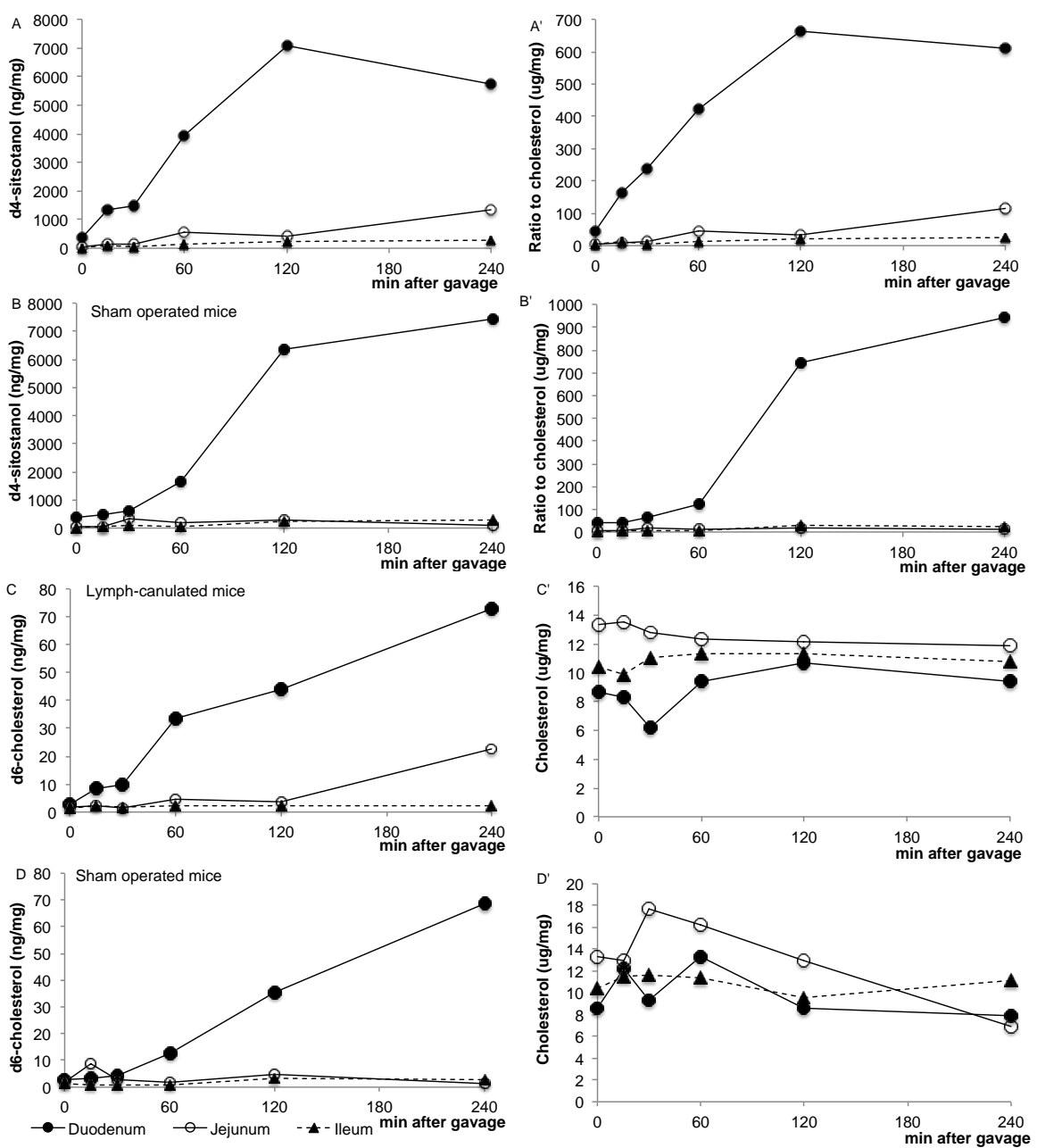

Supplemental figure 1: Study II: Time kinetics of d4-sitostanol levels in intestinal tissue of lymph-canulated mice $\left(A+A^{\prime}\right)$ and of sham operated mice $\left(B+B^{\prime}\right)$ at different time points. Results are expressed as absolute concentration and standardized for cholesterol. Each time point represent the mean of 2 or 3 animals. Time kinetics of d6-cholesterol (C) and cholesterol (C') concentrations of lymph-canulated mice and of sham-operated mice (D-D') are shown in panel C and C', and D and D', respectively. 


\section{CHAPTER 3}
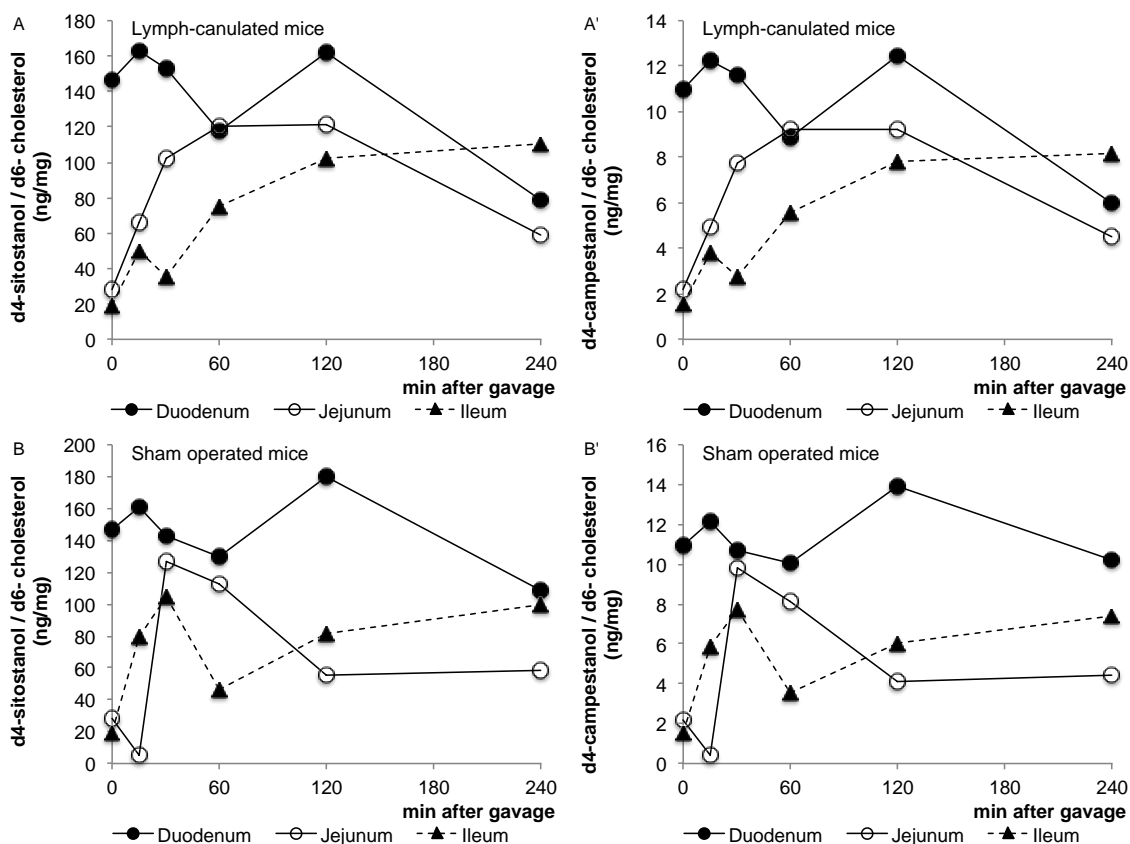

Supplemental figure 2: Study II: Time kinetics of d4-sitostanol/d6-cholesterol and d4-campestanol/d6cholesterol levels in the intestinal tissue of lymph-canulated $\left(A+A^{\prime}\right)$ and of sham operated mice $\left(B+B^{\prime}\right)$ at different time points. Each time point represent the mean of 2 or 3 animals. 
ACUTE EFFECTS ON INTESTINAL AND HEPATIC LIPID METABOLISM
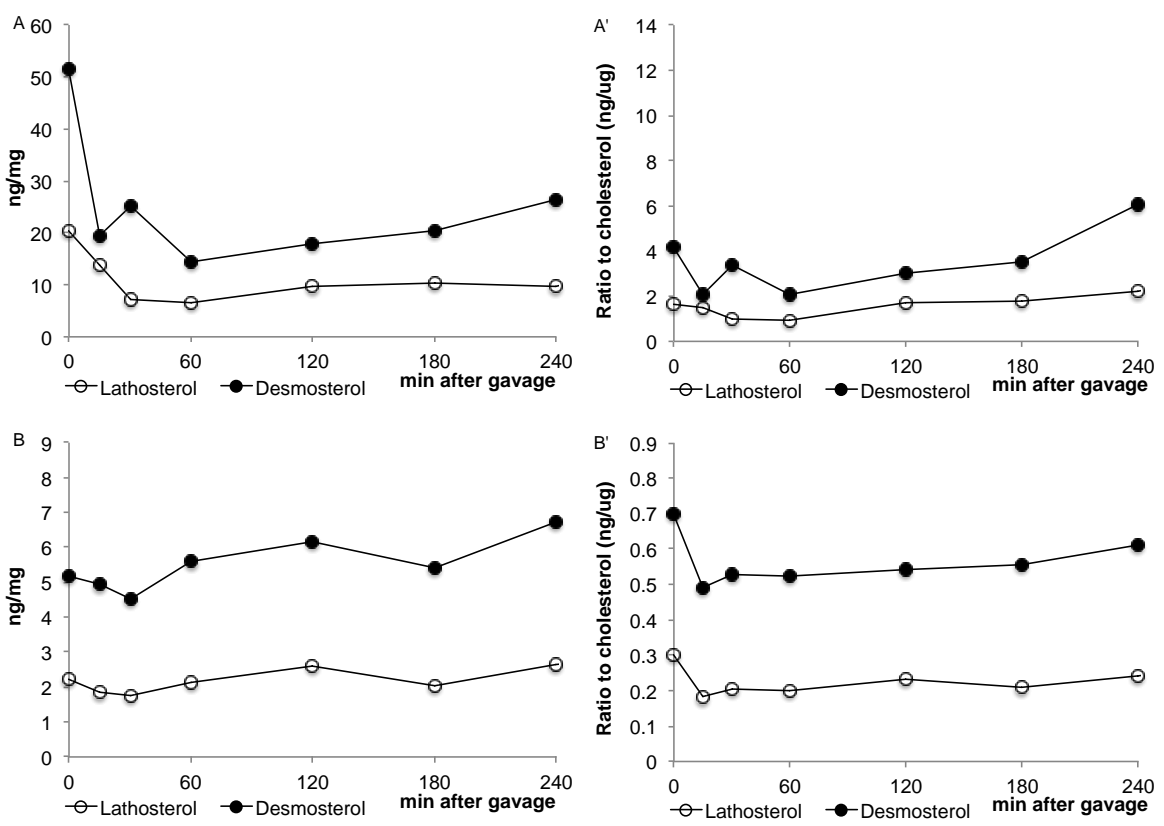

Supplemental figure 3: Study I: Time kinetics of lathosterol and desmosterol levels in the duodenum (A$\left.A^{\prime}\right)$ and in the liver (B-B') at different time points . Results are expressed as absolute concentration and standardized fot cholesterol. Each time point represent the mean of 2 or 3 animals. 


\section{CHAPTER 3}
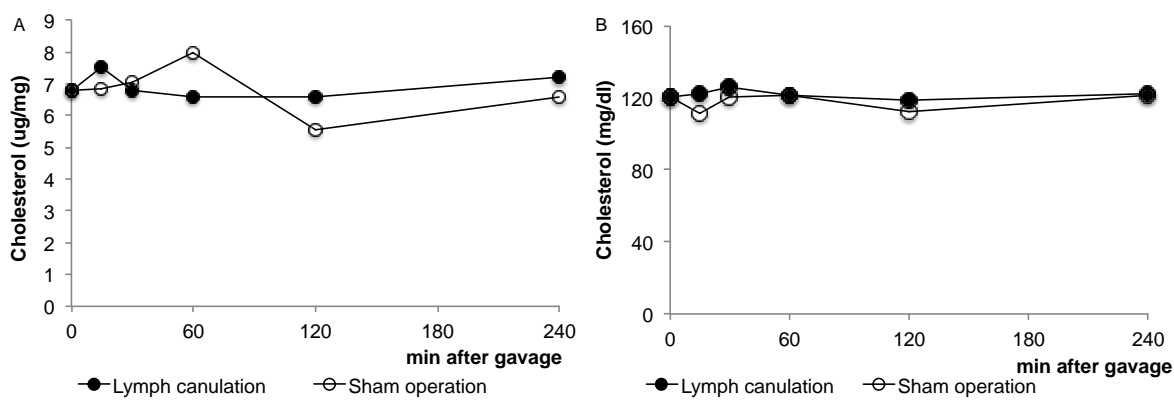

Supplemental figure 4: Study II: Time kinetics of cholesterol concentration in the liver (A) and in the serum (B) at different time points post-gavage. Results are expressed as an absolute concentration. Each time point represent the mean of 2 or 3 animals. The cholesterol concentration was measured in the liver and serum of lymph-canulated mice (closed circles) and sham operated mice (open circles). 


\section{ACUTE EFFECTS ON INTESTINAL AND HEPATIC LIPID METABOLISM}

\section{References}

1. Lauer, M.S. and P.B. Fontanarosa, Updated guidelines for cholesterol management. JAMA, 2001. 285(19): p. 2508-9.

2. Borgstrom, B., Partition of lipids between emulsified oil and micellar phases of glyceride-bile salt dispersions. J Lipid Res, 1967. 8(6): p. 598-608.

3. De Smet, E., R.P. Mensink, and J. Plat, Effects of plant sterols and stanols on intestinal cholesterol metabolism: suggested mechanisms from past to present. Mol Nutr Food Res, 2012. 56(7): p. 1058-72.

4. Yu, L., et al., Overexpression of ABCG5 and ABCG8 promotes biliary cholesterol secretion and reduces fractional absorption of dietary cholesterol. J Clin Invest, 2002. 110(5): p. 671-80.

5. Plosch, T., et al., Reduction of cholesterol absorption by dietary plant sterols and stanols in mice is independent of the Abcg5/8 transporter. J Nutr, 2006. 136(8): p. 2135-40.

6. Calpe-Berdiel, L., et al., Changes in intestinal and liver global gene expression in response to a phytosterol-enriched diet. Atherosclerosis, 2005. 181(1): p. 75-85.

7. Liang, Y.T., et al., Effect of phytosterols and their oxidation products on lipoprotein profiles and vascular function in hamster fed a high cholesterol diet. Atherosclerosis, 2011. 219(1): p. 12433.

8. Ho, S.S. and S. Pal, Margarine phytosterols decrease the secretion of atherogenic lipoproteins from HepG2 liver and Caco2 intestinal cells. Atherosclerosis, 2005. 182(1): p. 29-36.

9. Igel, M., et al., Comparison of the intestinal uptake of cholesterol, plant sterols, and stanols in mice. J Lipid Res, 2003. 44(3): p. 533-8.

10. Lutjohann, D., et al., Evaluation of deuterated cholesterol and deuterated sitostanol for measurement of cholesterol absorption in humans. J Lipid Res, 1993. 34(6): p. 1039-46.

11. Thelen, K.M., et al., High-dose statin treatment does not alter plasma marker for brain cholesterol metabolism in patients with moderately elevated plasma cholesterol levels. J Clin Pharmacol, 2006. 46(7): p. 812-6.

12. Sudhop, T., et al., Inhibition of intestinal cholesterol absorption by ezetimibe in humans. Circulation, 2002. 106(15): p. 1943-8.

13. Plat, J. and R.P. Mensink, Relationship of genetic variation in genes encoding apolipoprotein A-IV, scavenger receptor BI, HMG-CoA reductase, CETP and apolipoprotein E with cholesterol metabolism and the response to plant stanol ester consumption. Eur J Clin Invest, 2002. 32(4): p. 242-50.

14. Volger, O.L., et al., Dietary plant stanol esters reduce VLDL cholesterol secretion and bile saturation in apolipoprotein $E^{\star} 3$-Leiden transgenic mice. Arterioscler Thromb Vasc Biol, 2001. 21(6): p. 1046-52.

15. Powell, E.E. and P.A. Kroon, Low density lipoprotein receptor and 3-hydroxy-3-methylglutaryl coenzyme $A$ reductase gene expression in human mononuclear leukocytes is regulated coordinately and parallels gene expression in human liver. J Clin Invest, 1994. 93(5): p. 216874.

16. Plat, J. and R.P. Mensink, Effects of plant stanol esters on LDL receptor protein expression and on LDL receptor and HMG-CoA reductase mRNA expression in mononuclear blood cells of healthy men and women. FASEB J, 2002. 16(2): p. 258-60.

17. Nassir, F., et al., CD36 is important for fatty acid and cholesterol uptake by the proximal but not distal intestine. J Biol Chem, 2007. 282(27): p. 19493-501.

18. Mutch, D.M., et al., Regional variations in $A B C$ transporter expression along the mouse intestinal tract. Physiol Genomics, 2004. 17(1): p. 11-20.

19. Coppack, S.W., K.N. Frayn, and S.M. Humphreys, Plasma triacylglycerol extraction in human adipose tissue in vivo: effects of glucose ingestion and insulin infusion. Eur J Clin Nutr, 1989. 43(7): p. 493-6.

20. Motamed, M., et al., Identification of luminal Loop 1 of Scap protein as the sterol sensor that maintains cholesterol homeostasis. J Biol Chem, 2011. 286(20): p. 18002-12.

21. Spann, N.J., et al., Regulated accumulation of desmosterol integrates macrophage lipid metabolism and inflammatory responses. Cell, 2012. 151(1): p. 138-52.

22. Plat, J. and R.P. Mensink, Plant stanol esters lower serum triacylglycerol concentrations via a reduced hepatic VLDL-1 production. Lipids, 2009. 44(12): p. 1149-53.

23. Le May, C., et al., Transintestinal cholesterol excretion is an active metabolic process modulated by PCSK9 and statin involving ABCB1. Arterioscler Thromb Vasc Biol, 2013. 33(7): p. 1484-93. 


\section{CHAPTER 3}

24. Davidson, M.H., et al., Inhibition of intestinal cholesterol absorption with ezetimibe increases components of reverse cholesterol transport in humans. Atherosclerosis, 2013. 230(2): p. 3229.

25. Brufau, G., et al., A reappraisal of the mechanism by which plant sterols promote neutral sterol loss in mice. PLoS One, 2011. 6(6): p. e21576.

26. Chan, J.C., et al., A proprotein convertase subtilisin/kexin type 9 neutralizing antibody reduces serum cholesterol in mice and nonhuman primates. Proc Natl Acad Sci U S A, 2009. 106(24): p. 9820-5.

27. Stein, E.A., et al., Effect of a monoclonal antibody to PCSK9 on LDL cholesterol. N Engl J Med, 2012. 366(12): p. 1108-18.

28. Bozzetto, L., et al., Ezetimibe beneficially influences fasting and postprandial triglyceride-rich lipoproteins in type 2 diabetes. Atherosclerosis, 2011. 217(1): p. 142-8.

29. Relas, H., H. Gylling, and T.A. Miettinen, Effect of stanol ester on postabsorptive squalene and retinyl palmitate. Metabolism, 2000. 49(4): p. 473-8.

30. Thelen, K.M., et al., Brain cholesterol synthesis in mice is affected by high dose of simvastatin but not of pravastatin. J Pharmacol Exp Ther, 2006. 316(3): p. 1146-52. 


\section{CHAPTER 4}

An acute intake of plant stanol esters changes immunerelated pathways in the jejunum of healthy volunteers

Els De Smet, Ronald P. Mensink, Mark V. Boekschoten, Rogier de Ridder, Wilfred T.V. Germeraad, Tim G.A.M. Wolfs and Jogchum Plat

Submitted 


\section{CHAPTER 4}

\section{Abstract}

Plant sterols and stanols inhibit intestinal cholesterol absorption and consequently lower serum low-density lipoprotein cholesterol (LDL-C) concentrations. The underlying mechanisms are still unknown. In vitro and animal studies suggest that changes in intestinal sterol metabolism contributes to the LDL-C-lowering effects of plant stanol esters. Human data, however, is lacking. We therefore examined effects of an acute intake of plant stanol esters on expression profiles of genes of the upper small intestine of healthy volunteers.

In a double-blind crossover design, 14 healthy subjects (8 female / 6 male; $21-55$ years) with a BMI between $21-29 \mathrm{~kg} / \mathrm{m}^{2}$ received in random order a shake with or without plant stanol esters $(4 \mathrm{~g})$. Five hours later, biopsies from the duodenum (around the Papil van Vater) and from the jejunum $(20 \mathrm{~cm}$ distal from the Papil van Vater) were taken. Microarray analysis showed that the expression profile of genes involved in sterol metabolism did not change.

Surprisingly, pathways involved in T-cell functions were down regulated in the jejunum. Immunohistochemical analysis further showed that the number of CD3, CD4 and Foxp3-positive cells was reduced in the plant stanol ester condition compared to the control condition, which is in line with the microarray data. The physiological consequences of the plant stanol ester-induced reduction of intestinal T-cell based immune activity in healthy subjects deserves further investigation. 


\section{Introduction}

Plant sterols in habitual diets are mainly derived from vegetable oils, nuts, grains, fruit and vegetables, and daily intakes vary from 160 to $360 \mathrm{mg}$ [1]. Avoiding plant sterols from the diet slightly increases serum low-density lipoprotein cholesterol (LDL-C) concentrations [2]. On the other hand, increasing daily intakes toward 2 to $3 \mathrm{~g}$ through the use of functional foods lower serum LDL-C concentrations up to $10 \%$ [3]. Despite these well-known effects on serum LDL-C levels, detailed understanding of underlying mechanisms is missing. In vitro and animal studies suggest that plant sterols affect intestinal cholesterol metabolism at the cellular level [4]. There are multiple suggestions that plant sterols affect specific processes in the intestines. For example, Lee and colleagues [5] have demonstrated that $\beta$-sitosterol inhibited shortening of the colon, lowered macroscopic scores of the disease grade and myeloperoxidase activity, and inhibited proinflammatory cytokines release in mice treated with 2,4,6-trinitrobenzene to induce colitis. In addition, sitosterol inhibited growth of colon cancer cells in vitro, suggesting that it has chemopreventive effects [6]. More related to lipid metabolism, faecal neutral sterol excretion was increased in mice consuming plant sterols for 2 weeks, probably via activation of the transintestinal cholesterol excretion (TICE) pathway [7]. Field et al. [8] further showed that mRNA levels of 3-hydroxy-3-methylglutaryl-CoA (HMG-CoA) reductase were decreased after incubating $\mathrm{CacO} 2$ cells with micelles containing $\beta$-sitosterol. Finally, it has been postulated that plant sterols and stanols could act as local LXR agonists in enterocytes [9]. However, despite all these interesting observations, data on the effects on human enterocytes during consumption of plant sterol or stanol enriched foods are lacking. Therefore, to better understand the cellular effects in the intestine we examined acute changes in the transcriptome of the upper small intestine after consuming a plant stanol enriched shake at breakfast after an overnight fast. Pathways related to sterol metabolism were not changed in both the duodenum and the jejunum. Immune-related pathways, however, were down regulated in the jejunum. This extends our earlier in vitro finding that in subjects with a disturbed T-cell response sitostanol may have immune-modulatory effects [10]. Our study population, however, had no known immune disorders. Effects of plant stanol and sterol esters on the (intestinal) immune system therefore deserve further attention.

\section{Materials and methods}

\section{Study design}

This study was part of a previously published randomized double-blind crossover trial (submitted). In brief, 18 healthy normolipidemic volunteers participated in two experimental periods of four weeks, separated by a four weeks washout period. During the two screening visits, which were separated by at least 3 days, body weight, height and blood pressure were determined. An Omron M7 (Omron Healthcare Europe B.V., Hoofddorp, the Netherlands) was used to measure blood pressure in fourfold at the left arm. The first measurement was discarded and the last three measurements were averaged. Blood was sampled for analysis of serum total cholesterol concentrations. Subjects were excluded if the mean serum total cholesterol concentration was $>7.8 \mathrm{mmol} / \mathrm{L}$. 


\section{CHAPTER 4}

One week before the start of each experimental period, subjects were instructed to avoid products relatively rich in plant sterols and stanols. Immediately after this week, all subjects participated in a postprandial test to examine the acute effects of plant stanol esters on the intestinal gene expression profile. To further minimize differences between the two postprandial test days, all subjects consumed a standard lasagne meal at dinner the evening before the test days. Except for water, they were not allowed to consume any other foods or drinks after dinner till the morning of the postprandial test. In the morning, they arrived at our department by public transportation or by car to reduce physical activity as much as possible. After resting for 15 minutes in a supine position, an intravenous canula was inserted into the anticubital vein and a fasting blood sample was collected (T0). Next, subjects consumed a slice of white bread with jam and a high-fat shake with or without plant stanol esters ( $4 \mathrm{~g}$ plant stanols). The plant stanol ester mixture was incorporated into margarines as provided by Raisio (Raisio Nutrition Ltd, Finland) and was composed of sitostanol (73.2\%), campestanol (22\%), sitosterol (0.9\%), campesterol (1.6\%) and other sterols/stanols (2.3\%). Plant stanols were esterified with food grade fatty acids based on rapeseed oil. The margarine was incorporated into the shake (table 1).

Table 1: Nutritional composition and ingredients of the shake.

\begin{tabular}{ll}
\hline Energy $(\mathrm{kcal})$ & 731 \\
Protein $(\mathrm{g})$ & 11.5 \\
Carbohydrates $(\mathrm{g})$ & 59.2 \\
Total fat $(\mathrm{g})$ & 48.9 \\
Saturated fatty acids $(\mathrm{g})$ & 20.1 \\
Monounsaturated fatty acids $(\mathrm{g})$ & 18.4 \\
Polyunsaturated fatty acids $(\mathrm{g})$ & 7.6 \\
Cholesterol $(\mathrm{mg})$ & 250.2 \\
Plant stanols $(\mathrm{g})$ & 0 or 4 \\
\hline
\end{tabular}

Volunteers were requested to consume the shake and bread within 10 minutes and were not allowed to eat or drink anything except water during the next 5 hours. Five hours after consumption of the shake, intestinal biopsies were taken at the gastroenterology unit. During the gastroscopy, no sedatives were given to the subjects. To compare expression profiles at different parts of the proximal small intestine, we decided to take four mucosal tissue samples from the duodenum (around the Papil van Vater) and four from the jejunum $(20 \mathrm{~cm}$ distal from the Papil van Vater) using standard biopsy forceps. The diameter of the biopsies varied from $2.0 \mathrm{~mm}$ to $2.2 \mathrm{~mm}$. After sampling, the biopsies for microarray analysis were immediately frozen in liquid nitrogen. The biopsies intended for histology were first put on a drop of Tissue-Tek in isopentane followed by freezing in liquid nitrogen. The samples were all stored at $-80^{\circ} \mathrm{C}$ and analyzed at the end of the study within the same run. The study protocol was approved by the Medical Ethical Committee of the University Hospital Maastricht. All participants gave written informed consent before entering the study. The trial was registered on clinicaltrials.gov under study number NCT01574417. 


\section{Blood sampling}

Blood was sampled in serum and in NaF-containing vacutainer tubes (Becton Dickinson). Blood samples taken in serum tubes were allowed to clot for $30 \mathrm{~min}$ at $21^{\circ} \mathrm{C}$, followed by centrifugation at $1300 \times \mathrm{g}$ for $15 \mathrm{~min}$ at $21^{\circ} \mathrm{C}$ to obtain serum. The $\mathrm{NaF}$ tubes were placed on ice directly after sampling and centrifuged at $1300 \mathrm{xg}$ for $15 \mathrm{~min}$ at $4^{\circ} \mathrm{C}$ within $60 \mathrm{~min}$ after sampling. Serum and plasma aliquots were directly snap-frozen in liquid nitrogen and stored at $-80^{\circ} \mathrm{C}$ until analysis. All samples from one subject were analyzed within the same analytical run.

\section{Lipids}

In all fasting serum samples, serum total cholesterol (CHOD-PAP method; Roche Diagnostics Systems, Hofmann-La Roche) and triglycerides with correction for free glycerol (GPO Trinder; Sigma Diagnostics) were analyzed enzymatically.

\section{Glucose, insulin and hsCRP concentrations}

Plasma glucose (Roche Diagnostic Systems, Hoffmann-La Roche) concentrations were measured. Serum insulin concentrations were determined with a human insulin-specific radioimmunoassay kit (Linco Research). High sensitive C-reactive protein (hsCRP) was analyzed with a highly sensitive immunoturbidimetric assay (Kamiya Biomedical Company, Seattle, WA, USA).

\section{Microarray processing and data analysis}

Total RNA was extracted from frozen mucosal samples originating from the duodenum or the jejunum using TRIzol reagent (Invitrogen, Breda, the Netherlands) and purified on columns using the Qiagen RNeasy Micro Kit (Qiagen, Venlo, the Netherlands). Total RNA ( $35 \mathrm{ng} / \mu \mathrm{l}$ ) was labelled by Whole Transcript Sense Target Assay and hybridized to human whole-genome Affymetrix Gene 1.1 ST arrays targeting 19682 unique genes (Affymetrix, Santa Clara, CA). Individual genes were defined as changed when comparison of the normalized signal intensities showed a p-value $\leq 0.05$ in a 2-tailed paired intensity-based moderated t-statistics (IBMT). Further functional data analysis was performed on the filtered dataset with Gene Set Enrichment Analysis (GSEA) and on the differentially expressed genes with Ingenuity Pathway Analysis (IPA).

\section{Immunohistochemistry}

The frozen intestinal biopsies were sectioned at $5 \mu \mathrm{m}$ and fixed in filtered, ice-cold acetone for 15 minutes at $4^{\circ} \mathrm{C}$ as described [11]. Briefly, endogenous peroxidase activity was blocked with $0.3 \% \mathrm{H}_{2} \mathrm{O}_{2}$ in methanol. After washing, slides were blocked with bovine serum albumin for $30 \mathrm{~min}$ at room temperature. Subsequently, slides were incubated overnight at $4^{\circ} \mathrm{C}$ with the corresponding primary antibodies; i.e. a polyclonal rabbit anti-human CD3 antibody (DAKO A0452, DAKO Denmark, 1:1000), a monoclonal mouse-anti human CD4 antibody (Abcam ab846, Cambridge, UK, 1:50) or a monoclonal mouse anti-human Foxp3 antibody (eBioscience 147979, 1:250). After washing, sections were incubated during 1 hour at room 


\section{CHAPTER 4}

temperature with the appropriate secondary antibody; i.e. a biotin conjugated polyclonal swine anti-rabbit immunoglobulin (DAKO E0353, DAKO Denmark, 1:200), a biotine conjugated polyclonal goat-anti-mouse immunoglobulin (DAKO E0433, DAKO Denmark, 1:200) or a biotine conjugated goat anti-mouse immunoglobulin (DAKO E0433, DAKA Denmark, 1:200). The immunostaining was enhanced with Vectastain ABC peroxidase Elite kit (PK-6200, Vector Laboratories, Burlingame, CA, USA, 1:50) followed by a nickel sulfate-diaminobenzidine (NiDAB) staining. Sections were counterstained with $0.1 \%$ Nuclear Fast Red in $5 \%$ aluminium sulphate during 2 min and dehydrated in ascending ethanol series. Images of jejunum sections were acquired at $100 \times$ magnification using a Leica DM2000 microscope equipped with a Leica DFC295 digital camera (Leica Microsystems) and Leica Application Suite (LAS) software (Leica LAS V 3.7, Leica Microsystems). Since these stainings are laborious, these analysis were only performed in 3 randomly chosen subjects.

\section{Results}

\section{Subject characteristics}

Eighteen healthy participants completed the study. Intestinal samples from four participants were excluded before the actual microarray analysis since their ribonucleic acid (RNA) integrity numbers were too low to expect successful analysis. Baseline characteristics of the remaining 14 subjects are shown in table 2 .

Table 2: Baseline characteristics of the 14 participants.

\begin{tabular}{lc}
\hline Gender (F/M) & $8 / 6$ \\
Age $(y e a r s)$ & $32 \pm 13$ \\
BMI (kg/m²) & $23.9 \pm 2.8$ \\
Serum total cholesterol (mmol/L) & $5.20 \pm 1.07$ \\
Serum tryglicerides $(\mathrm{mmol} / \mathrm{L})$ & $1.14 \pm 0.40$ \\
Plasma glucose $(\mathrm{mmol} / \mathrm{L})$ & $5.24 \pm 0.37$ \\
Serum insuline $(\mu \mathrm{U} / \mathrm{mL})$ & $13.35 \pm 5.11$ \\
Serum hsCRP $(\mathrm{mg} / \mathrm{dL})$ & $1.04 \pm 1.17$ \\
Systolic blood pressure $(\mathrm{mmHg})$ & $118 \pm 12$ \\
Diastolic blood pressure $(\mathrm{mmHg})$ & $79 \pm 8$ \\
\hline
\end{tabular}

Except for gender, all values are means \pm SD.

\section{Microarray analysis}

From the 19,682 genes present on the microarray, 9,852 genes were expressed in the duodenum and 10,003 in the jejunum. After consumption of a shake enriched with $4 \mathrm{~g}$ plant stanol esters, the expression of 388 genes in the duodenum and 610 genes in the jejunum was significantly changed. However, only 20 genes were altered in both the duodenum and jejunum (figure 1). 


\section{AN ACUTE INTAKE CHANGES IMMUNE-RELATED PATHWAYS}

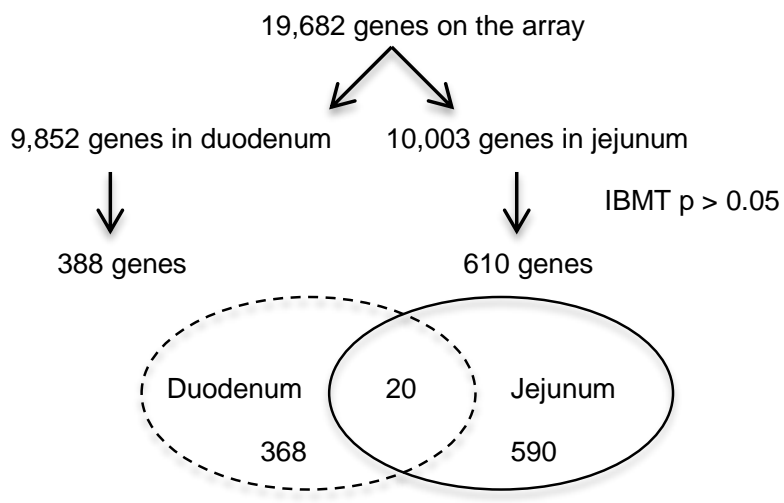

Figure 1: Venn diagram presenting the number of present and regulated genes via the microarray analysis performed on human intestinal biopsies. Probes were assigned to unique gene identifiers (Entrez). Genes were considered to be expressed when the intensity was $>20$ on at least 8 arrays. Only genes with six or more probes were considered for the analysis.

\section{Gene Set Enrichment Analysis}

Five hours after consumption of plant stanol esters, expression profiles of genes present in pathways involved in sterol metabolism were not changed in biopsies taken from the duodenum or jejunum. Gene sets that were changed after plant stanol ester consumption are shown in supplemental table 1. A consistent finding in the jejunum was down regulation in gene sets involved in T-cell receptor (TCR) signalling, generation of second messenger molecules, phosphorylation of CD3 and TCR zeta chains, and downstream TCR signalling (supplemental table 1). Part of the genes that were responsible for the observed enrichment in these gene sets were members of the cluster of differentiation (CD) family, which are all T-cell specific surface molecules (table 3). These effects were not observed in samples from the duodenum, where changes were more modest and seemingly random.

Table 3: Changes in cluster of differentiation genes in the jejunum after an acute intake of plant stanol ester.

\begin{tabular}{lll}
\hline Gene & Fold Change & p-value \\
\hline CD160 & -1.19 & 0.05 \\
CD2 & -1.14 & 0.04 \\
CD27 & -1.18 & 0.04 \\
CD3D & -1.18 & 0.03 \\
CD3G & -1.30 & 0.02 \\
CD4 & -1.20 & 0.02 \\
CD52 & -1.14 & 0.01 \\
CD59 & 1.09 & 0.04 \\
CD84 & -1.15 & 0.03 \\
CD97 & -1.16 & $<0.01$ \\
\hline
\end{tabular}




\section{CHAPTER 4}

\section{Ingenuity pathway analysis}

We also investigated the biological functions as defined by the Ingenuity software that were affected by the differentially regulated genes (figure 2). A z-score above 2 indicates an increase, whereas a z-score below -2 indicates a decrease in that specific function after plant stanol ester intake. An acute intake of plant stanol esters reduced the expression of genes associated with the quantity of double-positive thymocytes, as well as the interaction, activation, adhesion and chemoattraction of T-lymphocytes.

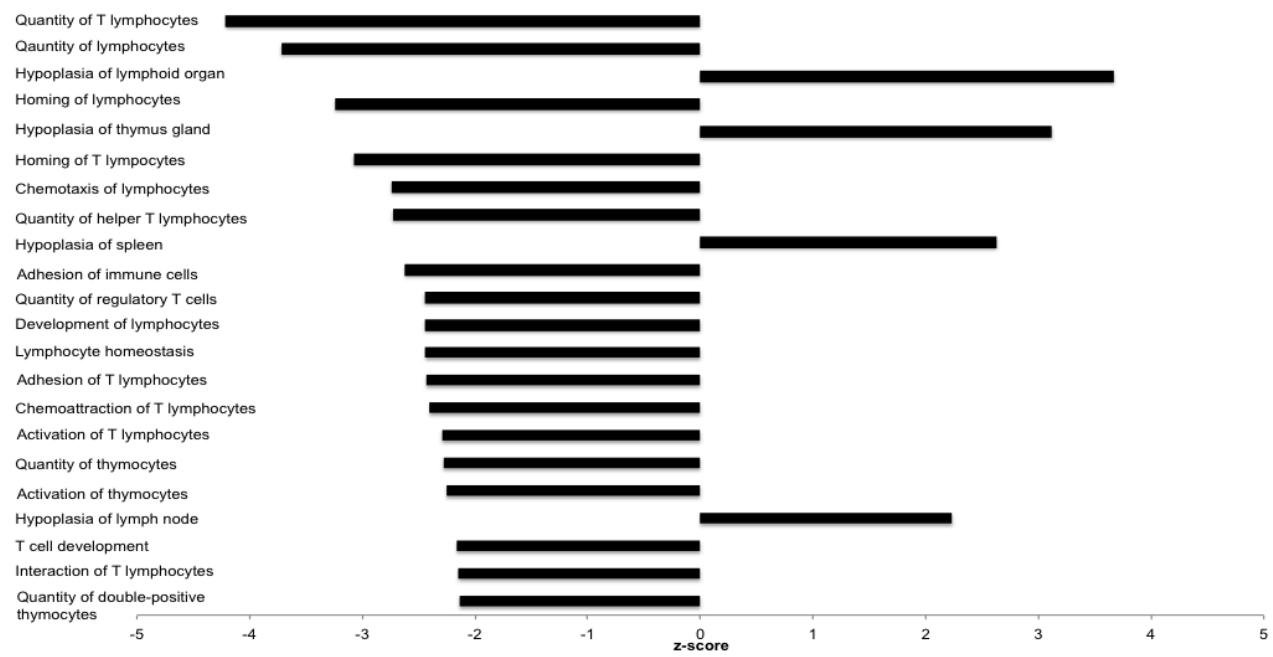

Figure 2: Analysis of immune-related functions using ingenuity pathway analysis in the jejunum after an acute intake of plant stanol esters. A z-score above 2 indicates an increase, whereas a z-score below -2 indicates a decrease in that specific function which was significantly changed after plant stanol ester intake.

Figure 3 displays heat maps of gene sets that relate either to quantity (panel A) or functionality (panel B) of T-cells, which were regulated after plant stanol ester intake according to IPA. These maps showed a highly consistent decrease in the transcript abundance of genes belonging to T-cell immune responses. Results for subject number 16 were highly aberrant, for which we have no explanation. 


\section{AN ACUTE INTAKE CHANGES IMMUNE-RELATED PATHWAYS}

Panel A

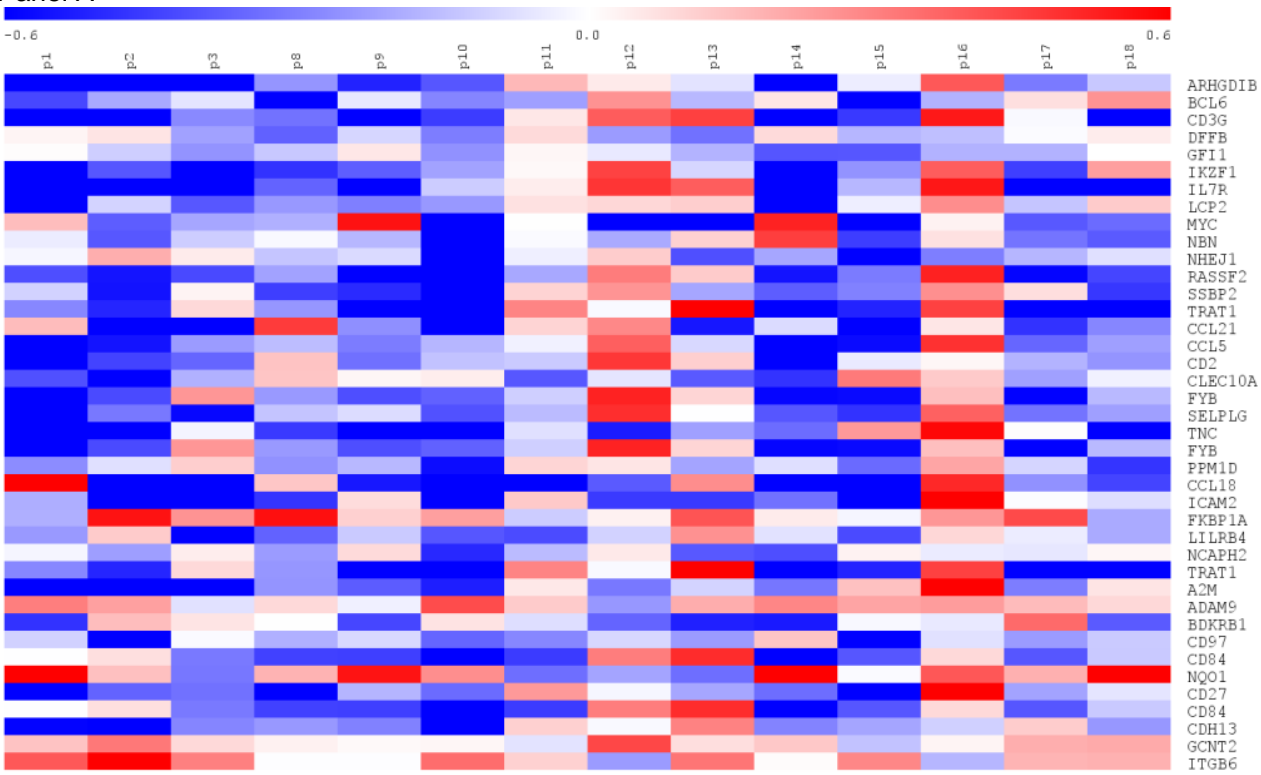

Panel B

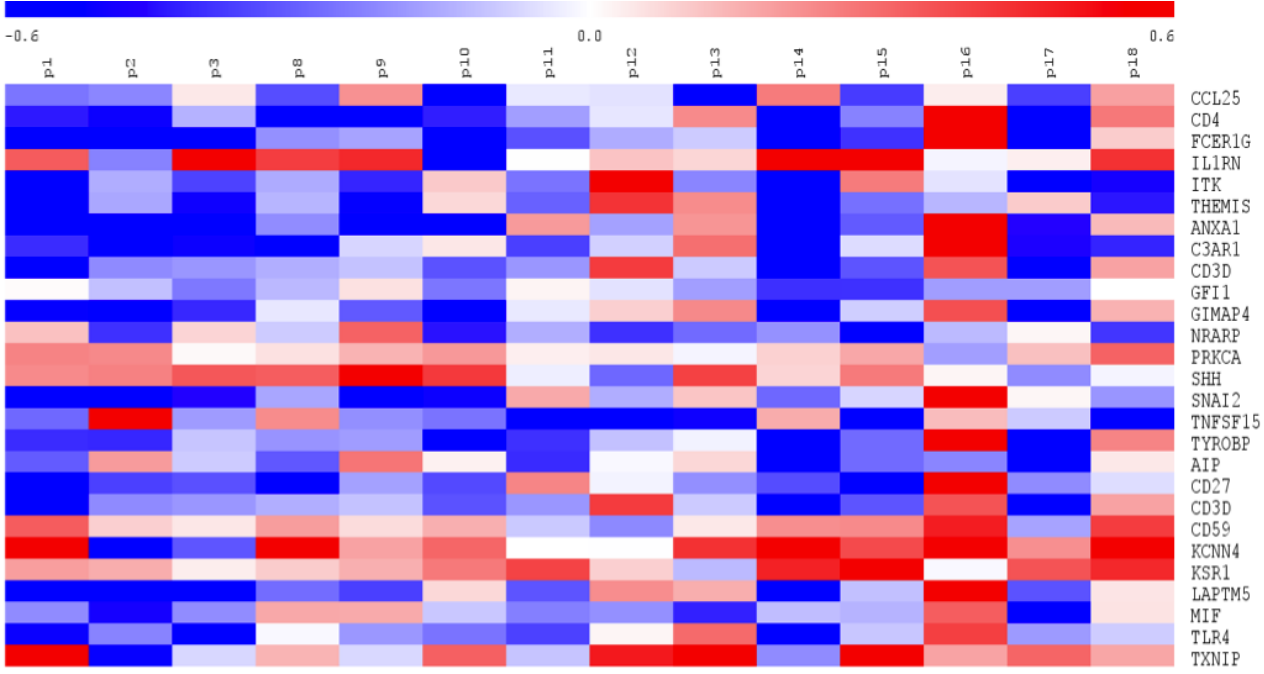

Figure 3: Gene sets that were downregulated in the jejunum after plant stanol ester consumption using gene set enrichment analysis (GSEA). The z-score was calculated by subtracting the mean expression value for each transcript from each of the values and then dividing the resulting values by standard deviation. Colour in the heat-maps reflects the relative transcript abundance level with blue being lower and red higher than the mean transcript abundance value. Immune functions were classified into functions related to quantity of T-cells $(A)$ or functionality of T-cells $(B)$. 


\section{CHAPTER 4}

\section{Immunohistochemical analysis}

To further examine the consistent changes in expression signatures related to the presence of T-cells in the biopsies from the jejunum, the number of CD3-positive cells in the jejunum of 3 randomly chosen subjects consuming control and plant stanol enriched shakes were quantified. CD3 is a T-cell specific surface glycoprotein. As shown in figure 4, the number of CD3-positive cells was less pronounced in the plant stanol ester condition when compared to the control condition. Microarray analysis also showed a decrease in the mRNA expression of T-helper lymphocytes and regulatory T-cells (Tregs). Therefore, CD4 and Forkhead box P3 (Foxp3) expressions were analyzed by immunohistochemistry in the biopsies. CD4 is a glycoprotein among others found on the surface of $T$ helper cells and Foxp3 is expressed in especially $\mathrm{CD}^{+}{ }^{+}$subpopulation of Tregs. Compared to the control condition, the number of CD4-positive cells and those of Foxp3-positive cells was reduced in the plant stanol ester condition, which further extends the microarray data. 


\section{AN ACUTE INTAKE CHANGES IMMUNE-RELATED PATHWAYS}

Negative control
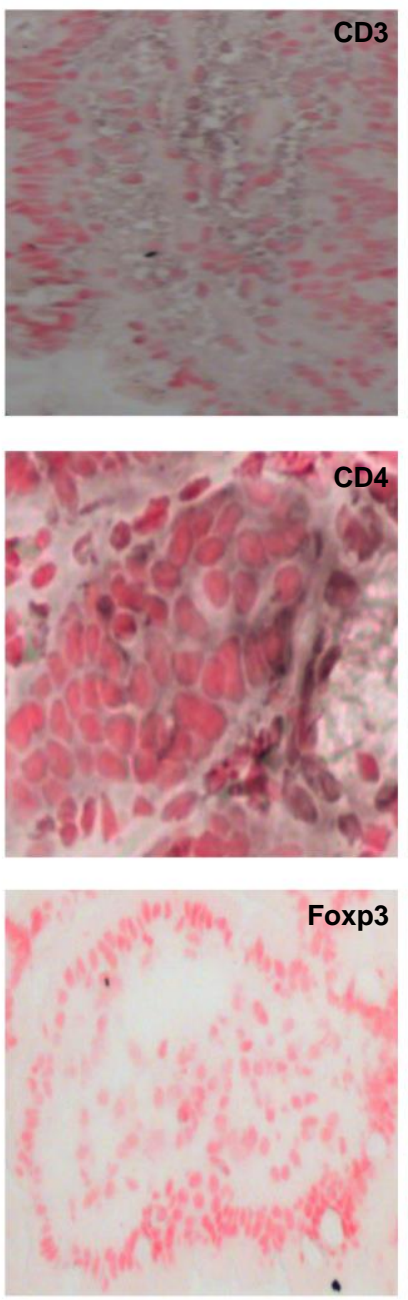

Control
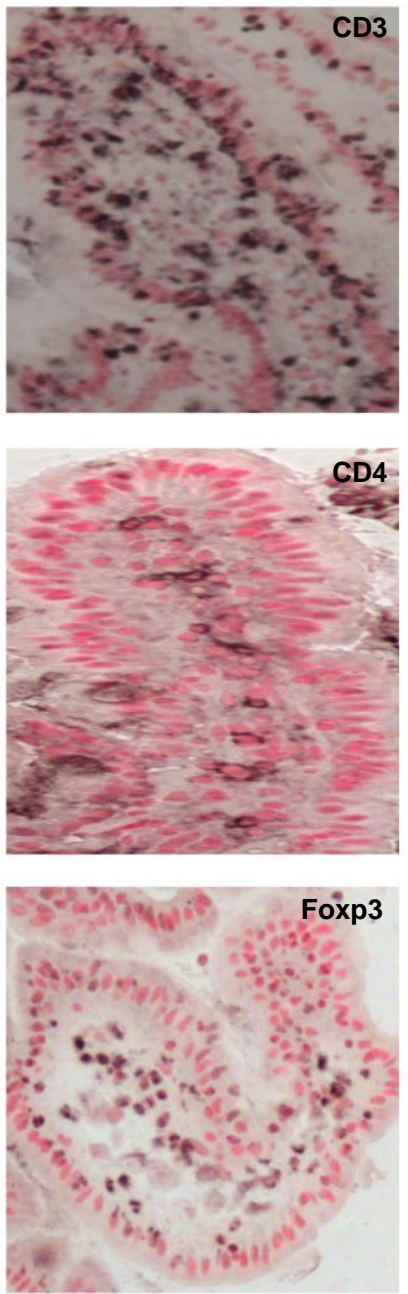

Plant stanol ester
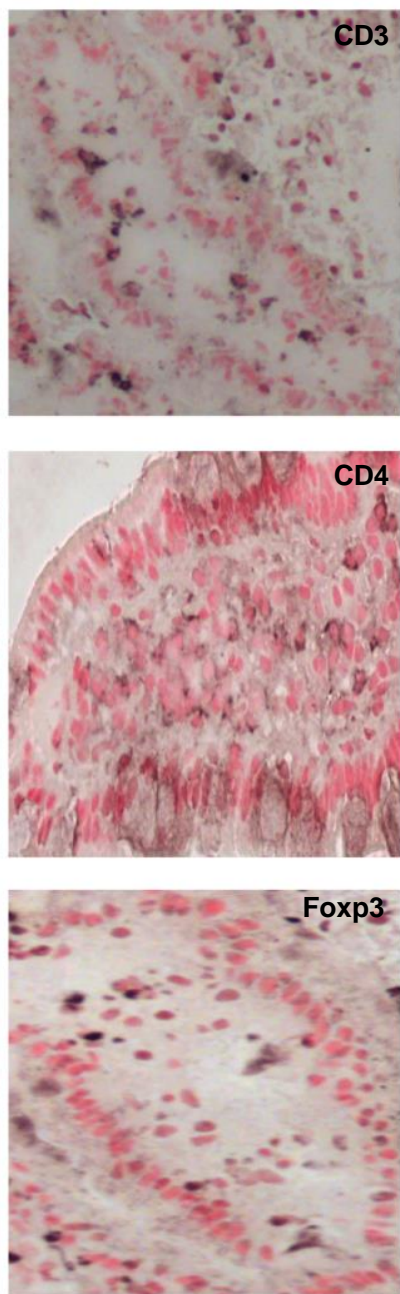

Figure 4: Immunohistochemical analysis of CD3, CD4 and Foxp3 in human jejunal biopsies five hours after consuming a shake enriched with or without plant stanol esters. Compared to the control condition, the number of CD3, CD4 and Foxp3 was reduced in the plant stanol ester condition. 


\section{CHAPTER 4}

\section{Discussion}

Numerous in vitro and animal studies have suggested effects of plant sterols/stanols on intestinal function [12-16], but there are no data for human studies. We therefore evaluated the acute effects of plant stanol esters on the expression profile of genes in the human duodenum and jejunum using microarray analyses. In contrast to our expectations, the expression profile of genes involved in sterol metabolism did not change. Immune-related T-cell oriented pathways, however, were consistently downregulated in the jejunum. The expression of villin 1-like protein (VILL), an enterocyte specific actin-regulatory protein involved in the formation of microvilli of enterocytes [17], was comparable between both test days (data not shown). This suggests that the number of enterocytes present in the biopsies during the control and the plant stanol ester intervention was comparable. Thus, the observed down regulation in T-cells and T-cell related pathways is not due to a large shift in cell populations in the biopsies.

Knowledge regarding the intestinal kinetics of plant sterols/stanols and effects on (intestinal) metabolism has rapidly evolved over the past decade. Not long ago, it was assumed that plant sterols and stanols were inert molecules and were hardly absorbed, as serum concentrations were low. However, it is now well acknowledged that concentrations within enterocytes can be increased up to 7-fold [18] without large changes in plasma concentrations. This can be explained by the presence of different sterol transporters in the apical membrane of the enterocytes [19-21] that regulate plant sterol uptake and secretion. The intracellular plant sterol and stanol concentrations can even reach concentrations well above the half maximal effective concentration (EC50) values for specific transcription factors [15]. This suggests that in vivo plant sterols and stanols might affect gene regulation and modify metabolic pathways.

To minimize the effects of plant sterols on intestinal sterol metabolism during both test days and to create a contrast as large as possible, subjects were instructed to avoid the consumption of products relatively high in plant sterols one week before the test day. Still, expression profiles of genes involved in sterol metabolism were not changed. It is unlikely that this can be explained by a lack of absorption within the 5-hour time frame of the study. In enterocytes of male C57BL/6OlaHsd mice, Igel et al. [18] already showed an increase in plant sterol concentrations after 15 minutes. In agreement, we found an increase in plant stanol concentrations within the scraped enterocytes of C57BL/6J mice 15 minutes post-gavage (unpublished data). Also, in the current setup, expression profiles changed within 5 hours after intake of the plant stanol esters. It might be possible that a 5-hour follow-up period was too short to observe changes in the expression profile of genes involved in sterol metabolism. In animal studies, gene regulation in the intestines was observed within 12-hours after administration of a phytosterol-derived LXR agonist YT-32 [22]. No measurements were made before this time point. A limited number of studies have also shown that in humans expression profiles of intestinal genes involved in sterol metabolism can be changed during the postprandial phase [23, 24]. Expression profiles of genes involved in the adaptive T-cell immune response were down regulated. We have already suggested before that plant sterols and stanols influence immune function, when the immune response is disturbed. Brüll et al. [10] showed that plant stanols induced a shift towards T-helper-1 cells (Th1) in isolated human 


\section{AN ACUTE INTAKE CHANGES IMMUNE-RELATED PATHWAYS}

peripheral blood mononuclear cells (PBMCs) from asthma patients. Further, the number of Tregs, which are important for maintaining the Th1/Th2 balance, tended to increase, whereas Treg's activity increased significantly. These ex vivo changes may be specific for a situation of skewed T-cell behaviour, as they were not observed in PBMCs from healthy subjects characterized by a balanced Th1/Th2 response [10]. In vivo, Calpe-Berdiel and colleagues [25] showed that administration of $2 \%$ phytosterols increased the Th1/Th2 ratio in mice treated with turpentine in order to induce an acute, aseptic inflammation model. The studies described so far suggest that the plant stanol/sterol-induced Th1 or Th2 response depend on the direction of the disturbed Th1/Th2 balance. Restoration of this imbalance is probably the result of alterations in the number and activity of Tregs [10]. In other words, when Th2 cells are over-activated, activating Tregs restores the balance by stimulating Th1 activity, which via feedback mechanisms results in Th2 dampening [26]. In the present study, however, the changes in expression profiles suggested a dampening of the intestinal T-cell mediated immune potential in general in healthy volunteers without an a priori skewed response. The physiological and functional consequences of these effects remain to be elucidated.

An intriguing question is how these effects on T-cells can be explained. One may speculate that plant stanol esters induce changes in the composition of the gut microbiota, which may be associated with immunological processes [27]. Recently, Martinez et al. [28] showed that the faecal microbiota of hamsters was significantly changed after feeding a plant sterol enriched diet for 4 weeks. However, it is not very likely that the gut microbiota has changed within the 5-hour time frame of our study. Another explanation is based on the observations of Bensinger and colleagues [29], who showed that the transcriptional regulation of intracellular cholesterol homeostasis is linked to cell proliferation and acquired immune responses. Ligand activation of LXR, thereby increasing the expression of ABCG1, prevented effective proliferative responses. On the other hand, activation of T-cells by an antigen was accompanied by an upregulation of the SREBP pathway, resulting in an increased availability of sterols needed for membrane biogenesis. Furthermore, the activities of the oxysterol-metabolizing enzyme sulfotransferase family cytosolic $2 \mathrm{~B}$ member 1 (SULT2B1) and multidrug resistance protein 1 (MRP1/ABCC1) were increased, thereby eliminating oxysterol ligands of LXR leading to T-cell expansion [29, 30]. Based on these findings, it can be speculated that plant stanols reduced the cellular oxycholesterol content of the intestinal T-cells, mimicking the effect of LXR activation, and resulting in a dampening of T-cell expansion. However, further research is needed to elucidate this possible association. Unfortunately, the amount of biopsy material we collected was too small to analyze for oxysterol levels. In this context, it is interesting to investigate whether the effects observed are specific for plant stanols or that similar effects could have been achieved through changing dietary cholesterol intake. In our in vitro [10] and ex vivo experiments [31] we have earlier used identical concentrations of cholesterol and plant stanols/sterols to evaluate the impact on changes in T-cell behaviour. These studies suggested that effects were plant stanol and sterol specific. However, further studies are needed to examine if these effects can be extrapolated to the results related to the present study. 


\section{CHAPTER 4}

In summary, an acute intake of plant stanol esters did not change expression profiles of genes involved in sterol metabolism 5 hours postprandial. However, pathways involved in T-cell functions were consistently down regulated in the jejunum. The physiological and functional relevance of the plant stanol ester-induced immunomodulatory effects deserves further investigation.

\section{Acknowledgement}

We would like to thank all study participants for their time and effort to make this study possible. We also thank Maud Beckers and Maurice Konings for their technical support and our dietician, Nina Wystyrk for nutritional counselling throughout the study. We thank Elhaseen Elamin, Nico Kloosterboer and Melanie Schnijderberg for the immunohistochemical analysis. E.D., R.P.M. and J.P. designed research; E.D. conducted research; E.D., R.P.M. M.V.B. and J.P. analyzed data; E.D., R.P.M., M.V.D., T.G.A.M.W., W.T.V.G. and J.P. wrote the paper; and J.P. had primary responsibility for final content. All authors read and approved the final manuscript. Authors have no conflict of interest. This study was financially supported by Raisio Life Sciences, Finland. 


\section{AN ACUTE INTAKE CHANGES IMMUNE-RELATED PATHWAYS}

\section{References}

1. Ling, W.H. and P.J. Jones, Dietary phytosterols: a review of metabolism, benefits and side effects. Life Sci, 1995. 57(3): p. 195-206.

2. Racette, S.B., et al., Dose effects of dietary phytosterols on cholesterol metabolism: a controlled feeding study. Am J Clin Nutr, 2010. 91(1): p. 32-8.

3. Plat, J., et al., Progress and prospective of plant sterol and plant stanol research: report of the Maastricht meeting. Atherosclerosis, 2012. 225(2): p. 521-33.

4. De Smet, E., R.P. Mensink, and J. Plat, Effects of plant sterols and stanols on intestinal cholesterol metabolism: suggested mechanisms from past to present. Mol Nutr Food Res, 2012. 56(7): p. 1058-72.

5. Lee, I.A., E.J. Kim, and D.H. Kim, Inhibitory effect of beta-sitosterol on TNBS-induced colitis in mice. Planta Med, 2012. 78(9): p. 896-8.

6. Baskar, A.A., et al., Chemopreventive potential of beta-Sitosterol in experimental colon cancer model--an in vitro and In vivo study. BMC Complement Altern Med, 2010. 10: p. 24.

7. Brufau, G., et al., A reappraisal of the mechanism by which plant sterols promote neutral sterol loss in mice. PLoS One, 2011. 6(6): p. e21576.

8. Field, F.J., E. Born, and S.N. Mathur, Effect of micellar beta-sitosterol on cholesterol metabolism in CaCo-2 cells. J Lipid Res, 1997. 38(2): p. 348-60.

9. Plat, J. and R.P. Mensink, Increased intestinal ABCA1 expression contributes to the decrease in cholesterol absorption after plant stanol consumption. FASEB J, 2002. 16(10): p. 1248-53.

10. Brull, F., et al., Beneficial effects of sitostanol on the attenuated immune function in asthma patients: results of an in vitro approach. PLoS One, 2012. 7(10): p. e46895.

11. Wolfs, T.G., et al., Endotoxin induced chorioamnionitis prevents intestinal development during gestation in fetal sheep. PLoS One, 2009. 4(6): p. e5837.

12. Chen, Q., et al., Dietary phytosterols and phytostanols alter the expression of sterol-regulatory genes in SHRSP and WKY inbred rats. Ann Nutr Metab, 2009. 55(4): p. 341-50.

13. Scoggan, K.A., et al., Increased incorporation of dietary plant sterols and cholesterol correlates with decreased expression of hepatic and intestinal Abcg5 and Abcg8 in diabetic BB rats. J Nutr Biochem, 2009. 20(3): p. 177-86.

14. Tachibana, S., et al., Cholesterol and plant sterol efflux from cultured intestinal epithelial cells is mediated by ATP-binding cassette transporters. Biosci Biotechnol Biochem, 2007. 71(8): p. 1886-95.

15. Plat, J., J.A. Nichols, and R.P. Mensink, Plant sterols and stanols: effects on mixed micellar composition and LXR (target gene) activation. J Lipid Res, 2005. 46(11): p. 2468-76.

16. Dieter, M.Z., et al., Expression and regulation of the sterol half-transporter genes ABCG5 and ABCG8 in rats. Comp Biochem Physiol C Toxicol Pharmacol, 2004. 139(4): p. 209-18.

17. Kang, C.K. and T.H. Lee, Medaka villin 1-like protein (VILL) is associated with the formation of microvilli induced by decreasing salinities in the absorptive ionocytes. Front Zool, 2014. 11(1): p. 2.

18. Igel, M., et al., Comparison of the intestinal uptake of cholesterol, plant sterols, and stanols in mice. J Lipid Res, 2003. 44(3): p. 533-8.

19. Repa, J.J., et al., Regulation of ATP-binding cassette sterol transporters ABCG5 and ABCG8 by the liver $X$ receptors alpha and beta. J Biol Chem, 2002. 277(21): p. 18793-800.

20. Davis, H.R., Jr., et al., Niemann-Pick C1 Like 1 (NPC1L1) is the intestinal phytosterol and cholesterol transporter and a key modulator of whole-body cholesterol homeostasis. J Biol Chem, 2004. 279(32): p. 33586-92.

21. Repa, J.J., J.M. Dietschy, and S.D. Turley, Inhibition of cholesterol absorption by SCH 58053 in the mouse is not mediated via changes in the expression of mRNA for ABCA1, ABCG5, or ABCG8 in the enterocyte. J Lipid Res, 2002. 43(11): p. 1864-74.

22. Kaneko, E., et al., Induction of intestinal ATP-binding cassette transporters by a phytosterolderived liver $X$ receptor agonist. J Biol Chem, 2003. 278(38): p. 36091-8.

23. Lally, S., et al., Messenger RNA levels of genes involved in dysregulation of postprandial lipoproteins in type 2 diabetes: the role of Niemann-Pick C1-like 1, ATP-binding cassette, transporters G5 and G8, and of microsomal triglyceride transfer protein. Diabetologia, 2006. 49(5): p. 1008-16.

24. Phillips, C., et al., Intestinal microsomal triglyceride transfer protein in type 2 diabetic and nondiabetic subjects: the relationship to triglyceride-rich postprandial lipoprotein composition. Atherosclerosis, 2006. 187(1): p. 57-64. 


\section{CHAPTER 4}

25. Calpe-Berdiel, L., et al., Dietary phytosterols modulate T-helper immune response but do not induce apparent anti-inflammatory effects in a mouse model of acute, aseptic inflammation. Life Sci, 2007. 80(21): p. 1951-6.

26. Mosmann, T.R. and R.L. Coffman, TH1 and TH2 cells: different patterns of lymphokine secretion lead to different functional properties. Annu Rev Immunol, 1989. 7: p. 145-73.

27. Koboziev, I., et al., Role of the enteric microbiota in intestinal homeostasis and inflammation. Free Radic Biol Med, 2013. 68C: p. 122-133.

28. Martinez, I., et al., Diet-induced alterations of host cholesterol metabolism are likely to affect the gut microbiota composition in hamsters. Appl Environ Microbiol, 2013. 79(2): p. 516-24.

29. Bensinger, S.J., et al., LXR signaling couples sterol metabolism to proliferation in the acquired immune response. Cell, 2008. 134(1): p. 97-111.

30. Glass, C.K. and K. Saijo, Immunology: Oxysterols hold T cells in check. Nature, 2008. 455(7209): p. 40-1.

31. Brull, F., et al., TLR2 activation is essential to induce a Th1 shift in human peripheral blood mononuclear cells by plant stanols and plant sterols. J Biol Chem, 2010. 285(5): p. 2951-8. 


\title{
CHAPTER 5
}

\begin{abstract}
Acute effects of plant stanol esters on postprandial metabolism and its relation with changes in serum lipids after longer-term intake
\end{abstract}

Els De Smet, Ronald P. Mensink and Jogchum Plat

Submitted 


\section{CHAPTER 5}

\section{Abstract}

Background/Objectives: Plant stanol esters lower serum LDL-cholesterol (LDL-C), but responses between individuals vary widely. As the ability of subjects to respond to acute dietary challenges may reflect the flexibility to adapt to changes on the longer-term, we related subjects' acute postprandial metabolic changes to changes in serum lipoproteins after longer-term intake of plant stanol esters.

Subjects/Methods: In a double-blind crossover design, healthy subjects (12 female/8male) received in random order a shake with or without plant stanol esters $(4 \mathrm{~g})$. Two subjects dropped-out. Blood samples were taken during 4 hours to examine lipid, glucose and lipoprotein profiles. Subjects receiving the shake with plant stanol esters, consumed for the next 3 weeks a plant stanol enriched $(3 \mathrm{~g} / \mathrm{d})$ margarine and visa versa.

Results: The margarine enriched with plant stanol esters lowered concentrations of total cholesterol by $7.3 \%(p<0.01)$, of LDL-C by $9.5 \%(p<0.01)$, and of apoB100 by $8.6 \%(p<0.01)$. Furthermore, particle concentrations of total VLDL, small VLDL and large LDL were reduced by $26.6 \%(p=0.02), 27.6 \%(p=0.02)$ and $12.3 \%(p=0.04)$, respectively. Plant stanol esters did not affect parameters related to lipid and glucose metabolism during the postprandial phase. However, the iAUC of the postprandial glucose concentration after consuming the control shake correlated positively with changes in fasting concentrations of total cholesterol, LDL-C, apoB100, total VLDL, small VLDL and IDL after 3 weeks.

Conclusion: A single dose of plant stanol esters does not change postprandial lipid and lipoprotein profiles. However, postprandial glucose responses may predict the effects of longer-term plant stanol ester consumption. 


\section{Introduction}

The cholesterol-lowering effect of plant sterols was already observed in 1950 . Numerous studies later, it is generally accepted that a daily intake of $2.5 \mathrm{~g}$ plant sterols or stanols lowers serum LDL-C concentrations up to $10 \%$ [1]. However, the mechanism underlying this effect is still under debate. As recently reviewed [2], the earliest explanations suggested an effect on mixed micelle composition, whereas more recent theories suggest involvement of several intestinal transporter molecules or activation of the recently described transintestinal cholesterol excretion (TICE) pathway [3]. Moreover, although serum LDL-C concentrations decrease in most individuals after consumption of plant sterol or stanol ester enriched foods, a large inter-individual variation exists [4]. Identification of factors related to this variability may help to identify responsive (sub)populations and add to a better understanding of the underlying mechanisms [5]. In this respect, postprandial challenge studies may be helpful. During the postprandial phase, not only glucose and insulin concentrations change profoundly, but also those of the intestine-derived cholesterol-containing chylomicrons. Until now, only a few studies have evaluated the effects of components that interfere with intestinal cholesterol absorption on postprandial glucose and lipoprotein metabolism. Bozzetto et al. [6] have shown that in type II diabetic patients with hypertriglyceridemia, six weeks ezetimibe treatment lowered the iAUC for apoB48 concentrations in the chylomicron fraction, but not the iAUC for chylomicron cholesterol or TAG concentrations. In line with these findings, Relas and colleagues [7] have shown that in normolipidemic men, an acute intake of plant stanol esters did not lower postprandial TAG or cholesterol concentrations in the chylomicron fraction. In these studies, relations between postprandial changes in lipid and lipoprotein or glucose metabolism to changes in fasting serum lipid and lipoprotein concentrations after longer-term consumption were not examined. This is unfortunate, as the ability of subjects to respond to acute dietary challenges may reflect the flexibility to adapt to changes on the longer-term [8]. Therefore, we evaluated whether it is possible to predict individual responses to longer-term consumption of plant stanol esters based on results obtained during a postprandial test at baseline. In addition, comparing the effects of an acute dietary challenge with and without plant stanol esters on postprandial lipid metabolism might also provide information on the cholesterol-lowering mechanism of plant stanols. We deliberately choose to compare the acute effects of a fat load containing no or $4 \mathrm{~g}$ plant stanols as their fatty acid esters after subjects had followed for one week a plant sterol and stanol poor diet. In this way, possible interference of day-to-day and inter-individual differences in plant sterol and stanol intake from the background diet was reduced, while an optimal contrast in intake was created.

\section{Materials and Methods}

\section{Study population}

Subjects were recruited in Maastricht and surrounding areas through advertisements in local newspapers and via posters in the university and hospital buildings. They were invited for 2 screening visits if they met the following inclusion criteria: $18-60$ years of age, BMI between 20 and $30 \mathrm{~kg} / \mathrm{m}^{2}$, stable body weight (weight gain or loss $<2 \mathrm{~kg}$ in the previous 3 months), no use of lipid-lowering 


\section{CHAPTER 5}

medication or a prescribed diet, no abuse of alcohol or drugs, no pregnancy or breast-feeding, not smoking, not suffering from diabetes, no history of coronary artery disease, no history of gastrointestinal disorders and no participation in another lifestyle or pharmaceutical intervention study for the past 30 days. During the two screening visits, which were separated by at least 3 days, body weight, height and blood pressure were determined and blood was sampled for analysis of serum total cholesterol concentrations. Subjects were excluded if the mean serum total cholesterol concentration was $>7.8 \mathrm{mmol} / \mathrm{L}$. Once included, the subjects were asked not to change their dietary habits, level of physical exercise, and alcohol intake during the duration of the study. In addition, those subjects regularly taking vitamin supplements were asked to discontinue this at least one month before the start of the study and prolonged during the study. This study was conducted according to the guidelines laid down in the Declaration of Helsinki and all procedures involving human subjects were approved by the Medical Ethical Committee of the Maastricht University Medical Centre. All participants gave written informed consent before entering the study. The trial was registered on clinicaltrials.gov under study number NCT01574417.

\section{Study design}

The study had a randomized, double blind cross-over design and consisted of two intervention periods of four weeks separated by a four weeks washout period. During randomization, subjects were stratified for age, gender and BMI. To examine the acute effects of plant stanol esters on postprandial lipid and lipoprotein metabolism, each intervention period started with a one-week period during which the subjects were instructed to avoid products relatively rich in plant sterols and stanols. These food items were listed and possible alternatives were discussed with a dietician. Furthermore, subjects were not allowed to consume products enriched with plant sterols/stanols during the study. To further minimize differences between the two postprandial test days, all subjects consumed the day before at dinner a standard lasagne meal, which was provided free of charge. Except for water, they were not allowed to consume any other foods or drinks after dinner, till the morning of the postprandial test. After a 12-hr overnight fast, participants visited our department by public transportation or by car avoiding physical activity. After resting for 15 minutes in a supine position, an intravenous canula was inserted into the anticubital vein and a fasting blood sample was collected (T0). Next, subjects received 1 of the 2 test meals consisting of a slice of white bread with jam and a high-fat shake that was either enriched with plant stanol esters or not. The shake contained 3.3 MJ (797.5 kcal) energy provided by $51.3 \mathrm{~g}$ fat [57.9 energy percent (en\%), of which $23.9 \mathrm{en} \%$ was saturated fatty acids, 22.9 en\% monounsaturated fatty acids, and $11.1 \mathrm{en} \%$ polyunsaturated fatty acids], $11.7 \mathrm{~g}$ protein (5.9 en\%), and $66.5 \mathrm{~g}$ carbohydrates (33.3 en\%). The subjects were requested to consume the bread and shake within 10 minutes and were not allowed to eat or drink anything else, except water during the next 4 hours. Subsequent blood samples were collected at $T=15$ min (T15) after meal consumption, $\mathrm{T}=30 \mathrm{~min}$ (T30), $\mathrm{T}=45 \mathrm{~min}$ ( $\mathrm{T} 45), \mathrm{T}=60 \mathrm{~min}(\mathrm{~T} 60), \mathrm{T}=120 \mathrm{~min}$ (T120), $\mathrm{T}=180 \mathrm{~min}$ (T180) and at $\mathrm{T}=240 \mathrm{~min}$ (T240). During the next 3 weeks, subjects consumed a margarine enriched with or without plant stanol esters $(3 \mathrm{~g} / \mathrm{d})$. Subjects receiving the shake with plant stanol esters continued with the margarine containing plant stanol esters and vice-versa. They consumed daily 20 gram of 
margarine, which was divided over two eating moments, i.e. at breakfast and at lunch. The margarines were packed in tubs of $140 \mathrm{~g}$, equivalent to margarine consumption for 7 days. All products were coded with a colour label to blind the subjects and the investigators. At the end of each test period (days 25, 28 and days $81,85)$, subjects came to the university twice for taking a fasting blood sample. Body weight was determined at the beginning and at the end of each test period. Participants recorded in dairies any signs of illness, medication used, alcohol consumption, any deviations of the study protocol and any other complaints. They also recorded their food intake during the two test periods by completing food frequency questionnaires (FFQ) to estimate their energy and nutrient intakes. These FFQs were checked and calculated by a registered dietician.

\section{Blood sampling}

Blood was sampled in serum tubes as well as EDTA- and NaF-containing vacutainer tubes (Becton Dickinson). The EDTA and NaF tubes were placed on ice directly after sampling and centrifuged at $1300 \times \mathrm{g}$ for $15 \mathrm{~min}$ at $4^{\circ} \mathrm{C}$ within 60 minutes after sampling. Blood samples taken in serum tubes (Becton Dickinson) were allowed to clot for $30 \mathrm{~min}$ at $21^{\circ} \mathrm{C}$, followed by centrifugation at $1300 \mathrm{xg}$ for $15 \mathrm{~min}$ at $21^{\circ} \mathrm{C}$ to obtain serum. Serum and plasma aliquots were directly snap-frozen in liquid nitrogen and stored at $-80^{\circ} \mathrm{C}$ until analysis. All samples from one subject were analyzed within the same analytical run.

\section{Lipids and (apo)lipoproteins}

In all fasting serum samples, serum total cholesterol (CHOD-PAP method; Roche Diagnostics Systems, Hofmann-La Roche), HDL cholesterol (HDL-C) (CHOD/PAP method; Roche Diagnostics Systems, Hofmann-La Roche) after precipitation of apoB-containing lipoproteins by adding phosphotungstic acid and magnesium ions (precipitation method; Monotest cholesterol, Boehringer Mannheim), and TAG with correction for free glycerol (GPO Trinder; Sigma Diagnostics) were analyzed enzymatically. LDL-C was calculated using the Friedewald equation [9]. ApoB-100 and apoA-1 were measured using an immunoturbidimetric reaction (UNI-KIT apoB and UNI-KIT apoA-1, Roche). In addition, serum TAG concentrations were also analyzed in the postprandial samples taken at all indicated time points.

\section{Lipoprotein profiles}

Serum lipoprotein profiles were determined using NMR spectroscopy (Liposcience, Raleigh, NC, United-States) in EDTA plasma at 5 time points during the postprandial tests (T0, T60, T120, T180 and T240) as well as in fasting samples obtained at the end of each 3 week intervention periods, i.e. days 28 and 85 . Concentrations (nmol/L for VLDL and LDL particles and $\mu \mathrm{mol} / \mathrm{L}$ for high-density lipoproteins (HDL) particles) of the following subclasses were analyzed: large VLDL (>60 nm), medium VLDL (35-60 nm), small VLDL (27-35 nm), intermediate-density lipoprotein (IDL) (23-27 $\mathrm{nm})$, large LDL (21.2-23 nm), small LDL (18-21.2 nm), medium small LDL (19.8-21.2 $\mathrm{nm})$, very small LDL (18-19.8 nm), large HDL (8.8-13 nm), medium HDL (8.2-8.8 $\mathrm{nm})$ and small HDL (7.3-8.2 nm). Since NMR distinguishes lipoprotein subclasses 


\section{CHAPTER 5}

on the basis of particle size alone the largest VLDL fraction also includes the chylomicrons, which are especially present in the postprandial samples [10].

\section{Serum plant sterols and stanols}

Concentrations of plant sterols, stanols and cholesterol precursors were determined at the start and at the end of each of the two experimental periods, i.e. in serum samples from days 8 and 28, and from days 64 and 85 , as described [11].

\section{Glucose, insulin, FFA and hsCRP concentrations}

Plasma glucose (Roche Diagnostic Systems, Hoffmann-La Roche) and free fatty acids (FFA) (Wako Biochemicals) concentrations were measured in NaF plasma at all time points during the postprandial test days as well as in fasting samples obtained on days $25,28,81$ and 85 . Serum insulin concentrations were determined at the same time points with a human insulin-specific radioimmunoassay (RIA) kit (Linco Research). High sensitive C-reactive protein (hsCRP) was analyzed with a highly sensitive immunoturbidimetric assay (Kamiya Biomedical Company, Seattle, WA, USA).

\section{Statistical analysis}

A paired t-test was used to compare differences in fasting concentrations of the variables at the end of the intervention and control periods. For each subject, results of the two measurements taken at week 3 (days 25 and 28) and at week 12 (days 81 and 85) were averaged before statistical analysis. Hs-CRP concentrations were not normally distributed and analyzed with the non-parametric Mann-Withney test. Changes over time of variables measured during the postprandial test were analyzed by linear mixed models with diet and time as fixed factors and with diet $x$ time as an interaction term. If this term was not significant, it was omitted from the model. Post hoc tests with Bonferroni correction were carried out if factor time was significant to compare each concentration to baseline concentrations. At the postprandial test days, the incremental AUC (iAUC) was calculated using the trapezoidal rule [12] for serum total cholesterol, TAG, glucose, insulin and all lipoprotein subfractions. Pearson correlation coefficients were determined between changes in the different parameters after the three weeks interventions and postprandial changes in serum lipid, TAG, FFA, glucose and insulin concentrations at baseline. A p-value $\leq 0.05$ was considered as statistically significant. All data are presented as means \pm standard deviation (SD) and all analyses were performed using SPSS 20.0 software (SPSS Inc, Chicago, IL). 


\section{ACUTE AND LONGER-TERM EFFECTS}

\section{Results}

Baseline characteristics and dietary intake data

Twenty subjects started the study. Due to flu the evening before the first test day and tonsillitis one week before the second test day for which antibiotics had to be used, two subjects dropped out. Both events occurred during the week in which a plant sterol poor diet was consumed, i.e. before plant stanol ester consumption started. Therefore, these events were considered not to be related to the active ingredients. Baseline characteristics of the 18 subjects who completed the study are shown in table 1. Energy and nutrient intakes did not differ between the two periods (supplemental table 1). There were also no significant changes in body weight during the study.

Table 1: Baseline characteristics of the 18 participants who completed the study.

\begin{tabular}{lc}
\hline Age (years) & $33 \pm 12$ \\
Gender (F/M) & $11 / 7$ \\
Body weight $(\mathrm{kg})$ & $71.4 \pm 11.3$ \\
BMI $(\mathrm{kg} / \mathrm{m} 2)$ & $23.9 \pm 2.8$ \\
Serum total cholesterol $(\mathrm{mmol} / \mathrm{L})$ & $5.61 \pm 0.96$ \\
Systolic blood pressure $(\mathrm{mmHg})$ & $117 \pm 12$ \\
Diastolic blood pressure $(\mathrm{mmHg})$ & $78 \pm 8$ \\
\hline
\end{tabular}

All values are means \pm SD.

Supplemental table 1: Energy and nutrient intake during the two test periods according to food frequency questionnaires.

\begin{tabular}{lccrc}
\hline & Control meal & $\begin{array}{l}\text { Plant stanol ester } \\
\text { meal }\end{array}$ & Change & p-value \\
\hline Energy (MJ/day) & $10.1 \pm 2.5$ & $10.1 \pm 2.8$ & $0.0 \pm 1.8$ & 0.97 \\
Protein (en\%) & $15.5 \pm 3.4$ & $15.4 \pm 3.6$ & $-0.1 \pm 2.3$ & 0.96 \\
Total fat (en\%) & $37.1 \pm 7.1$ & $36.6 \pm 7.9$ & $-0.5 \pm 4.5$ & 0.62 \\
SFA (en\%) & $11.9 \pm 2.7$ & $11.0 \pm 3.1$ & $-1 \pm 2.2$ & 0.08 \\
MUFA (en\%) & $14.3 \pm 4.0$ & $14.7 \pm 4.3$ & $0.4 \pm 2.7$ & 0.50 \\
PUFA (en\%) & $8.4 \pm 2.4$ & $8.5 \pm 2.6$ & $0.1 \pm 1.7$ & 0.90 \\
Carbohydrates (en\%) & $45.3 \pm 9.0$ & $45.6 \pm 10.3$ & $0.3 \pm 5.7$ & 0.80 \\
Fibre (g/MJ) & $2.7 \pm 0.7$ & $2.5 \pm 0.6$ & $-0.2 \pm 0.6$ & 0.13 \\
Alcohol (en\%) & $2.2 \pm 1.7$ & $2.4 \pm 1.8$ & $0.2 \pm 0.8$ & 0.51 \\
Cholesterol (mg/MJ) & $19.6 \pm 5.5$ & $21.1 \pm 7.1$ & $1.5 \pm 8.9$ & 0.70 \\
\hline
\end{tabular}

All values are means \pm SD.

Serum lipid, lipoproteins, glucose, insulin, free fatty acids and inflammation

Three weeks consumption of the margarine enriched with plant stanol esters reduced serum total cholesterol and LDL-C concentrations by $0.38 \pm 0.42 \mathrm{mmol} / \mathrm{L}$ $(7.1 \% ; p<0.01)$ and by $0.30 \pm 0.41 \mathrm{mmol} / \mathrm{L}(9.5 \% ; p<0.01)$, respectively. Serum apoB100 concentrations were reduced by $0.07 \pm 0.09 \mathrm{~g} / \mathrm{L}(8.6 \% ; p<0.01)$. Serum HDL-C, TAG and apoA1 concentrations did not change (table 2). As compared to the control period, the number of total VLDL-CM, small VLDL and large LDL particles 


\section{CHAPTER 5}

decreased with respectively $17.2 \pm 27.8(26.6 \% ; p=0.02), 9.4 \pm 15.5 \mathrm{mmol} / \mathrm{L}$ $(27.6 \% ; p=0.02)$ and $56.4 \pm 109.3 \mathrm{mmol} / \mathrm{L}(12.3 \% ; \mathrm{p}=0.04)$ during the plant stanol ester period (table 3). Glucose, insulin, FFA and hs-CRP concentrations did not differ between the control and intervention periods (table 2).

Table 2: Effect of 3-week consumption of plant stanol esters on parameters reflecting lipid, plant sterol, plant stanol, lathosterol, cholestanol, glucose metabolism and body weight.

\begin{tabular}{|c|c|c|c|c|}
\hline & $\begin{array}{l}\text { Control } \\
\text { margarine }\end{array}$ & $\begin{array}{l}\text { Plant stanol ester } \\
\text { margarine }\end{array}$ & Change $^{1}$ & $\mathrm{p}$-value \\
\hline $\begin{array}{l}\text { Total Cholesterol } \\
\text { (mmol/L) }\end{array}$ & $5.38 \pm 0.83$ & $5.00 \pm 0.82$ & $-0.38 \pm 0.42$ & $<0.01$ \\
\hline LDL-C (mmol/L) & $3.17 \pm 0.79$ & $2.87 \pm 0.70$ & $-0.30 \pm 0.41$ & 0.01 \\
\hline HDL-C (mmol/L) & $1.59 \pm 0.33$ & $1.59 \pm 0.33$ & $0.01 \pm 0.15$ & 0.82 \\
\hline Triglycerides $(\mathrm{mmol} / \mathrm{L})$ & $1.32 \pm 0.45$ & $1.21 \pm 0.44$ & $-0.11 \pm 0.30$ & 0.13 \\
\hline $\begin{array}{l}\text { Free fatty acids } \\
(\mu \mathrm{mol} / \mathrm{L})\end{array}$ & $303 \pm 87$ & $286 \pm 86$ & $-17.2 \pm 83.3$ & 0.39 \\
\hline Glucose $(\mathrm{mmol} / \mathrm{L})$ & $5.20 \pm 0.35$ & $5.28 \pm 0.42$ & $0.08 \pm 0.28$ & 0.26 \\
\hline Insulin $(\mu \mathrm{U} / \mathrm{mL})$ & $14.2 \pm 6.6$ & $13.5 \pm 4.8$ & $-0.67 \pm 5.85$ & 0.63 \\
\hline $\mathrm{CRP}(\mathrm{mg} / \mathrm{dl})$ & $1.30 \pm 1.61$ & $1.36 \pm 1.91$ & $0.06 \pm 0.82$ & 0.45 \\
\hline ApoA1 (g/l) & $1.48 \pm 0.22$ & $1.48 \pm 0.23$ & $-0.01 \pm 0.09$ & 0.69 \\
\hline ApoB100 (g/l) & $0.93 \pm 0.20$ & $0.85 \pm 0.20$ & $-0.07 \pm 0.09$ & $<0.01$ \\
\hline Sitosterol & $155 \pm 60$ & $111 \pm 39$ & $-45 \pm 28$ & $<0.01$ \\
\hline Campesterol & $249 \pm 92$ & $178 \pm 64$ & $-71 \pm 45$ & $<0.01$ \\
\hline Sitostanol & $5.7 \pm 1.5$ & $22.5 \pm 7.4$ & $17 \pm 7$ & $<0.01$ \\
\hline Campestanol & $3.7 \pm 1.2$ & $11.0 \pm 4.0$ & $7 \pm 3$ & $<0.01$ \\
\hline Lathosterol & $153 \pm 70$ & $161 \pm 48$ & $8 \pm 51$ & 0.49 \\
\hline Desmosterol & $66.0 \pm 18.9$ & $70.2 \pm 21.3$ & $4 \pm 9$ & 0.05 \\
\hline Body weight (kg) & $72.2 \pm 12.1$ & $73.1 \pm 12.2$ & $0.91 \pm 1.90$ & 0.06 \\
\hline
\end{tabular}

All values are means \pm SD. Plant sterols, stanols and cholesterol precursors (lathosterol and desmosterol) are expressed as $10^{2} \times \mu \mathrm{mol} / \mathrm{mmol}$ cholesterol

Table 3: Effect of 3-week consumption of plant stanol esters on fasting serum lipoprotein profiles.

\begin{tabular}{|c|c|c|c|c|}
\hline & $\begin{array}{l}\text { Control } \\
\text { margarine }\end{array}$ & $\begin{array}{l}\text { Plant stanol ester } \\
\text { margarine }\end{array}$ & Change $^{1}$ & $\mathrm{p}$-value \\
\hline Total VLDL (nmol/L) & $65 \pm 31$ & $47 \pm 26$ & $-18 \pm 28$ & 0.02 \\
\hline $\begin{array}{l}\text { Large VLDL-CM } \\
\text { (nmol/L) }\end{array}$ & $2 \pm 2$ & $3 \pm 4$ & $1 \pm 4$ & 0.28 \\
\hline Medium VLDL (nmol/L) & $29 \pm 20$ & $20 \pm 12$ & $-9 \pm 18$ & 0.52 \\
\hline Small VLDL (nmol/L) & $34 \pm 17$ & $25 \pm 15$ & $-9 \pm 15$ & 0.02 \\
\hline Total LDL (nmol/L) & $1042 \pm 340$ & $966 \pm 319$ & $-76 \pm 176$ & 0.08 \\
\hline IDL (nmol/L) & $34 \pm 30$ & $27 \pm 21$ & $-7 \pm 36$ & 0.39 \\
\hline Large LDL (nmol/L) & $457 \pm 156$ & $401 \pm 171$ & $-56 \pm 109$ & 0.04 \\
\hline Small LDL (nmol/L) & $551 \pm 329$ & $538 \pm 308$ & $-13 \pm 193$ & 0.79 \\
\hline $\begin{array}{l}\text { Medium small LDL } \\
(\mathrm{nmol} / \mathrm{L})\end{array}$ & $109 \pm 62$ & $114 \pm 65$ & $5 \pm 41$ & 0.64 \\
\hline $\begin{array}{l}\text { Very small LDL } \\
\text { (nmol/L) }\end{array}$ & $442 \pm 268$ & $425 \pm 245$ & $-17 \pm 156$ & 0.65 \\
\hline Total HDL $(\mu \mathrm{mol} / \mathrm{L})$ & $33 \pm 5$ & $32 \pm 5$ & $-1 \pm 3$ & 0.25 \\
\hline Large HDL $(\mu \mathrm{mol} / \mathrm{L})$ & $8 \pm 4$ & $8 \pm 3$ & $0 \pm 2$ & 0.98 \\
\hline Medium HDL ( $\mu \mathrm{mol} / \mathrm{L})$ & $5 \pm 5$ & $5 \pm 4$ & $0 \pm 3$ & 0.74 \\
\hline Small HDL $(\mu \mathrm{mol} / \mathrm{L})$ & $20 \pm 6$ & $19 \pm 5$ & $-1 \pm 4$ & 0.26 \\
\hline
\end{tabular}

All values are means \pm SD

${ }^{1}$ The change was calculated as the difference between 3 weeks consumption of plant stanol ester enriched margarine versus 3 weeks consumption of the control margarine. 
Serum plant sterols, plant stanols, lathosterol and desmosterol

As expected, consumption of plant stanol esters decreased cholesterolstandardized concentrations of serum sitosterol by $44.6 \pm 27.610^{2} \times \mu \mathrm{mol} / \mathrm{mmol}$ cholesterol $(p<0.01)$ and of campesterol by $71.3 \pm 44.710^{2} \times \mu \mathrm{mol} / \mathrm{mmol}$ cholesterol $(p<0.01)$. Serum cholesterol-standardized concentrations of sitostanol concentrations increased by $16.9 \pm 6.510^{2} \times \mu \mathrm{mol} / \mathrm{mmol}$ cholesterol $(p<0.01)$ and of campestanol by $7.3 \pm 3.310^{2} \times \mu \mathrm{mol} / \mathrm{mmol}$ cholesterol $(p<0.01)$. For markers of endogenous cholesterol synthesis, no significant effect was found for lathosterol, whereas for desmosterol, concentrations significantly increased by $4.2 \pm 8.610^{2} \mathrm{x}$ $\mu \mathrm{mol} / \mathrm{mmol}$ cholesterol $(p=0.05)$ (table 2$)$.

\section{Predictive value of the postprandial test for longer-term lipid lowering efficacy}

The major aim of the study was to evaluate whether metabolic characteristics of the postprandial response could be used to predict the response after 3-weeks plant stanol ester consumption. In this study, the serum total and LDL-C-lowering effect ranged from -14 to $+9 \%$ for total cholesterol and from -25 to $+15 \%$ for LDL-C, respectively.

Interestingly, the iAUC of the postprandial glucose concentration obtained during the control period and the change in fasting total cholesterol after 3 weeks plant stanol ester consumption were strongly correlated $(r=0.66, p<0.01)$ (figure 1$)$. Moreover, comparable positive correlations were found between the iAUC of the postprandial glucose concentration and the changes in fasting concentrations of LDL-C $(r=0.76$, $p<0.01)$, apoB100 $(r=0.68, p<0.01)$, total VLDL $(r=0.50, p=0.04)$, small VLDL $(r=0.47, p=0.05)$, and IDL $(r=0.48, p=0.05)$. The iAUC for insulin was not predictive for any of these parameters. In contrast to the iAUC for glucose, the baseline lathosterol / campesterol ratio, which has been suggested to predict the decrease in LDL-C after plant stanol ester consumption [13], did not correlate with the observed LDL-C response after three weeks plant stanol ester consumption ( $r=$ $0.25, p=0.31$ ). In agreement, this ratio also did not correlate with the iAUC for glucose $(r=0.05, p=0.84)$. 


\section{CHAPTER 5}

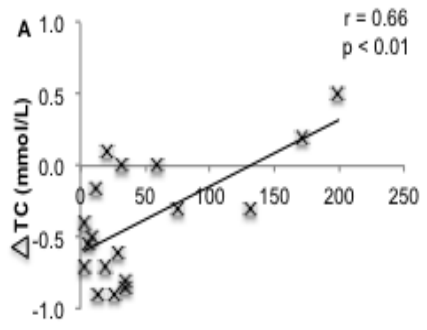

IAUC glucose (mmol $\mathrm{min} / \mathrm{L})$

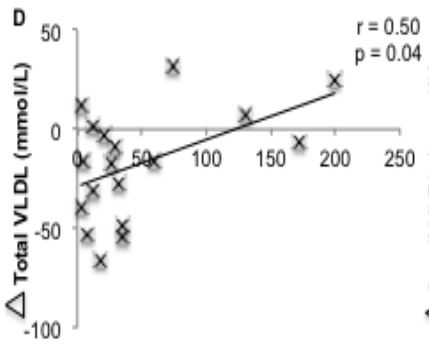

IAUC glucose (mmol min/L)

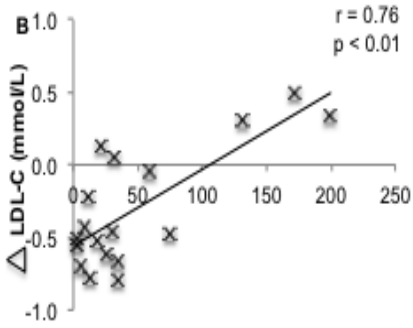

iAUC glucose (mmol $\mathrm{min} / \mathrm{L}$ )

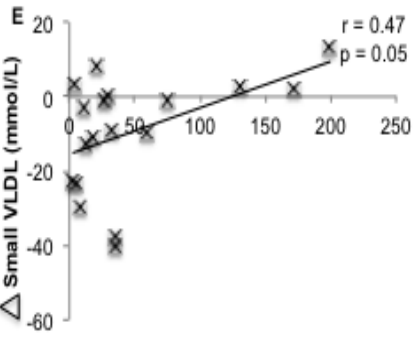

IAUC glucose (mmol min/L)
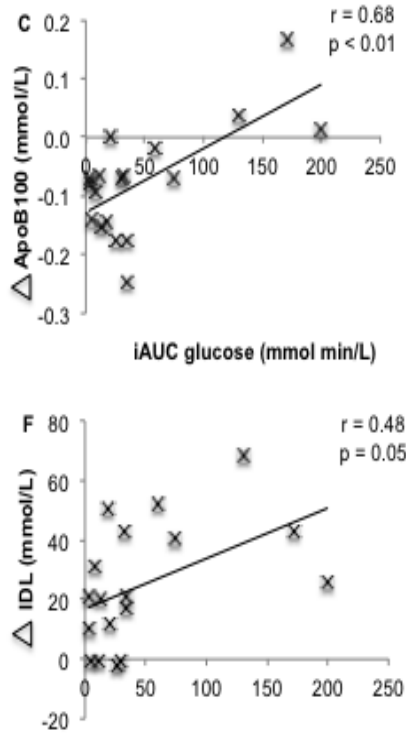

IAUC glucose (mmol min/L)

Figure 1: Relationship between the postprandial iAUC of glucose with the changes in the concentrations of total cholesterol (A), LDL-C (B), apoB100 (C), total VLDL (D), small VLDL (E) and IDL (F). Each correlation plot consists of 18 data points corresponding to the number of subjects, which consumed in random order a shake enriched with or without $4 \mathrm{~g}$ plant stanol esters.

\section{Effects of plant stanol esters on postprandial lipemia and glycemia}

Fasting concentrations of serum total cholesterol, TAG, glucose and insulin before the 4-hour postprandial period did not differ significantly. After the meals, serum total cholesterol concentrations decreased and those of TAG increased over time, $(p=$ 0.02 and $p<0.01$, respectively; supplemental figure 1 ). These changes were comparable after the plant stanol ester and control meals. Also, the iAUC of serum cholesterol and TAG were comparable after consumption of both meals $(p=0.55$ and $p=0.27$, respectively). Glucose and insulin concentrations increased after both meals. The factor time was significant for both conditions, but changes did not differ between the two meals. The iAUCs of glucose and insulin were also comparable after consumption of both meals ( $p=0.07$ and $p=0.13$, respectively). 


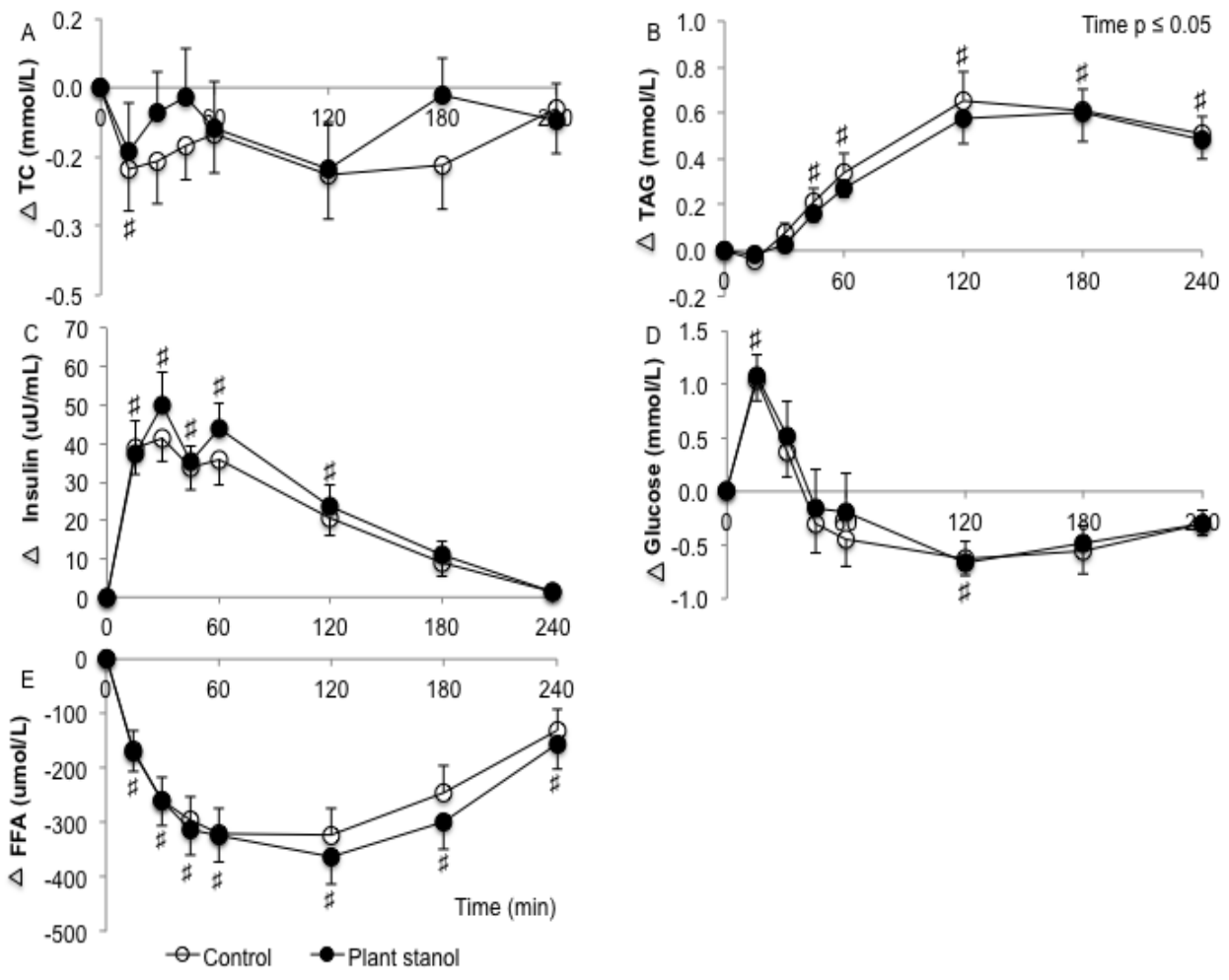

Supplemental figure 1: Mean changes ( \pm SEM) in serum concentrations of total cholesterol $(A), T A G(B)$, insulin (C) and plasma concentrations of glucose (D) and free fatty acids (E) following a shake enriched with $(-$ ) or without $(O)$ plant stanol esters in a randomized crossover study with normolipidemic subjects $(n=18)$. Data were analyzed using linear mixed models. After consumption of the shake, there was a decrease in the concentration of total cholesterol and an increase in the concentration of TAG, insulin, glucose and free fatty acids, which was significant for the factor time $(p \leq 0.05)$. Values between the shakes did not differ $(p>0.05)$. " After Bonferroni's correction significantly different from baseline $(p \leq$ 0.05).

As shown in table 4, there were no significant changes in lipoprotein profiles over the 4-hr postprandial period after intakes of the plant stanol ester and control meals. We only observed some diet-independent effects such as increases over time in the total numbers of VLDL-CM, large VLDL-CM and medium VLDL particles. No effect was found on concentrations of small VLDL particles. Interestingly, the concentrations of large and medium HDL particles were immediately increased after consuming the shake and those of small HDL particles decreased. Surprisingly, postprandial concentrations of large LDL particles, which is recognized as a postprandial appearing lipoprotein subclass [14], tended to decrease $(p=0.06)$. The total number of LDL as well as those of the various small LDL particles increased during the 4-hr follow up period. 


\section{CHAPTER 5}

As expected, there was a strong positive correlation between the iAUC of the postprandial TAG concentration and the iAUC of the postprandial concentration of large VLDL-CM particles $(r=0.76, p<0.01$ and $r=0.88, p<0.01$ for the control and the plant stanol ester periods, respectively). The iAUC of the postprandial TAG concentrations also correlated positively with the iAUC of the postprandial concentration of medium VLDL particles in the control group $(r=0.57, p=0.01)$. For the other lipoprotein particles, no significant correlations were found. 
ACUTE AND LONGER-TERM EFFECTS

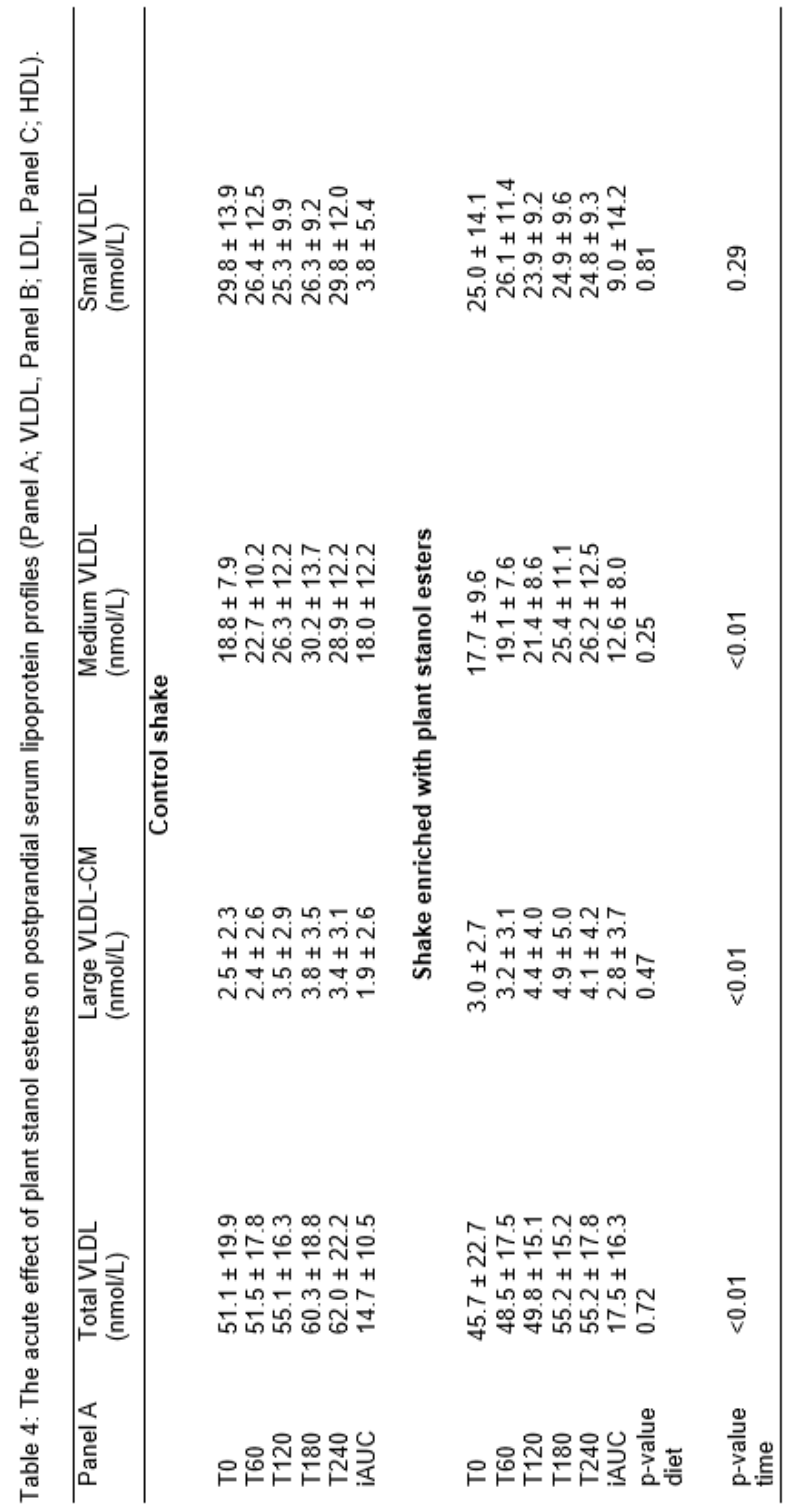


CHAPTER 5

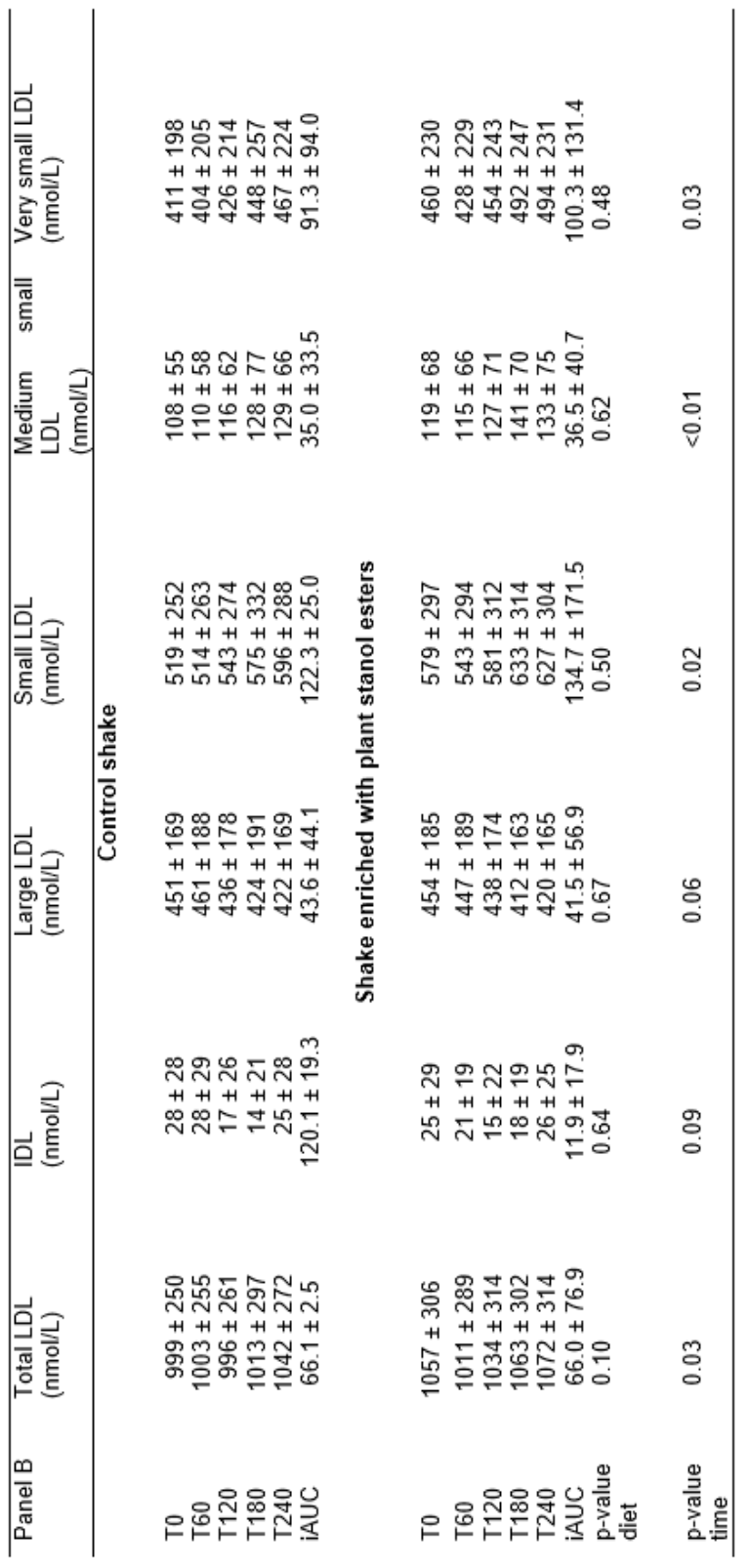


ACUTE AND LONGER-TERM EFFECTS

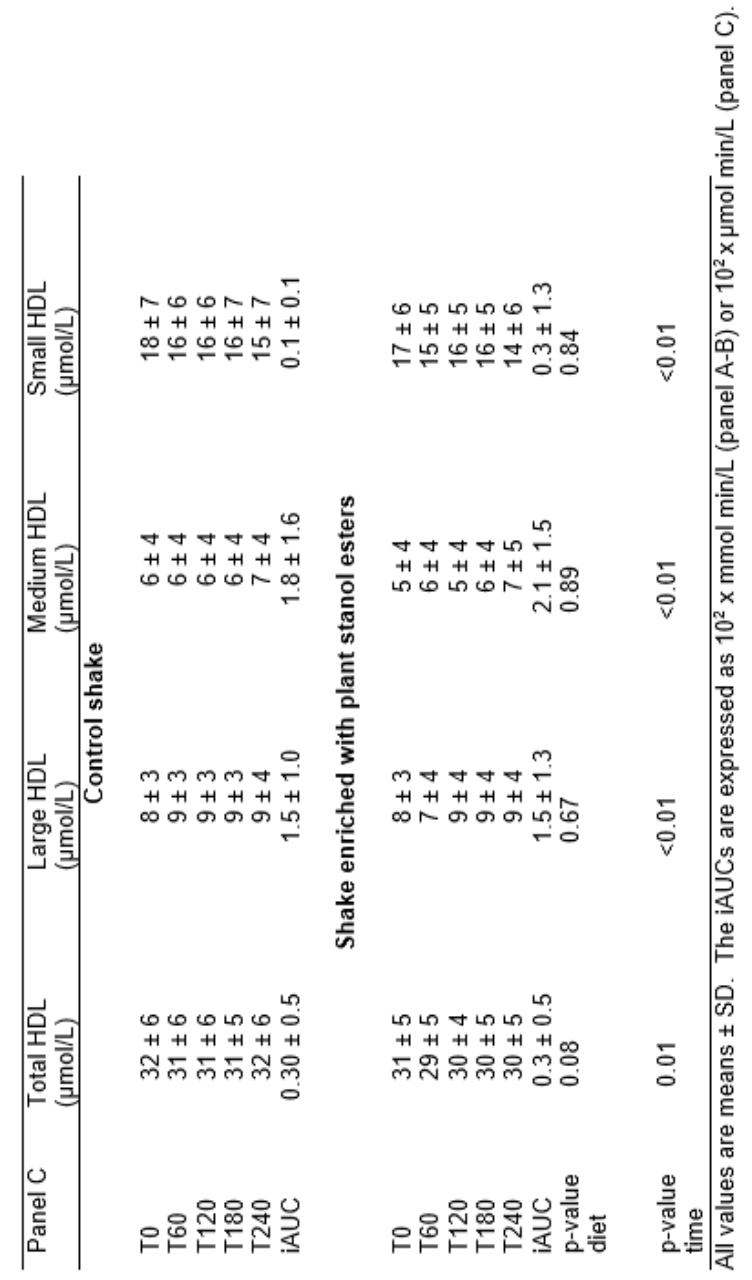




\section{CHAPTER 5}

\section{Discussion}

The mechanism underlying the beneficial effects of plant stanol esters on fasting serum LDL-C and possibly TAG concentrations [15-17] has not been unravelled yet. To further understand these mechanisms and variations in responsiveness, acute dietary challenge studies may be helpful $[8,18]$. After the intake of an acute single dose of plant stanol esters, however, no major postprandial changes were observed in parameters related to lipid and glucose metabolism. Yet, we found a clear association between the iAUC of the postprandial glucose concentration at baseline and changes in the concentrations of total cholesterol, LDL-C, apoB100, total VLDL, small LDL and IDL after 3 weeks plant stanol ester consumption. This suggests that subjects with a more pronounced postprandial glucose response are less sensitive for the longer-term LDL-C-lowering effect of plant stanol ester consumption.

As expected [16, 19], three weeks consumption of plant stanol esters lowered serum LDL-C concentrations in normolipidemic subjects. In addition, we found reductions in the number of total VLDL particles, and in the concentrations of small VLDL and of large LDL particles. No decrease in small dense LDL particles was observed, which could be explained by the fact that these are metabolic products of the large TAG-rich VLDL particles [20], which were unchanged. Earlier studies have reported a significant reduction in the total number of LDL particles [16] or in large and medium VLDL particles [21] after consumption of plant stanol esters. However, these studies were performed in subjects with familial hypercholesterolemia and in subjects diagnosed with the metabolic syndrome, and it cannot be excluded that effects in these populations are different. In contrast to our results, others have found in normolipidemic subjects a reduction in the number of large VLDL and IDL particles after plant stanol ester consumption [17], for which we have no explanation. Thus, based on these limited number of studies, it is not possible to draw a conclusion on the effects of plant stanol esters on lipoprotein subclasses.

In general, plant stanol ester intervention studies show a large inter-individual variation in the cholesterol-lowering efficacy [13]. To explain this inter-individual variation, various studies have focussed on genetic background [22] or individual characteristics like being a cholesterol-absorber or not [23]. For this, the plasma ratio of lathosterol to campesterol is frequently used [24]. However, in our study this ratio did not correlate with the changes in the fasting lipid and lipoprotein profile. We did find, however, a strong positive correlation between the postprandial iAUC of glucose with changes in total cholesterol, LDL-C, apoB100, total VLDL, small VLDL and IDL. It should be noticed that the matrix (shake vs margarine) and the dose of plant stanol esters (4 g vs $3 \mathrm{~g}$ ) were different in the acute and semi-long term intervention. However, it is not likely that this will affect the predictive value, since it was shown previously that the food matrix was not a determinant of the LDL-Clowering efficacy of plant stanols [25]. Our findings regarding a potential link with glucose concentrations are in agreement with the observations of Watts et al. [26], who suggested that subjects who are insulin resistant have a reduced susceptibility to interventions that lower intestinal cholesterol absorption. If true, the hypocholesterolemic effect of plant sterols/stanols in a metabolic syndrome population should be lower due to the lower intestinal absorption observed in these subjects [27, 28]. In contrast, based on the available data from a number controlled intervention studies, we have earlier concluded that the response towards plant 


\section{ACUTE AND LONGER-TERM EFFECTS}

sterol and stanol esters seemed to be larger in subjects with the metabolic syndrome [13]. The question still remains how we can explain the inconsistency between the results from those studies and the current study together with the study from Watts et al. [26]. It should, however, be realized that no side-by-side comparisons regarding LDL-C lowering responsiveness in healthy and for example diabetic subjects have been made. A logical explanation for our results could be that it relates not only to glucose but also to regulatory effects of insulin. However, the iAUC for insulin as well as the HOMA index were not predictive indicating that it is not insulin sensitivity as such which predicts responsiveness. Clearly, the data presented here suggests that the effects on cholesterol metabolism due to inhibition of intestinal cholesterol absorption could be mediated via changes in determinants of glucose metabolism. Future studies should therefore focus on transcription factors linking lipid, glucose and insulin metabolism like sterol regulatory element-binding protein2 (SREBP2), carbohydrate-responsive element-binding protein (ChREBP) and SREBP-1C.

Unfortunately, we could not observe any plant stanol ester-induced effect on the postprandial lipoprotein profile, which is in agreement with the 4-hour postprandial study of Gylling et al. [29]. It could be possible that the acute 4-hour postprandial follow-up period in our study was not long enough to observe any significant change in the postprandial lipid and lipoprotein profile induced by the plant stanol ester treatment. Also, results could be different when subjects were studied after longerterm intake of plant stanol esters.

In summary, the results of our study demonstrate that a single dose of plant stanol esters does not have an acute effect on postprandial glucose, lipid and lipoprotein metabolism. However, glucose responses during a postprandial test at baseline seemed predictive for individual responses in lipid and lipoprotein metabolism after 3 weeks plant stanol ester consumption. This may suggest that the plant stanol ester induced effects on cholesterol metabolism are associated with subjects' characteristics of glucose metabolism.

\section{Acknowledgements}

We would like to thank all study participants for their cooperation and enthusiasm. We also thank the technical and dietary staff from our department for their support. We thank Anja Kerksiek for the analysis of the plant sterols, stanols and cholesterol precursors. E.D., R.P.M. and J.P. designed research; E.D. conducted research; E.D., R.P.M. and J.P. analyzed data; E.D., R.P.M. D.L. and J.P. wrote the paper; and J.P. had primary responsibility for final content. All authors read and approved the final manuscript. Authors have no conflict of interest. The study was financially supported by Raisio, Finland. 


\section{CHAPTER 5}

\section{References}

1. Baumgartner S, Mensink RP, Plat J. Plant sterols and stanols in the treatment of dyslipidemia: new insights into targets and mechanisms related to cardiovascular risk. Curr Pharm Des, 2011. 17(9): p. 922-32.

2. De Smet E, Mensink RP, Plat J. Effects of plant sterols and stanols on intestinal cholesterol metabolism: suggested mechanisms from past to present. Mol Nutr Food Res, 2012. 56(7): p. 1058-72.

3. Brufau G, Kuipers F, Lin Y, Trautwein EA, Groen AK. A reappraisal of the mechanism by which plant sterols promote neutral sterol loss in mice. PLoS One, 2011. 6(6): p. e21576.

4. Rideout TC, Chan YM, Harding SV, Jones PJ. Low and moderate-fat plant sterol fortified soymilk in modulation of plasma lipids and cholesterol kinetics in subjects with normal to high cholesterol concentrations: report on two randomized crossover studies. Lipids Health Dis, 2009. 8: p. 45.

5. Ottestad I, Ose L, Wennersberg MH, Granlund L, Kirkhus B, Retterstol K. Phytosterol capsules and serum cholesterol in hypercholesterolemia: a randomized controlled trial. Atherosclerosis, 2013. 228(2): p. 421-5.

6. Bozzetto L, Annuzzi G, Corte GD, Patti L, Cipriano P, Mangione A et al. Ezetimibe beneficially influences fasting and postprandial triglyceride-rich lipoproteins in type 2 diabetes. Atherosclerosis, 2011. 217(1): p. 142-8.

7. Relas H, Gylling H, Miettinen TA. Effect of stanol ester on postabsorptive squalene and retinyl palmitate. Metabolism, 2000. 49(4): p. 473-8.

8. van Dijk SJ, Mensink M, Esser D, Feskens EJ, Muller M, Afman LA. Responses to high-fat challenges varying in fat type in subjects with different metabolic risk phenotypes: a randomized trial. PLoS One, 2012. 7(7): p. e41388.

9. Friedewald WT, Levy RI, Fredrickson DS. Estimation of the concentration of low-density lipoprotein cholesterol in plasma, without use of the preparative ultracentrifuge. Clin Chem, 1972. 18(6): p. 499-502.

10. Freedman DS, Otvos JD, Jeyarajah EJ, Shalaurova I, Cupples LA, Parise H et al. Sex and age differences in lipoprotein subclasses measured by nuclear magnetic resonance spectroscopy: the Framingham Study. Clin Chem, 2004. 50(7): p. 1189-200.

11. Plat J, Mensink RP. Effects of diets enriched with two different plant stanol ester mixtures on plasma ubiquinol-10 and fat-soluble antioxidant concentrations. Metabolism, 2001. 50(5): p. 520-9.

12. Matthews JN, Altman DG, Campbell MJ, Royston P. Analysis of serial measurements in medical research. BMJ, 1990. 300(6719): p. 230-5.

13. Plat J, Mackay D, Baumgartner S, Clifton PM, Gylling H, Jones PJ. Progress and prospective of plant sterol and plant stanol research: report of the Maastricht meeting. Atherosclerosis, 2012. 225(2): p. 521-33.

14. Dayspring T. Images, lipoproteins, drugs, and atherothrombotic events. Menopause, 2009. 16(4): p. 632-4.

15. Rideout TC, Harding SV, Jones PJ. Consumption of plant sterols reduces plasma and hepatic triglycerides and modulates the expression of lipid regulatory genes and de novo lipogenesis in C57BL/6J mice. Mol Nutr Food Res, 2010. 54 Suppl 1: p. S7-13.

16. Theuwissen E, Plat J, van der Kallen CJ, van Greevenbroek MM, Mensink RP. Plant stanol supplementation decreases serum triacylglycerols in subjects with overt hypertriglyceridemia. Lipids, 2009. 44(12): p. 1131-40.

17. Plat J, Mensink RP. Plant stanol esters lower serum triacylglycerol concentrations via a reduced hepatic VLDL-1 production. Lipids, 2009. 44(12): p. 1149-53.

18. Strassburg K, Esser D, Vreeken RJ, Hankemeier T, Muller M, van Duynhoven $\mathrm{J}$ et al. Postprandial fatty acid specific changes in circulating oxylipins in lean and obese men after high-fat challenge tests. Mol Nutr Food Res, 2014. 58(3): p. 591-600.

19. Katan MB, Grundy SM, Jones P, Lau M, Miettinen T, Paoletti R. Efficacy and safety of plant stanols and sterols in the management of blood cholesterol levels. Mayo Clin Proc, 2003. 78(8): p. 965-78.

20. Packard CJ, Shepherd J. Lipoprotein heterogeneity and apolipoprotein B metabolism. Arterioscler Thromb Vasc Biol, 1997. 17(12): p. 3542-56.

21. Plat J, Brufau G, Dallinga-Thie GM, Dasselaar M, Mensink RP. A plant stanol yogurt drink alone or combined with a low-dose statin lowers serum triacylglycerol and non-HDL cholesterol in metabolic syndrome patients. J Nutr, 2009. 139(6): p. 1143-9. 


\section{ACUTE AND LONGER-TERM EFFECTS}

22. Berge KE, von Bergmann K, Lutjohann D, Guerra R, Grundy SM, Hobbs HH et al. Heritability of plasma noncholesterol sterols and relationship to DNA sequence polymorphism in ABCG5 and ABCG8. J Lipid Res, 2002. 43(3): p. 486-94.

23. Rideout TC, Harding SV, Mackay DS. Metabolic and genetic factors modulating subject specific LDL-C responses to plant sterol therapy. Can J Physiol Pharmacol, 2012. 90(5): p. 509-14.

24. Thuluva SC, Igel M, Giesa U, Lutjohann D, Sudhop T, von Bergmann K. Ratio of lathosterol to campesterol in serum predicts the cholesterol-lowering effect of sitostanol-supplemented margarine. Int J Clin Pharmacol Ther, 2005. 43(7): p. 305-10.

25. Demonty I, Ras RT, van der Knaap HC, Duchateau GS, Meijer L, Zock PL et al. Continuous dose-response relationship of the LDL-cholesterol-lowering effect of phytosterol intake. J Nutr, 2009. 139(2): p. 271-84.

26. Watts GF, Chan DC, Ooi EM, Nestel PJ, Beilin LJ, Barrett PH. Fish oils, phytosterols and weight loss in the regulation of lipoprotein transport in the metabolic syndrome: lessons from stable isotope tracer studies. Clin Exp Pharmacol Physiol, 2006. 33(9): p. 877-82.

27. Paramsothy $\mathrm{P}, \mathrm{Knopp} \mathrm{RH}, \mathrm{Kahn} \mathrm{SE}$, Retzlaff BM, Fish B, Ma L et al. Plasma sterol evidence for decreased absorption and increased synthesis of cholesterol in insulin resistance and obesity. Am J Clin Nutr, 2011. 94(5): p. 1182-8.

28. Hernandez-Mijares A, Banuls C, Jover A, Sola E, Bellod L, Martinez-Triguero ML et al. Low intestinal cholesterol absorption is associated with a reduced efficacy of phytosterol esters as hypolipemic agents in patients with metabolic syndrome. Clin Nutr, 2011. 30(5): p. 604-9.

29. Gylling H, Hallikainen M, Simonen P, Miettinen HE, Nissinen MJ Miettinen TA. Serum and lipoprotein sitostanol and non-cholesterol sterols after an acute dose of plant stanol ester on its long-term consumption. Eur J Nutr, 2012. 51(5): p. 615-22. 



\section{CHAPTER 6}

The effects of oral amoxicillin on serum lipids and glucose concentrations in slightly hypercholesterolemic subjects

Els De Smet, Jogchum Plat and Ronald P. Mensink

Submitted 


\section{CHAPTER 6}

\section{Abstract}

Animal studies have indicated that the gut microbiota influences lipid and glucose metabolism. Results from human studies are, however, less clear. We therefore investigated whether oral amoxicillin, a moderate-spectrum antibiotic, changes lipid and glucose metabolism in slightly hypercholesterolemic subjects. The primary outcome parameter was changes in low-density lipoprotein-cholesterol (LDL-C).

In a randomized, placebo-controlled, double-blind study, 34 subjects (16 female/18 male) received placebo and 37 subjects (16 female/21 male) received amoxicillin during 1 week. They were instructed to take 2 capsules of $250 \mathrm{mg} 3$ times daily after each meal. Fasting blood samples were taken on days 1, 4 and 8, but also during the washout period, i.e. on days 12 and 16.

Amoxicillin intake had no effect on serum concentrations of LDL-C, insulin, blood pressure and body weight. The interaction terms between treatment and baseline HDL-C $(p=0.025)$, triacylglycerol (TAG, $p<0.001)$, glucose $(p=0.021)$, HOMA index $(p=0.010)$ and hsCRP $(p=0.027)$ were significant. More specifically, amoxicillin intake decreased concentrations of HDL-C, glucose and the HOMA index, and increased those of TAG in subjects with elevated baseline values. Differences in TAG and HDL-C concentrations between the amoxicillin and placebo high-baseline groups tended to decrease during the wash-out period, suggesting that these effects were not only due to changes in the composition of the microbiota.

In conclusion, amoxicillin intake might improve glucose metabolism, whereas it could be disadvantageous for lipids. Further studies are needed to identify the specific microbiota responsible for these effects and to examine the direct effects of antibiotics on gene expression. 


\section{Introduction}

Trillions of non-pathogenic commensal organisms live in the human gut, contributing to the digestion, formation and absorption of many nutrients [1]. It has even been estimated that colonic fermentation of indigestible dietary compounds provides up to $10-15 \%$ of the human daily energy supply [2]. Therefore, the composition of the microbiota may play a role in the development of metabolic aberrations. In fact, the proportion of gram-positive Firmicutes to gram-negative Bacteroidetes is higher in obese animals and in obese humans compared with lean controls. This may result into an increased degradation of otherwise indigestible dietary polysaccharides, and absorption of monosaccharides and short-chain fatty acids (SCFA) [3]. Furthermore, lowering the number of gram-positive bacteria (predominantly Firmicutes), thereby increasing gram-negative bacteria via vancomycin treatment decreased insulin sensitivity [4]. Finally, enrichment with gram-negative species increased lipopolysaccharide (LPS) absorption, which after binding to toll-like receptor 4 cluster of differentiation 14 (TLR4-CD14) complex may stimulate the release of proinflammatory cytokines, leading to insulin resistance [5]. These latter studies [4, 5] suggest a more beneficial role on glucose metabolism for gram-positive bacteria than for gram-negative bacteria.

Besides energy and glucose metabolism, also lipid metabolism may be related to gut microbiota. Compared with germ-free mice, conventionally raised mice on a chow diet had lower serum chylomicron concentrations, comparable very-low density lipoprotein (VLDL)-triacylglycerol and high-density lipoprotein cholesterol (HDL-C) concentrations, and higher low-density lipoprotein cholesterol (LDL-C) concentrations [6]. Several mechanisms have been proposed to explain the effects of gut microbiota on lipid metabolism. In mice, the increased carbohydrate flow to the liver and the adipocytes after fermentation of indigestible polysaccharides into SCFA may enhance de novo lipogenesis via stimulation of 2 nuclear receptors of lipogenic enzymes: i.e. carbohydrate response element-binding protein (chREBP) and sterol response element-binding protein 1c (SREBP-1C). Furthermore, via a so far unknown cross-talk route, microbiota composition affects the expression of fasting-induced adipose factor (fiaf) in the intestinal epithelium, thereby increasing LPL activity and decreasing the expression of peroxisomal proliferator-activated receptor coactivator (PGC-1 $\alpha$ ). A similar mechanism may explain the link between microbiota composition and AMP-activated protein kinase (AMPK) activity in muscle and liver [7]. Finally, as also described for associations with glucose metabolism [4, 5], changes in intestinal microbiota composition may affect lipid metabolism by the excretion of LPS into the circulation. Finally, it has been suggested that gut-floradependent metabolism of the dietary lipid phosphatidylcholine promotes cardiovascular disease in man [8]. Thus, there is substantial evidence from animal studies that the gut microbiota is related to lipid and lipoprotein metabolism. However, from human studies there is less evidence. Therefore, the primary aim of the present study was to examine the effects of oral amoxicillin intake on serum LDLC concentrations in slightly hypercholesterolemic subjects. Changes in other parameters related to lipid or glucose metabolism were determined as well. 


\section{CHAPTER 6}

\section{Materials and methods}

\section{Subjects}

Subjects were recruited in Maastricht and surrounding areas through advertisements in local newspapers and via posters in the university and hospital buildings or among subjects who had participated in earlier studies at the department. They were invited for two screening visits if they were aged between 18-70 years. Fasting blood was sampled for analyses of serum lipids and creatinine. In addition, body weight, height and blood pressure were determined. Exclusion criteria were impairment of kidney function (creatinine clearance $<30 \mathrm{~mL} / \mathrm{min}$ ), serum total cholesterol (TC) $<5 \mathrm{mmol} / \mathrm{L}$ or $>8 \mathrm{mmol} / \mathrm{L}$, serum triacylglycerol (TAG) $>3 \mathrm{mmol} / \mathrm{L}$, unstable body weight (weight gain or loss $>2 \mathrm{~kg}$ in the past 3 months), use of medication or a prescribed diet known to affect lipid and glucose metabolism, abuse of alcohol and drugs, pregnancy or breast-feeding, history of coronary artery disease, known allergy to antibiotics, intension to change their physical activity pattern during the study or being a blood donor eight weeks before the start of the study or during the study. They were also asked not to use fish oil supplements, laxantia, prebiotica, probiotica, antibiotica and gastric acid inhibitors at least one month before the start of the study as well as during the study. Furthermore, they had to complete a medical and general questionnaire. Women who reported the use of oral anticonceptives were excluded.

The study was approved by the Medical Ethical Committee of Maastricht University and was registered at ClinicalTrials.gov under study number NCT01566266. All participants gave written informed consent before entering the study.

\section{Study design}

The study had a randomized, double-blind, placebo-controlled parallel design. Before the start of the study, the subjects were assigned to use capsules containing placebo or amoxicillin, which is a moderate-spectrum antibiotic belonging to the beta-lactam antibiotics. It acts by inhibiting the synthesis of bacterial peptidoglycan that constitutes the cell wall of bacteria. The randomization list was made by Basic Pharma (Geleen, The Netherlands), an external independent party. The randomization code was concealed from the study investigators until the primary endpoint analysis was completed. The placebo capsules were filled with gelatine, cellulosum microcristallinum $\mathrm{PH} 102$.

On day 1, a fasting blood sample was taken. For the next 7 days, subjects received capsules containing either $250 \mathrm{mg}$ placebo or $250 \mathrm{mg}$ amoxicillin. They were instructed to take 2 capsules 3 times a day after each meal with a glass of water which resulted in a daily intake of $1500 \mathrm{mg}$ amoxicillin for 7 days, which is a full clinically applied treatment regimen. The remaining capsules were returned on day 8 to calculate compliance. Blood was also sampled at days 4, 8, 12 and 16 . At these days, blood pressure and body weight were also determined. Weight was measured without shoes and heavy clothing. An Omron M7 (Omron Healthcare Europe B.V., Hoofddorp, The Netherlands) was used to measure the blood pressure in fourfold at the left arm. The first measurement was discarded and the last three measurements were averaged. At the beginning of the intervention, the subjects were asked to 
record their food intake by completing a food frequency questionnaire (FFQ) to estimate their energy and nutrient intakes. These FFQs were checked and calculated by a registered dietician. On day 8 and on day 16, they were asked to fill in a short questionnaire to evaluate changes in food intake and complaints due to the capsules. Subjects also recorded in dairies any signs of illness, medication used, alcohol consumption, any deviations of the study protocol and any other complaints.

\section{Blood sampling and analysis}

\section{Blood sampling}

Blood samples were collected after an overnight fast. On the day before blood sampling, subjects were asked not to engage in any strenuous physical exercise or to consume alcohol. They visited the university by public transport or by car after a 12 hours overnight fast. Venipuncture was performed under standardized conditions by the same person. All samples from one subject were analyzed within the same run.

\section{Plasma measurements}

Blood was sampled in $2 \mathrm{ml} \mathrm{NaF-containing} \mathrm{vacutainer} \mathrm{tubes} \mathrm{(Becton} \mathrm{Dickinson)} \mathrm{for}$ analysis of glucose (Roche Diagnostic Systems, Hoffmann-La Roche) and free fatty acids (FFA) (Wako Biochemicals). These tubes were kept on ice and centrifuged at $1300 \times \mathrm{g}$ for $15 \mathrm{~min}$ at $4^{\circ} \mathrm{C}$ within 60 minutes after sampling to obtain plasma. The samples were directly snap-frozen in liquid nitrogen and stored and $-80^{\circ} \mathrm{C}$ until analysis at the end of the study.

\section{Serum measurements}

Blood samples taken in serum tubes (Becton Dickinson) were allowed to clot for 30 minutes at $21^{\circ} \mathrm{C}$, followed by centrifugation at $11300 \times \mathrm{g}$ for $15 \mathrm{~min}$ at $21^{\circ} \mathrm{C}$. These samples were also stored at $-80^{\circ} \mathrm{C}$ until analysis at the end of the study. In all fasting serum samples, serum TC (CHOD-PAP method; Roche Diagnostics Systems, Hofmann-La Roche), HDL cholesterol (HDL-C) (CHOD/PAP method; Roche Diagnostics Systems, Hofmann-La Roche) after precipitation of apoB-containing lipoproteins by adding phosphotungstic acid and magnesium ions (precipitation method; Monotest cholesterol, Boehringer Mannheim) and TAG with correction for free glycerol (GPO Trinder; Sigma Diagnostics) were analyzed enzymatically. LDL$C$ was calculated by using the Friedewald equation [9]. Serum insulin concentrations were determined with a human insulin-specific radioimmunoassay (RIA) kit (Linco Research). High sensitive C-reactive protein (hsCRP) was analyzed with a highly sensitive immunoturbidimetric assay (Kamiya Biomedical Company, Seattle, WA, USA) and creatinine (Roche Diagnostics Systems, Hofmann-La Roche) was also determined enzymatically. Creatinine clearance was estimated with the CockroftGault equation from creatinine values [10]. 


\section{CHAPTER 6}

\section{Statistical analysis}

Effects of the treatment were examined using ANCOVA with values at the end of the intervention period (day 8 ) as dependent variable and values at the start of the study (day 0) as covariate. To examine if differences were related to baseline values, an interaction term (baseline value*treatment) was introduced into the model. If this interaction term did not reach statistical significance $(p \leq 0.05)$, it was omitted from the model. If the interaction term was significant, the subjects were further divided into subjects with low and high baseline values for that corresponding parameter. Subjects with a baseline value above the median were classified as subjects with high baseline values and subjects with a baseline value below the median were classified as subjects with low baseline values. To visualize the interaction effect, values during the study were plotted for subjects with low and high baseline levels. Values are presented as means \pm SD. Statistical analysis was performed using SPSS 20.0 software (SPSS Incorporated, Chicago, IL, USA).

\section{Results}

\section{Baseline characteristics}

One hundred nineteen subjects were screened. Based on our inclusion criteria, fasting serum TC levels of thirty-one subjects were too low, of five subjects too high, while for TAG concentrations two subjects were too high. Of the 80 subjects who met all the inclusion criteria, 3 decided not to participate for personal reasons. In total, thirty-two women and thirty-nine men started the study and were randomized to the amoxicillin or the placebo group. Three subjects dropped out during the intervention. One woman had a flu on the second day, one man was bitten by a dog and had to start immediately with the intake of antibiotics, and one man was not able to ingest the capsules. Three subjects with $\mathrm{hsCRP}>10 \mathrm{mg} / \mathrm{L}$ at one of the time points were excluded from the analysis. Baseline characteristics of the 71 subjects who completed the study are shown in table 1.

Table 1: Baseline characteristics of the subjects who completed the study.

\begin{tabular}{|c|c|c|c|}
\hline & $\begin{array}{l}\text { All } \\
(n=71)\end{array}$ & $\begin{array}{l}\text { Placebo group } \\
(\mathrm{n}=34)\end{array}$ & $\begin{array}{l}\text { Amoxicillin group } \\
(\mathrm{n}=37)\end{array}$ \\
\hline Age (years) & $59 \pm 11$ & $60 \pm 10$ & $58 \pm 13$ \\
\hline Gender (F/M) & $32 / 39$ & $16 / 18$ & $16 / 21$ \\
\hline $\mathrm{BMI}\left(\mathrm{kg} / \mathrm{m}^{2}\right)$ & $25.9 \pm 3.4$ & $25.5 \pm 3.5$ & $26.2 \pm 3.3$ \\
\hline $\begin{array}{l}\text { Total cholesterol } \\
(\mathrm{mmol} / \mathrm{L})\end{array}$ & $6.38 \pm 0.81$ & $6.43 \pm 0.90$ & $6.34 \pm 0.73$ \\
\hline $\begin{array}{l}\text { Triacylglycerol } \\
(\mathrm{mmol} / \mathrm{L})\end{array}$ & $1.40 \pm 0.57$ & $1.31 \pm 0.56$ & $1.45 \pm 0.58$ \\
\hline $\begin{array}{l}\text { Systolic blood } \\
\text { pressure }(\mathrm{mmHg})\end{array}$ & $130 \pm 18$ & $131 \pm 22$ & $130 \pm 13$ \\
\hline $\begin{array}{l}\text { Diastolic blood } \\
\text { pressure }(\mathrm{mmHg})\end{array}$ & $84 \pm 11$ & $84 \pm 14$ & $84 \pm 8$ \\
\hline
\end{tabular}




\section{AMOXICILLIN, LIPID AND GLUCOSE METABOLISM}

Energy and nutrient intakes did not differ between the two groups at baseline (supplemental table 1). Subjects did not report to have changed their food intake due to the intake of the capsules. Also, body weight did not change during the study. Two subjects in the placebo group and two subjects in the amoxicillin group had suffered from diarrhea. Another subject in the amoxicillin group suffered from headaches.

Supplemental table 1: Energy and nutrient intake at baseline according to food frequency questionnaires.

\begin{tabular}{lcc}
\hline & Placebo group & Amoxicillin group \\
\hline Energy (MJ/day) & $9.7 \pm 2.3$ & $9.8 \pm 3.5$ \\
Protein (en\%) & $16.8 \pm 4.3$ & $16.0 \pm 30$ \\
Total fat (en\%) & $38.3 \pm 7.6$ & $38.8 \pm 7.6$ \\
SFA (en\%) & $12.4 \pm 3.0$ & $11.8 \pm 2.7$ \\
MUFA (en\%) & $13.4 \pm 3.6$ & $14.8 \pm 4.8$ \\
PUFA (en\%) & $8.9 \pm 3.1$ & $8.9 \pm 3.4$ \\
Carbohydrates (en\%) & $42.4 \pm 9.5$ & $43.1 \pm 8.6$ \\
Fibre (g/MJ) & $2.5 \pm 0.9$ & $2.7 \pm 1.3$ \\
Alcohol (en\%) & $2.7 \pm 3.7$ & $2.2 \pm 2.5$ \\
Cholesterol (mg/MJ) & $24.0 \pm 7.4$ & $23.4 \pm 8.7$ \\
\hline
\end{tabular}

All values are means \pm SD. Thirty-four subjects participated in the placebo group and 37 subjects in the amoxicillin group.

\section{Compliance}

The capsules were provided in boxes containing 44 capsules, which was 2 more than needed. Subjects were instructed to return the boxes at day 8 with the remaining capsules to calculate compliance. The number of capsules returned in the placebo and the amoxicillin group was $3.2 \pm 2.9$ and $2.6 \pm 1.3$, respectively.

\section{Lipid metabolism}

There were no statistically significant differences in serum concentrations of TC, LDL-C, HDL-C and TAG between the two groups on day 1 of the study. Compared to the placebo group, the use of amoxicillin did not change serum TC $(p=0.672)$ and LDL-C concentrations $(p=0.715)$. However, a statistically significant interaction between amoxicillin treatment and baseline HDL-C and TAG was found ( $p=0.025$ and $p<0.001$, respectively) (table 2 ). 
CHAPTER 6

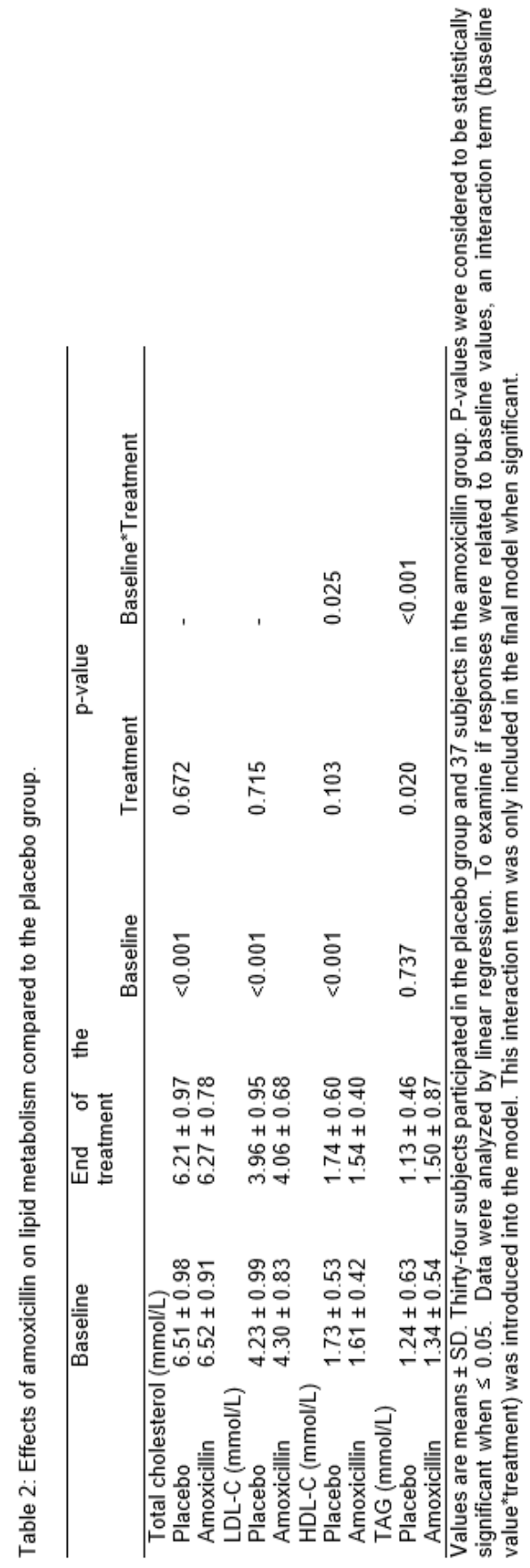




\section{AMOXICILLIN, LIPID AND GLUCOSE METABOLISM}

Amoxicillin decreased serum HDL-C concentrations more pronounced in subjects with higher serum HDL-C concentration at baseline (figure 1, panel A). One week after treatment, the HDL-C concentration in this amoxicillin high-baseline subgroup was still somewhat lower than the concentration in the placebo high-baseline subgroup. For TAG, we found that the increase after amoxicillin intake was more pronounced in subjects with higher baseline values (figure 1, panel B). Moreover, the TAG concentration remained higher in this subgroup than in the placebo group.
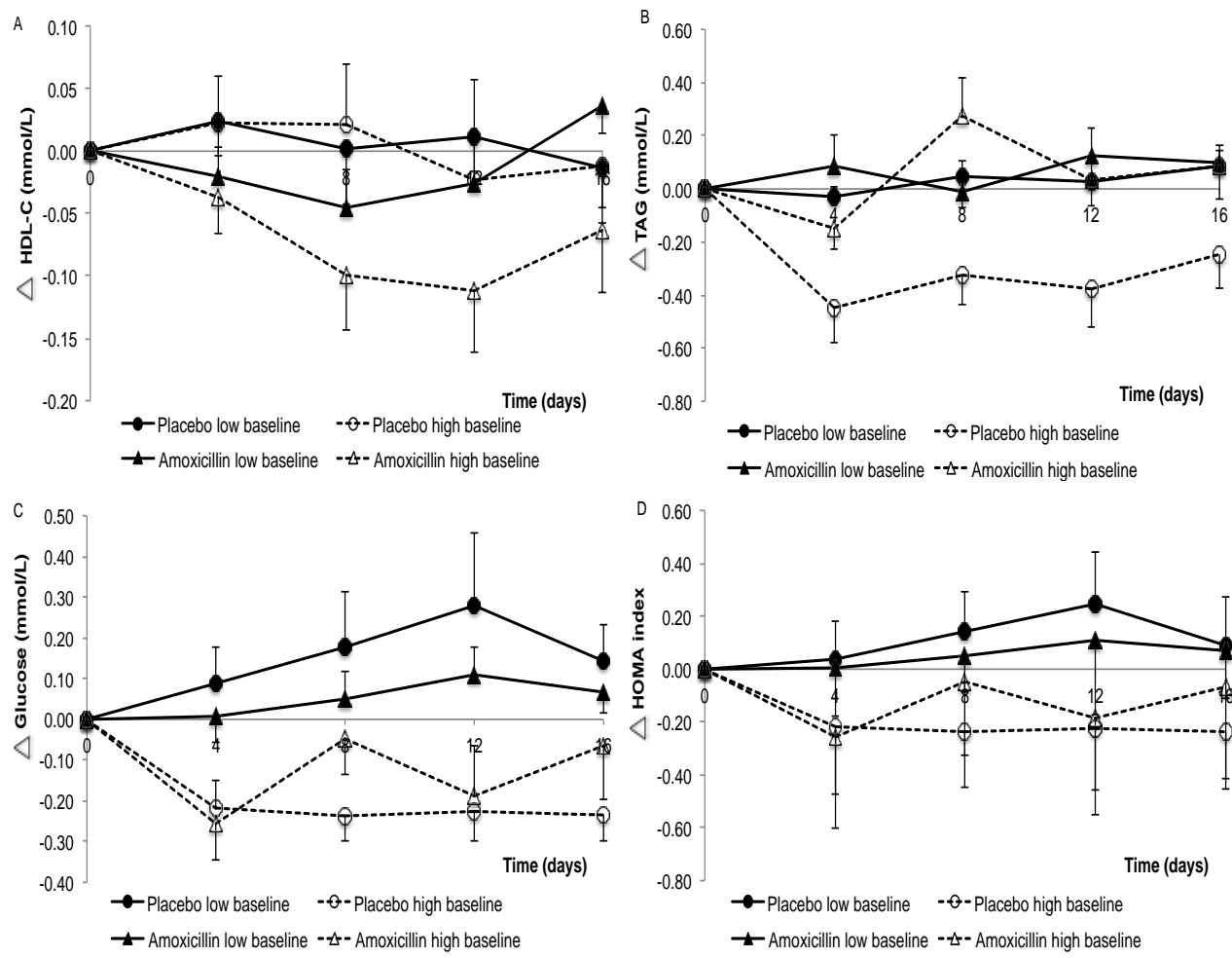

Figure 1: Mean changes ( \pm SEM) in serum concentrations of HDL-C (A), TAG $(B)$, and plasma glucose (C) and the HOMA index (D). Subjects with a baseline value above the median were classified as subjects with high baseline values and subjects with a baseline.

\section{Glucose metabolism}

Changes in plasma glucose concentrations and HOMA index did not differ among the groups at baseline. There was a significant difference in serum insulin concentrations between the two groups on day $1(p=0.014)$. Intake of amoxicillin did not change the insulin concentrations compared to the placebo group $(p=$ 0.280). However, the interaction term between treatment and baseline HOMA index and plasma glucose concentrations was significantly different $(p=0.010$ and $p=$ 0.021 , respectively) (table 3 ). 
CHAPTER 6

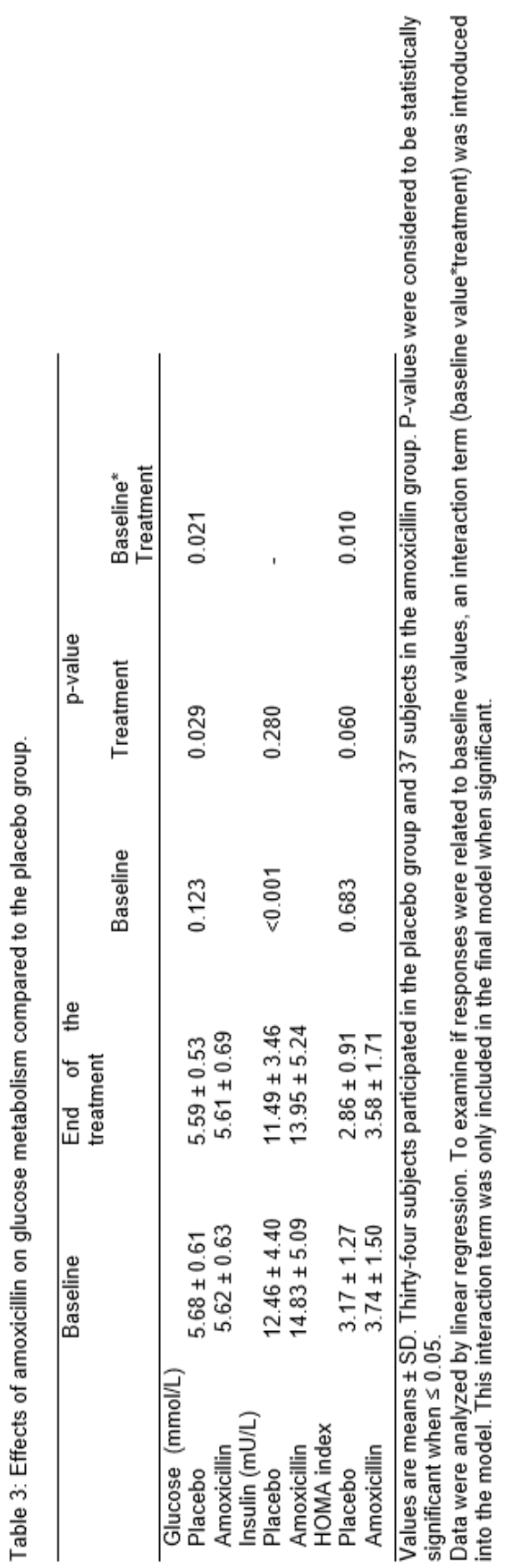


In the amoxicillin as well as in the placebo group, the glucose concentration decreased in the subjects with high baseline values after 4 days (figure 1, panel $\mathrm{C}$ ). For the next 12 days, glucose concentrations remained practically stable in the placebo high-baseline group, whereas levels increased in the amoxicillin highbaseline group. The same pattern was observed for the HOMA index (figure 1, panel D).

Weight, blood pressure, CRP and creatinine clearance

Body weight, systolic and diastolic blood pressure were not significantly different among the groups at day 1 . Treatment with amoxicillin did not change weight $(p=$ $0.247)$ and diastolic blood pressure $(p=0.173)$ compared to the placebo group. However, systolic blood pressure tended to decrease after amoxicillin intake ( $p=$ $0.074)$ compared to the placebo group. Concentrations of hsCRP were significantly different $(p=0.017)$ between the two groups at the start of the study. A significant interaction between baseline concentrations of hsCRP and response-to-treatment was found $(p=0.027)$. Creatinine concentrations and creatinine clearance were the same between both groups on day 1 and did not change significantly after amoxicillin treatment compared to the placebo group ( $p=0.986$ and $p=0.479$, respectively) (table 4). 
CHAPTER 6

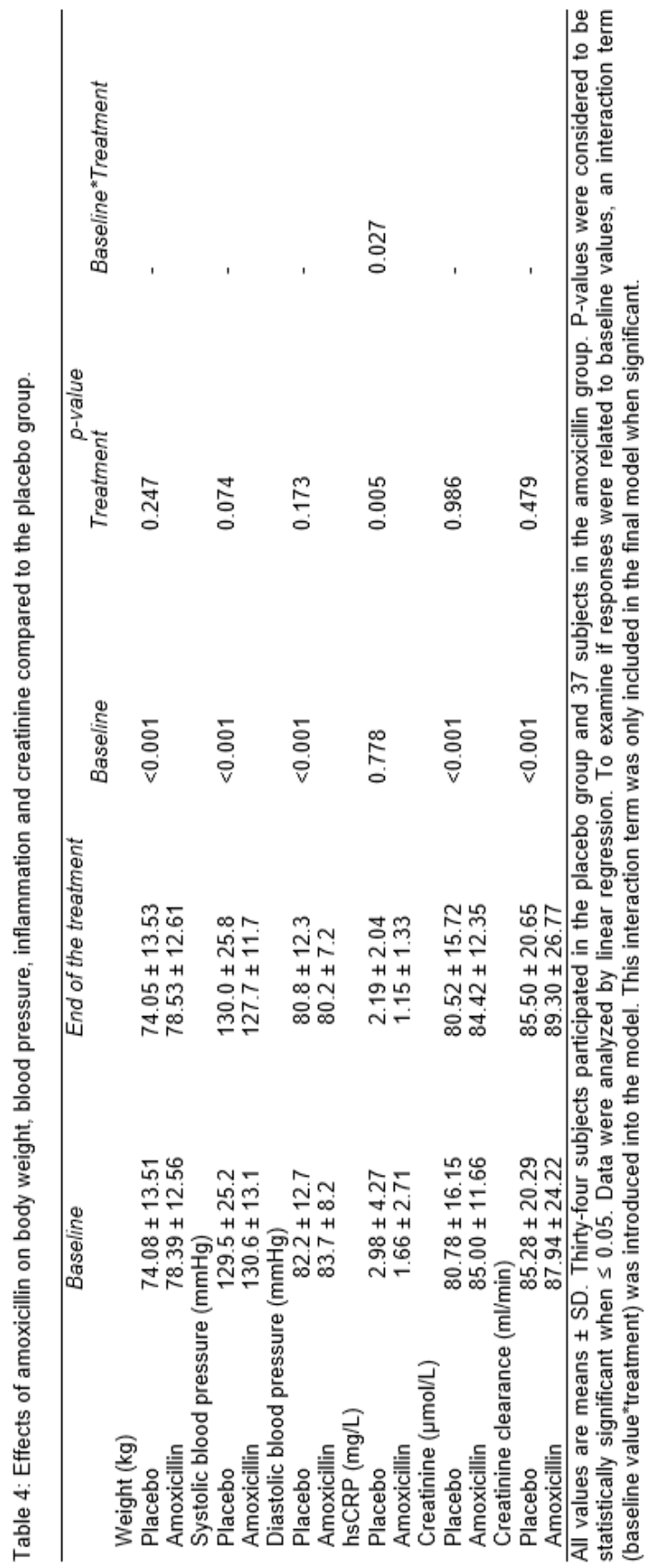




\section{Discussion}

This study was designed to examine the effects of the changes in gut microbiota on lipid and glucose metabolism in slightly hypercholesterolemic subjects using amoxicillin, a moderate-spectrum aminopenicilline antibiotic against gram-positive and gram-negative bacteria. No effects were found on serum TC, LDL-C, insulin, blood pressure and body weight. However, amoxicillin treatment decreased concentrations of HDL-C, glucose, and hsCRP and the HOMA index, but increased TAG concentrations in subjects with increased levels at baseline.

Animal studies have suggested that the gut microbiota accelerate cholesterol catabolism, thereby decreasing serum TC concentrations [6]. In humans, however, results are less clear. The cholesterol-lowering effect of orally administered neomycin, an antibiotic with a strong activity against in particular gram-negative bacteria, was already reported in 1958 [11]. In a later study, Kesäniemi et al. [12] reported that daily administration of $1.5 \mathrm{~g}$ neomycin for 2 to 3 months to 6 slightly hypercholesterolemic men decreased serum concentrations of TC by $20 \%$, of LDLC by $25 \%$, and of HDL-C by $16 \%$. Faecal excretion of neutral steroids was increased, absorption of exogenous cholesterol decreased, and apoB100 synthesis rates lowered, which may explain the effects on LDL-C. No effects on serum TAG concentrations were found. Other longer-term studies in type II hyperlipoproteinemic patients and in hypercholesterolemic type 2 diabetics found comparable effects on serum TC, LDL-C and TAG concentrations $[13,14]$. The latter study also reported a decrease in HDL-C concentrations of 30\% [14]. Altogether, longer-term treatment with orally administered neomycin may lower serum concentrations of LDL-C and HDL-C, but not those of TAG. No short-term human studies with neomycin have been published, which makes it difficult to compare these results with our results. However, in a short-term study with amoxicillin and omeprazole in patients suffering from Helicobacter pylori infection, no changes in serum lipid or lipoprotein concentrations were found after 2 weeks treatment [15]. Very recently, Vrieze et al. [4] compared the effects of one-week oral administration of amoxicillin versus those of vancomycin $1.5 \mathrm{~g} / \mathrm{d}$ in obese men with the metabolic syndrome. Although median concentrations of LDL-C decreased by $0.6 \mathrm{mmol} / \mathrm{L}$ in the amoxicillin group and by $0.8 \mathrm{mmol} / \mathrm{L}$ in the vancomycin group, these effects did not reach statistical significance. As only 10 men were studied in each group, it is possible that this may have been due to a lack of statistical power. However, using the same dose and applying the same study duration we here present also no effects of amoxicillin on LDL-C in a much larger study population. It cannot be excluded, that longer-term treatment may have affected LDL-C concentrations. In our study, amoxicillin decreased serum concentrations of HDL-C and increased those of TAG in subjects who had increased levels at baseline. These effects were not related to gender or $\mathrm{BMI}$. Effects on TAG should be interpreted with some caution as these were due to aspecific changes in the placebo group, which may be partly related to regression to the mean. However, due to the parallel design of the study, similar effects would have been expected in the intervention group and the difference in effect between the two groups can therefore be attributed to amoxicillin treatment. Vrieze et al. [4] did not observe any effects of amoxicillin or vancomycin on HDL-C, which may have been due to the low baseline HDL-C concentrations (around $1.0 \mathrm{mmol} / \mathrm{L}$ ) of their metabolic syndrome subjects. In that study, serum TAG concentrations tended to decrease after amoxicillin treatment, but not after vancomycin treatment. Why we 


\section{CHAPTER 6}

observed only effects in subjects with increased serum HDL-C and TAG levels at baseline, remains to be determined. Increases in cholesteryl ester transfer protein (CETP) activity during amoxicillin treatment are a possibility, as this would have resulted in increased TAG and decreased HDL-C concentrations [16].

Treating obese mice with norfloxacin and ampicillin reduced body weight, and improved fasting glycaemia and glucose tolerance [17]. In agreement, we also found a decrease in glucose concentrations after amoxicillin intake in subjects with higher glucose concentrations at baseline. Also, the HOMA-index, which correlates with measures for insulin resistance obtained during a hyperglycemic clamp [18], decreased after amoxicillin treatment. For humans, the importance of the gut microbiota on glucose metabolism was shown by Vrieze and colleagues [19], who found that transplantation of lean donor gut microbiota into obese subjects with the metabolic syndrome altered the composition of the intestinal microbiota, and improved hepatic and peripheral insulin sensitivity. In a later study, Vrieze et al. [4] demonstrated that vancomycin decreased peripheral insulin sensitivity, reduced gut microbiota diversity, and decreased the number of gram-positive bacteria. At the same time, however, the number of gram-negative bacteria was increased. Many gram-positive bacteria are able to deconjugate, oxidize and dehydroxylate primary bile acids into secondary bile acids, whereas only two strains of the gram-negative Bacteriodes have deconjugation activity [20]. It was hypothesized that decreases in the production of secondary bile acids could ultimately result in increased peripheral insulin resistance [4]. It was surprising, however, that amoxicillin in that study had no effect at all on microbial diversity or on the total number of fecal bacteria, and on insulin sensitivity.

In contrast to changes in glucose concentrations and the HOMA index, differences in TAG and HDL-C concentrations between the amoxicillin and placebo highbaseline groups tended to decrease during the wash-out period. If true, it is not likely that this can be explained by a recovery of the gut microbiota, since this takes several weeks to months before it has revered to its original composition [21]. An explanation for this rapid return may be that antibiotics themselves changed gene expression, as has been demonstrated in human adipose tissue for genes involved in lipid metabolism [22]. In that case the effects observed after antibiotic treatment are at least partly caused by direct gene regulation of the antibiotic without interfering in the microbiota composition. However, further studies are needed to unravel the potential association between antibiotic intake and effects on genes involved in lipid and glucose metabolism.

To summarize, amoxicillin intake increased TAG concentrations, and reduced HDL$\mathrm{C}$ and glucose concentrations and the HOMA index, especially in subjects with elevated baseline values. This study therefore supports the growing evidence that the gut microbiota may affect lipid and glucose metabolism. Further studies are however needed to identify the specific microbiota responsible for these effects and to examine the direct effects of antibiotics on gene expression. 


\section{Acknowledgements}

We would like to thank all study participants for their cooperation and enthusiasm. We also thank the technical and dietary staff from our department for their support. The authors' responsibilities were as follows: E.D., J.P. and R.P.M. designed research; E.D. conducted research; E.D. and R.P.M. analyzed data; E.D., J.P. and R.P.M. wrote the paper; and R.P.M. had overall responsibility for the study. All authors read and approved the final manuscript. Neither of the authors had any financial or personal conflicts of interest. 


\section{CHAPTER 6}

\section{References}

1. Backhed, F., et al., Host-bacterial mutualism in the human intestine. Science, 2005. 307(5717): p. 1915-20.

2. de Graaf, A.A. and K. Venema, Gaining insight into microbial physiology in the large intestine: a special role for stable isotopes. Adv Microb Physiol, 2008. 53: p. 73-168.

3. Turnbaugh, P.J., et al., An obesity-associated gut microbiome with increased capacity for energy harvest. Nature, 2006. 444(7122): p. 1027-31.

4. Vrieze, A., et al., Vancomycin decreases insulin sensitivity and is associated with alterations in intestinal microbiota and bile acid composition in obese subjects with metabolic syndrome. $\mathrm{J}$ Hepatol, 2013.

5. Cani, P.D. and N.M. Delzenne, Interplay between obesity and associated metabolic disorders: new insights into the gut microbiota. Curr Opin Pharmacol, 2009. 9(6): p. 737-43.

6. Velagapudi, V.R., et al., The gut microbiota modulates host energy and lipid metabolism in mice. J Lipid Res, 2010. 51(5): p. 1101-12.

7. Backhed, F., et al., Mechanisms underlying the resistance to diet-induced obesity in germ-free mice. Proc Natl Acad Sci U S A, 2007. 104(3): p. 979-84.

8. Wang, Z., et al., Gut flora metabolism of phosphatidylcholine promotes cardiovascular disease. Nature, 2011. 472(7341): p. 57-63.

9. Friedewald, W.T., R.I. Levy, and D.S. Fredrickson, Estimation of the concentration of lowdensity lipoprotein cholesterol in plasma, without use of the preparative ultracentrifuge. Clin Chem, 1972. 18(6): p. 499-502.

10. Cockcroft, D.W. and M.H. Gault, Prediction of creatinine clearance from serum creatinine. Nephron, 1976. 16(1): p. 31-41.

11. Samuel, P. and A. Steiner, Effect of neomycin on serum cholesterol level of man. Proc Soc Exp Biol Med, 1959. 100(1): p. 193-5.

12. Kesaniemi, Y.A. and S.M. Grundy, Turnover of low density lipoproteins during inhibition of cholesterol absorption by neomycin. Arteriosclerosis, 1984. 4(1): p. 41-8.

13. Schade, R.W., et al., A comparative study of the effects of cholestyramine and neomycin in the treatment of type II hyperlipoproteinaemia. Acta Med Scand, 1976. 199(3): p. 175-80.

14. Gylling, H. and T.A. Miettinen, The effect of cholesterol absorption inhibition on low density lipoprotein cholesterol level. Atherosclerosis, 1995. 117(2): p. 305-8.

15. Zhang, L., et al., A randomized factorial study of the effects of long-term garlic and micronutrient supplementation and of 2-wk antibiotic treatment for Helicobacter pylori infection on serum cholesterol and lipoproteins. Am J Clin Nutr, 2006. 84(4): p. 912-9.

16. Leanca, C.C., et al., Metabolism of plasma cholesterol and lipoprotein parameters are related to a higher degree of insulin sensitivity in high HDL-C healthy normal weight subjects. Cardiovasc Diabetol, 2013. 12: p. 173.

17. Vrieze, A., et al., The environment within: how gut microbiota may influence metabolism and body composition. Diabetologia, 2010. 53(4): p. 606-13.

18. Tripathy, D., et al., Contribution of insulin-stimulated glucose uptake and basal hepatic insulin sensitivity to surrogate measures of insulin sensitivity. Diabetes Care, 2004. 27(9): p. 2204-10.

19. Vrieze, A., et al., Transfer of intestinal microbiota from lean donors increases insulin sensitivity in individuals with metabolic syndrome. Gastroenterology, 2012. 143(4): p. 913-6 e7.

20. Jones, B.V., et al., Functional and comparative metagenomic analysis of bile salt hydrolase activity in the human gut microbiome. Proc Natl Acad Sci U S A, 2008. 105(36): p. 13580-5.

21. Dethlefsen, L., et al., The pervasive effects of an antibiotic on the human gut microbiota, as revealed by deep 16S rRNA sequencing. PLoS Biol, 2008. 6(11): p. e280.

22. Pereira, M.J., et al., The immunosuppressive agents rapamycin, cyclosporin $A$ and tacrolimus increase lipolysis, inhibit lipid storage and alter expression of genes involved in lipid metabolism in human adipose tissue. Mol Cell Endocrinol, 2013. 365(2): p. 260-9. 
CHAPTER 7

General discussion 


\section{CHAPTER 7}

Foods enriched with fatty acids of plant sterols and stanols are well known for their low-density lipoprotein cholesterol (LDL-C) lowering activity. These functional foods are helpful in reducing CVD risk for subjects with elevated LDL-C concentrations if they are part of a healthy diet low in saturated fatty acids. The underlying mechanisms of the hypocholesterolemic effect of plant sterols/stanols are still unknown. Besides plant sterols / stanols, animal studies also suggest a possible role for the gut microbiota on lipid metabolism. Within this context, we investigated the role of plant stanol esters and gut microbiota on lipid metabolism.

\section{Acute effects of plant stanol esters on expression profiles of genes involved in sterol metabolism}

In our first study (chapter 3 ), we investigated the acute effects of plant stanol esters on the expression profile of genes involved in sterol metabolism in the liver and in the intestine. Cell studies have demonstrated that plant sterols/stanols have an effect on genes involved in sterol metabolism [1]. Results from in vivo studies are however conflicting. This may be due to the various amounts of plant sterols in the background diets, resulting in different tissue and serum concentrations, which may affect pathways underlying the cholesterol-lowering activity of the added plant sterols/stanols. Indeed, tissue concentrations of plant sterols increase if mice were fed a diet containing higher amounts of plant sterols. Therefore, in the first study, we fed female mice (F0) a plant sterol/stanol poor diet from weaning. They were used in a breeding protocol and their pups (F1) were fed the same diet from weaning. In our study, the intestinal cellular cholesterol concentration decreased despite the presence of cholesterol in the gavage. The intestinal sitostanol concentration increased already after 15 minutes. The decrease in intestinal cellular cholesterol concentrations could explain the upregulation of sterol regulatory element binding protein 2 (SREBP2) and its target genes. The increased mRNA expression of 3hydroxy-3-methyl-glutaryl-Coenzyme A (HMG-CoA) reductase did not result in increased concentrations of lathosterol and desmosterol. Despite the increased expression of SREBP2, the intestinal cholesterol concentration did not return to baseline values during the 4-hr follow-up period. Surprisingly, changes in gene expression profiles in the liver were opposite to those in the intestine. The hepatic cholesterol concentration remained nearly unchanged during the entire post-gavage period, while the sitostanol concentration increased again 15 minutes post-gavage. After this rapid appearance, sitostanol concentrations decreased and increased again after 120 minutes, which could be explained by the uptake of chylomicron remnants by the liver. One important question that is raised by this study is how sitostanol originating from the gavage reached the liver within 15 minutes without clear changes in serum sitostanol concentrations at this early time-point. We tried to unravel the route of entrance in a second study using deuterium labelled plant stanols and cholesterol in the gavage. The absence of an increase in the hepatic sitostanol concentration 15 minutes post-gavage in the lymph-canulated mice indicates that the entrance is lymph-dependent. However, these lymph-canulated mice showed an increase in hepatic sitostanol concentrations 1 hour after the gavage for which we have no explanation. At that time point, there were again no changes in plant stanol concentrations in the serum or the portal vein. The hepatic expression of SREBP2 and its target genes was downregulated. We could speculate that this is due to a direct effect of the increased hepatic sitostanol concentrations, 
i.e. the hepatocytes cannot distinguish between elevated cholesterol or plant stanol concentrations as suggested before [2]. However, this explanation does not agree with the observed upregulation of SREBP2 in the enterocytes. The 5 -fold increased intestinal LDL receptor (LDLr) expression is suggestive for an enhanced clearance of cholesterol via the enterocytes. Nevertheless, a phytosterol-enriched diet decreased plasma cholesterol levels in LDLr-- mice [3]. Whether effects are less pronounced in these knockout mice as compared to other mouse models is not known. To further study the importance of the LDLr, a side-by-side comparison between heterozygote versus homozygote LDLr knockout mice could be performed. However, it can be speculated that the increased intestinal LDLr expression contributes to activation of the transintestinal cholesterol excretion (TICE) by plant stanols [4], resulting in enhanced faecal neutral sterol loss via secretion into the intestinal lumen. In this way, it can also be explained why there are no human interventional trials showing clear changes on postprandial chylomicron formation or composition [5, 6]. However, the suggested plant stanol ester-induced TICE so far is all based on animal data and needs to be confirmed in human studies. Moreover, plant stanols also actively lower serum LDL-C concentrations in homozygous $\mathrm{FH}$ patients [7] suggesting that effects can be achieved independent from functional LDLr.

The expression profiles of genes involved in sterol efflux were opposite between the liver and the intestine. The expression of liver X receptor $\alpha(L X R \alpha)$ target genes was increased in the liver, whereas it remained nearly unchanged in the intestine. The increase in hepatic expression of LXRa target genes could be explained by an indirect effect, i.e. increases in intracellular cholesterol and consequent oxysterol concentrations or by a direct effect of sitostanol. The latter possibility is not likely, since the sitostanol concentration was also increased in the enterocytes, without affecting expression of LXRa target genes. Theoretically, if plant stanols act as LXR agonists, we would expect that these effects were more pronounced in the intestine compared to the liver, since the absorption of plant stanols is poor thereby reaching higher intracellular concentrations in the intestine. However, it should be noticed that hepatic sitostanol concentrations increased already 15 minutes post-gavage to rather pronounced levels. The assumption that plant stanols act as local instead of systemic LXR agonists is further supported by our findings (chapter 5 ) that longerterm plant stanol ester consumption did not affect serum triacylglycerol (TAG) concentrations in normolipidemic subjects, which would be increased after systemic LXR activation [8]. In fact, plant stanols may lower serum TAG concentrations instead of elevate, especially in subjects with elevated baseline TAG concentrations [9-11]. This effect is also ascribed to hepatic specific effects [10]. In support, Brufau et al. recently showed that the hepatic very-low density lipoprotein (VLDL) production is decreased in C57BL/6J mice after consuming plant sterol or stanol ester enriched diets for 3 weeks (unpublished data). It could also be speculated that differences in hepatic and intestinal desmosterol concentrations might have influenced tissue specific LXR activation. Recently, Spann et al. [12] have demonstrated that desmosterol may regulate LXR activation in macrophages. In our study, the intestinal desmosterol concentration decreased post-gavage, whereas those in the liver remained stable. The large difference in desmosterol concentrations between intestine and liver could therefore be a possible explanation for the observed increase in the expression profile of hepatic LXR target genes. 


\section{CHAPTER 7}

We also investigated whether plant stanol esters exert an acute effect on intestinal gene expression profile in healthy, normolipidemic subjects (chapter 4). To the best of our knowledge, there are no human interventional trials that have investigated changes in intestinal gene expression profiles after plant sterol/stanol consumption. Since we do not know which part of the proximal small intestine is most responsive, we decided to take biopsies both from the duodenum (around the Papil van Vater) and the jejunum (20 cm distal from the Papil van Vater). Our subjects were instructed to avoid the consumption of products relatively rich in plant sterols/stanols one-week before the intestinal biopsies were taken. In this way, an optimal contrast in plant stanol ester intake was created and inter-individual variability due to differences in plant sterol/stanol intake were minimized. During the test day, subjects consumed in random order a shake enriched with or without $4 \mathrm{~g}$ plant stanol esters. Five hours later, intestinal biopsies were taken. In contrast to our findings in the animal study (chapter 3), we could not observe significant changes in the expression profile of genes involved in sterol metabolism. We could speculate that it may take more than 5 hours before changes in genes involved in sterol metabolism could be detected. Ideally, we had to take biopsies both in the acute phase and after longer-term consumption of plant stanol esters. However, this was considered not to be possible from an ethical point of view unless we had chosen for a parallel instead of a crossover design.

We did find, however, a highly interesting observation in the jejunal biopsies, i.e. a significant downregulation in the expression profile of genes belonging to immunerelated pathways. The downregulated gene sets could be clustered into functions related to T-cells such as T-cell development, homeostasis, activation, quantity, adhesion and chemotaxis. In vitro as well as ex vivo studies have already shown an effect of plant sterols/stanols on the immune system [13, 14]. It should be noticed, however, that these studies were performed in subjects with a disturbed T-helper-1 cell/T-helper-2 cell (Th1/Th2) balance, which was not the case in our study. Thus, effects of plant sterols/stanols are not limited to lipid and lipoprotein metabolism. A link between cholesterol homeostasis and the immune system has already been demonstrated. Bensinger et al. [15] indicated that the activity of the SREBP pathway was increased and that of LXR was decreased when T-cells were activated by antigens. In this way, there is sufficient cholesterol available for membrane formation and cellular proliferation. It could also be speculated that consumption of plant stanol esters reduces the cellular cholesterol content of the intestinal T-cells, thereby dampening its expansion.

Acute and semi-long term effects of plant stanol esters on lipid and lipoprotein metabolism

Besides the decrease in LDL-C, some studies have also suggested a role for plant sterols/stanols in TAG metabolism [11, 16]. In addition, a large inter-individual variation in the cholesterol-lowering efficacy of plant stanol ester treatment exists [17]. It is highly relevant to identify factors related to this variability in response-totreatment to elucidate underlying mechanisms. Therefore, we decided to evaluate whether it is possible to predict an individual's LDL-lowering response to longer-term consumption of plant stanol esters based on postprandial changes in metabolic parameters. In our study (chapter 5), 3 weeks consumption of plant stanol esters reduced serum concentration of total cholesterol by $7.1 \%$, LDL-C by $9.5 \%$ and 
apoB100 by $8.6 \%$ compared to the control group. No TAG-lowering effect was found, which could be due to the fact that we only included normolipidemic subjects. Demonty et al. [16] have indicated earlier that the modest decrease in TAG concentrations is dependent on baseline TAG levels. Compared to the control group, the number of total VLDL-CM, small VLDL and large LDL particles are reduced after consumption of plant stanol esters. This is in contrast to another study [10], which was also performed in normolipidemic subjects, showing a decrease in large VLDL and intermediate-density lipoprotein (IDL) particles. We do not have an explanation for these differences. It should, however, be noticed that there are differences between both studies (i.e. parallel versus cross-over design, 8 weeks versus 3 weeks plant stanol ester consumption, daily plant stanol ester intake: $3.8-4.1 \mathrm{~g} / \mathrm{day}$ versus $3 \mathrm{~g} / \mathrm{d}$ ). The number of studies investigating the effects of plant stanol esters on lipoprotein particle characteristics like size density and composition is scarce and some studies have been performed in subjects suffering from metabolic syndrome [9] or familial hypercholesterolemia [11], making it difficult to draw a straightforward conclusion.

There were no significant changes in lipid, lipoprotein and glucose metabolism during the postprandial phase. The 4-hr follow-up period may not have been long enough to observe significant changes. This assumption is in agreement with the fact that also no changes in the expression profiles of genes involved in sterol metabolism 5 hours after an acute intake of plant stanol esters (chapter 4) were found. It may be hypothesized that new steady state conditions should be reached first before significant changes could be found. Finally, but highly interesting, we observed that the incremental area under the curve (iAUC) of the postprandial glucose response could be used to predict an individual's response to plant stanol ester treatment. A significant, positive correlation was found between the iAUC of postprandial glucose and the change in fasting concentrations of total cholesterol, LDL-C, apoB100, total VLDL, small VLDL and IDL. The change was calculated as the difference between three weeks consumption of a margarine enriched with plant stanol esters ( $3 \mathrm{~g} /$ day) versus three weeks consumption of control margarine. The lathosterol/campesterol ratio [18], which is frequently used as a predictor for the decrease in LDL-C after plant stanol ester treatment did not correlate with the observed decrease in LDL-C concentrations in our study, nor with the iAUC of the postprandial glucose concentration. There is some inconsistency between the relation of insulin sensitivity and the response to interventions reducing the intestinal cholesterol absorption. Watts et al. [19] have demonstrated earlier that insulinresistant subjects, showing a lower cholesterol absorption and increased cholesterol synthesis, are less susceptible to treatments interfering with cholesterol absorption. This is in agreement with our finding, showing that subjects with a more pronounced postprandial glucose response are less sensitive to the LDL-C lowering efficacy of plant stanol esters. In contrast, it has been indicated that the response was larger instead of smaller in metabolic syndrome patients [18]. In the future, it would be interesting to make a side-by-side comparison between healthy normolipidemic subjects and subjects with impaired glucose response such as diabetics. Surprisingly, the serum desmosterol concentration was slightly increased after plant stanol ester consumption for 3 weeks, whereas we could not observe changes in lathosterol concentrations. As mentioned previously, desmosterol can act as a LXR agonist [12], thereby mediating a hypolipidemic effect via stimulation of the reverse cholesterol transport and inhibition of intestinal cholesterol absorption. Moreover, 


\section{CHAPTER 7}

LXR is not only an important regulator of cholesterol, but also of fatty acid and glucose homeostasis [20]. The disadvantage of systemic LXR activation is the potential development of hepatic steatosis. LXR stimulates lipogenesis, which is partly mediated via the increased expression of SREBP-1c, but also directly via increased expression of lipogenic enzymes such as fatty acid synthase (FAS), acetyl-CoA carboxylase (ACC) and stearoyl-CoA desaturase-1 (SCD1). The increased expression of lipogenic enzymes could also be described to the stimulatory effect of LXR agonist on carbohydrates responsive element binding protein (chREBP), a glucose sensitive transcription factor. Thus, the mechanism of reducing LDL-C by plant stanol esters may not be limited to parameters involved in lipid metabolism. Other metabolic parameters such as glucose and insulin might also be involved. Therefore, in future studies, it is necessary to focus on transcriptional pathways linking lipid, fatty acid and glucose metabolism. However, it should be noticed that the expression profiles of these genes depends on the health status of an individual. For example, Hurtado del Pozo et al. [21] showed that hepatic chREBP mRNA levels were much higher in obese that in lean subjects. Similarly, subjects with impaired glucose tolerance or type 2 diabetes mellitus have an increased expression of chREBP in the liver [22], suggesting that chREBP activation might be involved in the early stage of the metabolic syndrome. For FAS, it was also shown that its expression is significantly higher in obese and in type 2 diabetes subjects compared to lean controls [23]. Finally, mRNA levels of Niemann-Pick C1-like 1 (NPC1L1) and microsomal triglyceride transfer protein (MTTP) are increased and those of adenosine thriphosphate binding cassette transporter G5/G8 (ABCG5/ABCG8) are decreased in type 2 diabetic patients [24]. Despite these differences, Lau et al. [25] showed that consumption of plant sterols is efficacious in lowering LDL-C in both type 2 diabetic and nondiabetic subjects. The inhibition of intestinal cholesterol absorption induced by plant sterol supplementation results in a compensatory increase in cholesterol synthesis. This increase could be suppressed by insulin. As type 2 diabetic patients have a reduced postprandial insulin peak, HMG-CoA reductase activity, which is increased by insulin, will be decreased in these subjects [26].

\section{The role of the gut microbiota on lipid metabolism}

During the last couple of years, the gut microbiota became an important factor potentially contributing to metabolic aberrations in pathological conditions such as obesity [27], NASH [28], diabetes [29] and CVD [30] (figure 1). The composition of the gut microbiota is influenced by different factors, including host genetics [31], immunological factors [32], antibiotic treatment [33,34] and also dietary effects [35, 36]. Velagapudi et al. [37] indicated that a link exist between gut microbiota and lipid metabolism in mice. Conversion of cholesterol into coprostanol and deconjugation of primary bile acids into secondary bile acids might explain the hypocholesterolemic effect of gut microbiota. These assumptions need to be further investigated in humans. Therefore, we decided to examine this in slightly hypercholesterolemic subjects (chapter 6). In the meantime, Vrieze et al. [38] published a study in which they compared the effects of one-week oral administration of vancomycin versus those of amoxicillin $1.5 \mathrm{~g} / \mathrm{d}$ in obese men with the metabolic syndrome. In contrast to the animal studies, but in agreement with our study, using the same dose and applying the same study duration, they could not find an effect on LDL-C. In our 
study, amoxicillin decreased serum concentrations of HDL-C and increased those of TAG in subjects who had increased levels at baseline. This latter finding is in line with data from animal studies, showing a decrease in serum TAG and an increase in liver TAG concentrations in the presence of gut microbiota [37]. It is postulated that alterations in gut microbiota could affect the microbiota-mediated suppression of fasting-induced adipose tissue factor (FIAF/ANGPTL4) expression, thereby increasing lipoprotein lipase (LPL) activity resulting in enhanced lipid clearance and increased fatty acid uptake into adipocytes and liver. In mice overexpression FIAF, the expression of adipose TAG lipase (ATGL) was increased by $50 \%$ in adipose tissue and muscle, two insulin sensitive tissues. It is likely that elevated plasma free fatty acids and glycerol levels are caused by enhanced lipolysis via increased expression of ATGL, resulting in impaired glucose tolerance [39]. Altogether, it seems that a link exists between gut micriobiota composition and peripheral adipose tissue and skeletal muscle lipid metabolism. Finally, in our study, the decrease in glucose after amoxicillin intake was higher in subjects with increased baseline glucose concentrations. It was earlier demonstrated that antibiotic treatment in ob/ob mice improved oral glucose tolerance, glycemia and insulinemia. It is plausible that lipopolysaccharides (LPS) absorbed from gram-negative bacteria may induce insulin resistance [40]. In the gut, LPS is a ligand for Toll-like receptor 4 (TLR4), and activation of this receptor leads to the expression of tumor necrosis factor $\alpha$ (TNFa). Excessive production of this proinflammatory cytokine is also related to insulin resistance [41]. In addition, serum adiponectin concentrations increased after antibiotic treatment in ob/ob mice [40], resulting in enhanced mitochondrial fatty acid oxidation, decreased activity of lipogenic enzymes such as FAS and ACC1 and reduced circulating TNFa concentrations as well as reduced production of hepatic TNFa. Vrieze et al. [38] also could not find an effect of amoxicillin on insulin sensitivity. However, they showed earlier that the gut microbiota plays an important role in the glucose metabolism since transplantation of lean donor gut microbiota into obese subjects with the metabolic syndrome altered the composition of the intestinal microbiota, and improved hepatic and peripheral insulin sensitivity [42]. Altogether, it would be interesting to investigate in the future whether manipulation of the gut microbiota composition affects lipid and glucose metabolism in serum, adipose tissue and skeletal muscle in subjects with and without impaired glucose tolerance. Furthermore, evaluating the effects on cytokine profile, expression profiles of transcription factors (e.g.SREBP-1c, chREBP) and its target genes involved in lipid/glucose metabolism and on faecal microbiota composition would be useful to elucidate the role of gut microbiota in health and disease. 


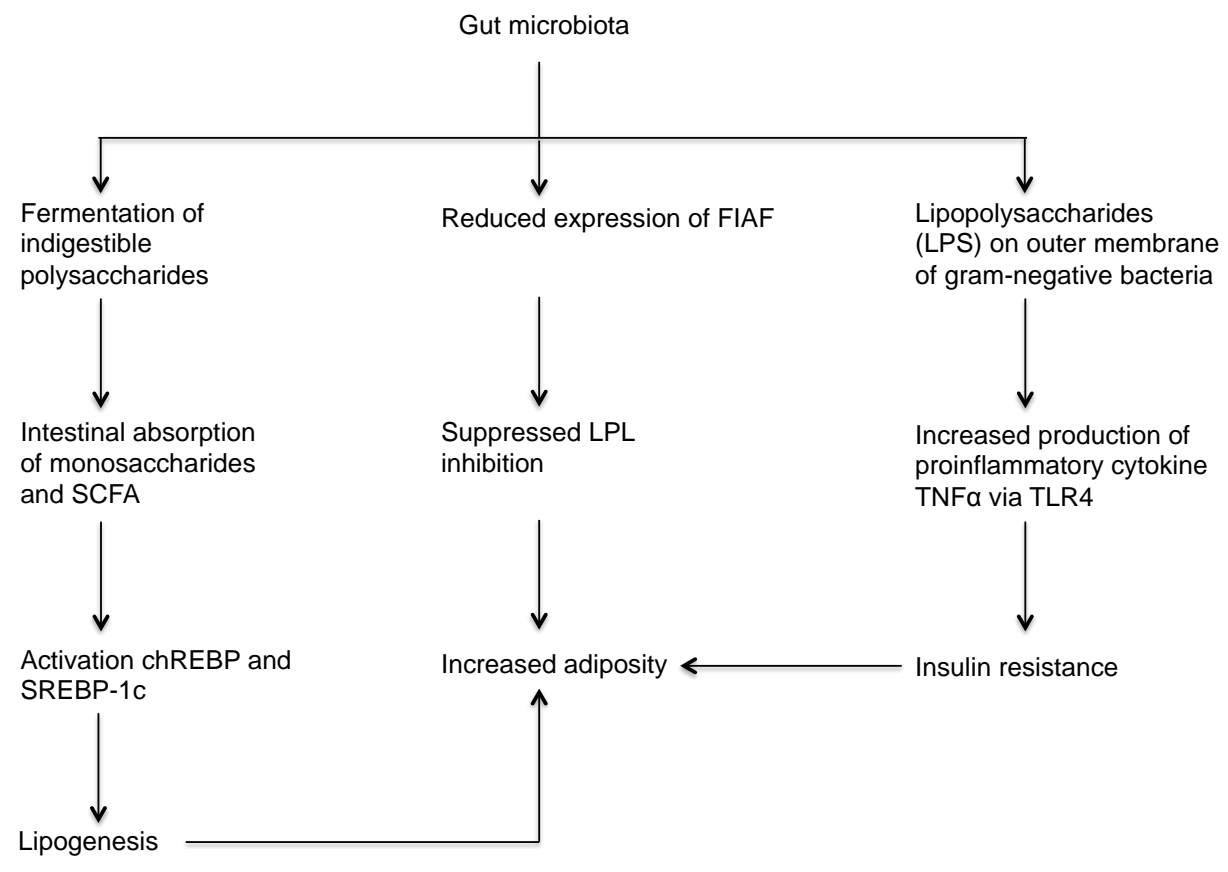

Figure 1: Processes that are influenced by the composition of the gut microbiota.

\section{Conclusions and recommendations}

As dietary cholesterol contributes to elevated LDL-C and decreasing LDL-C is cardioprotective, adding plant sterols/stanols to a variety of foods is a suitable approach in managing CVD risk. An acute bolus of plant stanol esters rapidly changed the expression of intestinal and hepatic genes involved in sterol metabolism in mice. These effects were not found in the human intestine, but immune-related pathways were downregulated in the jejunum. The effect on immune cells is in line with earlier observations, indicating that plant stanol esters may be attractive for other purposes instead of only being used as a cholesterol-lowering compound. Moreover, we found that individual responses in lipid and lipoprotein metabolism after 3 weeks plant stanol ester consumption were related to glucose responses during a postprandial test at baseline. Future studies, investigating the relationship between lipid and glucose metabolism could be helpful to unravel the mechanisms of plant stanol esters. Finally, modulation of the composition and metabolism of the gut microbiota has become very interestingly in order to improve long-term health status. In animals, it has been shown that this can be achieved by changes in diet. How these findings compare to the human situation and whether plant stanol ester consumption affects microbiota composition warrant further study. 


\section{References}

1. Plat, J., J.A. Nichols, and R.P. Mensink, Plant sterols and stanols: effects on mixed micellar composition and LXR (target gene) activation. J Lipid Res, 2005. 46(11): p. 2468-76.

2. Field, F.J., E. Born, and S.N. Mathur, Effect of micellar beta-sitosterol on cholesterol metabolism in CaCo-2 cells. J Lipid Res, 1997. 38(2): p. 348-60.

3. Calpe-Berdiel, L., et al., Changes in intestinal and liver global gene expression in response to a phytosterol-enriched diet. Atherosclerosis, 2005. 181(1): p. 75-85.

4. Brufau, G., et al., A reappraisal of the mechanism by which plant sterols promote neutral sterol loss in mice. PLoS One, 2011. 6(6): p. e21576.

5. Bozzetto, L., et al., Ezetimibe beneficially influences fasting and postprandial triglyceride-rich lipoproteins in type 2 diabetes. Atherosclerosis, 2011. 217(1): p. 142-8.

6. Relas, H., H. Gylling, and T.A. Miettinen, Effect of stanol ester on postabsorptive squalene and retinyl palmitate. Metabolism, 2000. 49(4): p. 473-8.

7. Jakulj, L., et al., Plant stanols do not restore endothelial function in pre-pubertal children with familial hypercholesterolemia despite reduction of low-density lipoprotein cholesterol levels. J Pediatr, 2006. 148(4): p. 495-500.

8. Schultz, J.R., et al., Role of LXRs in control of lipogenesis. Genes Dev, 2000. 14(22): p. 28318.

9. $\quad$ Plat, J., et al., A plant stanol yogurt drink alone or combined with a low-dose statin lowers serum triacylglycerol and non-HDL cholesterol in metabolic syndrome patients. J Nutr, 2009. 139(6): p. 1143-9.

10. Plat, J. and R.P. Mensink, Plant stanol esters lower serum triacylglycerol concentrations via a reduced hepatic VLDL-1 production. Lipids, 2009. 44(12): p. 1149-53.

11. Theuwissen, E., et al., Plant stanol supplementation decreases serum triacylglycerols in subjects with overt hypertriglyceridemia. Lipids, 2009. 44(12): p. 1131-40.

12. Spann, N.J., et al., Regulated accumulation of desmosterol integrates macrophage lipid metabolism and inflammatory responses. Cell, 2012. 151(1): p. 138-52.

13. Brull, F., et al., TLR2 activation is essential to induce a Th1 shift in human peripheral blood mononuclear cells by plant stanols and plant sterols. J Biol Chem, 2010. 285(5): p. 2951-8.

14. Desai, F., et al., Comparison of the immunomodulatory effects of the plant sterol beta-sitosterol to simvastatin in peripheral blood cells from multiple sclerosis patients. Int Immunopharmacol, 2009. 9(1): p. 153-7.

15. Bensinger, S.J., et al., LXR signaling couples sterol metabolism to proliferation in the acquired immune response. Cell, 2008. 134(1): p. 97-111.

16. Demonty, I., et al., The effect of plant sterols on serum triglyceride concentrations is dependent on baseline concentrations: a pooled analysis of 12 randomised controlled trials. Eur J Nutr, 2013. 52(1): p. 153-60.

17. Rideout, T.C., et al., Low and moderate-fat plant sterol fortified soymilk in modulation of plasma lipids and cholesterol kinetics in subjects with normal to high cholesterol concentrations: report on two randomized crossover studies. Lipids Health Dis, 2009. 8: p. 45.

18. Plat, J., et al., Progress and prospective of plant sterol and plant stanol research: report of the Maastricht meeting. Atherosclerosis, 2012. 225(2): p. 521-33.

19. Watts, G.F., et al., Fish oils, phytosterols and weight loss in the regulation of lipoprotein transport in the metabolic syndrome: lessons from stable isotope tracer studies. Clin Exp Pharmacol Physiol, 2006. 33(9): p. 877-82.

20. Beltowski, J., Liver $X$ receptors (LXR) as therapeutic targets in dyslipidemia. Cardiovasc Ther, 2008. 26(4): p. 297-316.

21. Hurtado del Pozo, C., et al., ChREBP expression in the liver, adipose tissue and differentiated preadipocytes in human obesity. Biochim Biophys Acta, 2011. 1811(12): p. 1194-200.

22. Kursawe, R., et al., Decreased transcription of ChREBP-alpha/beta isoforms in abdominal subcutaneous adipose tissue of obese adolescents with prediabetes or early type 2 diabetes: associations with insulin resistance and hyperglycemia. Diabetes, 2013. 62(3): p. 837-44.

23. Bluher, M., et al., Fas and FasL expression in human adipose tissue is related to obesity, insulin resistance, and type 2 diabetes. J Clin Endocrinol Metab, 2014. 99(1): p. E36-44.

24. Lally, S., et al., Messenger RNA levels of genes involved in dysregulation of postprandial lipoproteins in type 2 diabetes: the role of Niemann-Pick C1-like 1, ATP-binding cassette, transporters G5 and G8, and of microsomal triglyceride transfer protein. Diabetologia, 2006. 49(5): p. 1008-16. 


\section{CHAPTER 7}

25. Lau, V.W., M. Journoud, and P.J. Jones, Plant sterols are efficacious in lowering plasma $L D L$ and non-HDL cholesterol in hypercholesterolemic type 2 diabetic and nondiabetic persons. Am J Clin Nutr, 2005. 81(6): p. 1351-8.

26. Osborne, A.R., et al., Identification of insulin-responsive regions in the HMG-CoA reductase promoter. Biochem Biophys Res Commun, 2004. 318(4): p. 814-8.

27. Cani, P.D. and N.M. Delzenne, Interplay between obesity and associated metabolic disorders: new insights into the gut microbiota. Curr Opin Pharmacol, 2009. 9(6): p. 737-43.

28. Moschen, A.R., S. Kaser, and H. Tilg, Non-alcoholic steatohepatitis: a microbiota-driven disease. Trends Endocrinol Metab, 2013. 24(11): p. 537-45.

29. Zhang, X., et al., Human gut microbiota changes reveal the progression of glucose intolerance. PLoS One, 2013. 8(8): p. e71108.

30. Wang, Z., et al., Gut flora metabolism of phosphatidylcholine promotes cardiovascular disease. Nature, 2011. 472(7341): p. 57-63.

31. Khachatryan, Z.A., et al., Predominant role of host genetics in controlling the composition of gut microbiota. PLoS One, 2008. 3(8): p. e3064.

32. Guamer, F., [Role of intestinal flora in health and disease]. Nutr Hosp, 2007. 22 Suppl 2: p. 149.

33. Relman, D.A., Microbiology: Learning about who we are. Nature, 2012. 486(7402): p. 194-5.

34. Walker, A.W., et al., Dominant and diet-responsive groups of bacteria within the human colonic microbiota. ISME J, 2011. 5(2): p. 220-30.

35. Duncan, S.H., et al., Reduced dietary intake of carbohydrates by obese subjects results in decreased concentrations of butyrate and butyrate-producing bacteria in feces. Appl Environ Microbiol, 2007. 73(4): p. 1073-8.

36. Flint, H.J., et al., Microbial degradation of complex carbohydrates in the gut. Gut Microbes, 2012. 3(4): p. 289-306.

37. Velagapudi, V.R., et al., The gut microbiota modulates host energy and lipid metabolism in mice. J Lipid Res, 2010. 51(5): p. 1101-12.

38. Vrieze, A., et al., Impact of oral vancomycin on gut microbiota, bile acid metabolism, and insulin sensitivity. J Hepatol, 2013.

39. Mandard, S., et al., The fasting-induced adipose factor/angiopoietin-like protein 4 is physically associated with lipoproteins and governs plasma lipid levels and adiposity. J Biol Chem, 2006. 281(2): p. 934-44.

40. Membrez, M., et al., Gut microbiota modulation with norfloxacin and ampicillin enhances glucose tolerance in mice. FASEB J, 2008. 22(7): p. 2416-26.

41. Hotamisligil, G.S., N.S. Shargill, and B.M. Spiegelman, Adipose expression of tumor necrosis factor-alpha: direct role in obesity-linked insulin resistance. Science, 1993. 259(5091): p. 8791.

42. Vrieze, A., et al., Transfer of intestinal microbiota from lean donors increases insulin sensitivity in individuals with metabolic syndrome. Gastroenterology, 2012. 143(4): p. 913-6 e7. 
SUMMARY 


\section{SUMMARY}

Cardiovascular diseases (CVD) are still the number one cause of death for men and women globally. Some risk factors for CVD (e.g. age and family history of early heart diseases) cannot be modified, but other can (e.g. smoking, hypertension, lack of physical activity, being overweight, unhealthy dietary habits and abnormal serum lipid and lipoprotein concentrations). Adopting a healthy lifestyle is therefore a cornerstone to decrease the risk for CVD. In this respect, functional foods, targeted to lower the atherogenic low-density lipoprotein cholesterol (LDL-C) concentrations, can be helpful. Functional foods contain (or lack) one or more components, thereby providing positive health effects beyond their traditional nutritional value. Plant stanol esters are an example of such components. They are incorporated into margarines and other food products, and reduce intestinal cholesterol absorption. The (intestinal) mechanism underlying the hypocholesterolemic effect of plant stanol esters is still unknown. Beside plant stanol esters, also other factors could be targeted to modulate intestinal cholesterol metabolism. In this context, animal studies have suggested that the gut microbiota plays a role in (intestinal) cholesterol metabolism. The aim of the studies described in this thesis was therefore to investigate the effects of plant stanol esters and amoxicillin, a moderate-spectrum antibiotic, which could change the composition of the gut microbiota, on (intestinal) lipid metabolism.

In the first study the acute effects of plant stanol esters on serum, intestinal and hepatic plant sterol and stanol concentrations was examined to gain more insight into the kinetics of plant stanol esters (chapter 3 ). In addition, acute effects on intestinal and hepatic expression profiles of genes involved in sterol metabolism were investigated. To reduce the impact of plant sterol and stanol already present in serum and tissues as much as possible, C57BL/6J mice were fed a plant sterol and stanol poor diet from weaning. At the age of 8 weeks, the mice received an oral gavage consisting of $0.25 \mathrm{mg}$ cholesterol and of $50 \mathrm{mg}$ plant stanols, which were provided as their fatty acids, dissolved in $500 \mu \mathrm{l}$ refined plant sterol poor olive oil. The mice were fasted 2 hours before the gavage and sacrificed at 7 different time points post-gavage. The plant stanol concentrations increased in the intestine, but also in the liver 15 minutes after administration. This latter finding was highly unexpected, since it suggests that it takes only 15 minutes for plant stanol esters to be digested and absorbed into the enterocytes, incorporated and secreted as chylomicrons in the lymph, and taken up by the liver after entering the circulation. In addition, there was no clear change in serum plant stanol or cholesterol concentrations at this early time point. It could be possible that plant stanols reach the liver via the portal vein, independent of chylomicron formation. Therefore, a second study was performed to address the route of entrance into the liver. In this study, C57BL/6J mice were fed the same plant sterol and stanol poor diet from weaning. At the age of 8 weeks, mice were anesthetized and the ductus lymphaticus thoracicus was canulated proximal from the cisternae magnum via an abdominal approach. The mice in the control group were subjected to a sham operation, leaving the lymph circulation intact. They were given the same oral gavage, except that deuterium labelled plant stanols and cholesterol were used to follow concentrations and amounts of plant stanols and cholesterol from the gavage into the circulation and the tissues over time. The mice remained under anaesthesia until sacrificing at 6 different time points. The rapid hepatic appearance of deuterated-plant stanols was absent in the lymph-canulated mice. The intestinal uptake was, however, 
comparable between the lymph-canulated and the sham-operated mice. Altogether, this study showed that the appearance of plant stanols in the liver is lymph dependent. No deuterated-cholesterol was detected in the liver. This suggests that the rapid hepatic appearance was specific for plant stanols. Alternatively, it is possible that the detection limit for deuterated-cholesterol was too low due to dilution with cholesterol already present in the liver. The question still remains how and in which form (i.e. free or esterified), plant stanols enter the liver after 15 minutes without clear changes in serum concentrations.

Another finding was that changes in the expression profile of genes involved in sterol metabolism in the liver were opposite to those in the intestine. The increased intestinal expression of sterol regulatory element binding protein 2 (SREBP2) and its target genes can be explained by decreased intestinal cholesterol concentrations. In the liver, the expression of ABCG5/ABCG8, two liver $X$ receptor (LXR) target genes, was increased, but hardly changed in the intestine. This could be due to differences in desmosterol concentrations in the liver and the intestine, which act as an important regulator of LXR activation in macrophages. Finally, the pronounced increases in intestinal LDLreceptor and proprotein convertase subtilisin/kexin type 9 (PCSK9) expressions are suggestive for an enhanced clearance of cholesterol via the transintestinal cholesterol excretion (TICE). However, these speculations warrant further studies.

To study the acute effects of plant stanol esters on the expression profiles of genes from human enterocytes, 18 healthy normolipidemic volunteers received in a randomized double-blind placebo-controlled crossover design a shake enriched with or without $4 \mathrm{~g}$ plant stanol esters after an overnight fast (chapter 4). One week before the test, subjects were instructed to avoid products relatively rich in plant sterols and stanols. Five hours after consumption of the shake, intestinal biopsies were taken originating from the duodenum (around the Papil van Vater) and the jejunum $(20 \mathrm{~cm}$ distal from the Papil van Vater). No changes in the expression profile of genes involved in sterol metabolism were found. However, immune-related T-cell pathways were downregulated in the jejunum. In humans with a disturbed immune response, plant stanol esters have already been observed to activate the immune system. In our study with healthy men, however, the immune response was dampened. The functional and physiological consequence of this effect deserves further investigation.

In that study, the acute effects of plant stanol esters on the postprandial lipid and lipoprotein profile were also examined (chapter 5). Furthermore, it was examined whether individual responses to longer-term consumption of plant stanol esters were related to results from the postprandial test. After an overnight fast, 18 healthy normolipidemic volunteers received a shake enriched with or without $4 \mathrm{~g}$ plant stanol esters. Blood samples were taken during the next 4 hours. Subjects receiving the shake with plant stanol esters during the postprandial test, continued with the margarine containing plant stanol esters for the next 3 weeks and vice-versa. The two intervention periods were separated by a washout period of four weeks. A positive correlation was found between the postprandial incremental area under the curve (iAUC) of glucose with changes in the concentration of total cholesterol, LDLC, apoB100, total VLDL, small VLDL and IDL after 3 weeks consumption of a margarine enriched with plant stanol esters. This suggests that subjects with a more 


\section{SUMMARY}

pronounced postprandial glucose response are less sensitive to the longer-term LDL-C-lowering effect of plant stanol ester consumption. However, there were no correlations with the iAUC of insulin and of the HOMA index. More research is needed which should focus on transcription factors associated with lipid, glucose and insulin metabolism such as SREBP2, SREBP-1c and carbohydrate-responsive element-binding protein (chREBP) to unravel the plant stanol ester-induced inhibition of intestinal cholesterol absorption.

After the shake, serum total cholesterol concentrations decreased and those of triacylglycerol (TAG), glucose and insulin increased over time. These changes were comparable after consumption of the control or the plant stanol ester enriched shake. Also, the iAUC of serum TAG, insulin and plasma glucose were comparable after both meals. Changes in lipoprotein profiles were comparable after intakes of the plant stanol ester and control shakes.

As expected, three weeks consumption of a margarine enriched with plant stanol esters $(3 \mathrm{~g} / \mathrm{d})$ reduced serum concentrations of total cholesterol, LDL-C and apoB100. Serum HDL-C, TAG and apoA1 concentrations did not change. Furthermore, the number of total VLDL-CM, small VLDL and large LDL particles decreased compared to the control condition.

Animal studies have shown that the composition of the gut microbiota is related to lipid and lipoprotein metabolism (chapter 6). Therefore, effects of oral amoxicillin intake on lipid and glucose metabolism were examined in slightly hypercholesterolemic subjects. In a randomized, double-blind, placebo-controlled design, 74 subjects were assigned to use capsules containing placebo or amoxicillin during 1 week. Fasting blood samples were taken on days 1, 4, 8, 12 and 16 . The last two time points were part of a washout period. Amoxicillin did not change serum concentrations of total cholesterol, LDL-C, TAG, C-reactive protein, glucose, insulin and the HOMA index. Body weight and blood pressure also did not change. However, a significant interaction term was found between amoxicillin treatment and baseline concentrations of HDL-C, TAG, glucose and the HOMA index. More specifically, amoxicillin decreased serum HDL-C concentrations more pronounced in subjects with higher serum HDL-C concentrations at baseline. For TAG, we found that the increase after amoxicillin intake was more pronounced in subjects with higher baseline values. After amoxicillin intake, glucose concentrations decreased in subjects with higher glucose concentrations at baseline. The HOMA index followed the same pattern as glucose. Finally, differences in HDL-C and TAG concentrations between the amoxicillin and placebo high-baseline groups tended to decrease during the washout period. A possible explanation for this rapid return might be changes on gene expression profiles. However, more research is needed to examine the effect of antibiotics on gene expression. Moreover, it is also interesting to investigate if amoxicillin intake changes the composition of the gut microbiota. Finally, it would be interesting to identify the specific microbiota responsible for the observed effects. 


\section{SAMENVATTING}




\section{SAMENVATTING}

Hart- en vaatziekten (HVZ) zijn wereldwijd de belangrijkste doodsoorzaak voor mannen en vrouwen. Sommige risicofactoren, zoals leeftijd en genetische belasting, kunnen we niet veranderen. Factoren zoals roken, hypertensie, een tekort aan lichamelijke activiteit, overgewicht, ongezonde voedingsgewoontes en afwijkende lipidenconcentraties in het serum, zijn echter wel te beïnvloeden. Om het risico op het krijgen van $\mathrm{HVZ}$ te verlagen is een gezonde levensstijl erg belangrijk. Het gebruik van functionele voedingsmiddelen, die het aantal atherogene LDL-deeltjes verlagen, kan het risico op HVZ verminderen. Functionele voedingsmiddelen bevatten (of missen) een of meerdere stoffen en hebben daarom een gunstig effect op de gezondheid. Plantaardige stanolesters, verwerkt in margarines, zijn hiervan een bekend voorbeeld. Ze verlagen de cholesterolabsorptie in de darm via een tot nu toe onbekend mechanisme. Behalve plantaardige stanolesters zijn er nog andere factoren die een effect hebben op het cholesterolmetabolisme in de darm. Het doel van de studies, die in dit proefschrift staan beschreven, was dan ook om de rol van plantaardige stanolesters en amoxicilline, een antibioticum dat de samenstelling van de darmbacteriën (microbiota) kan veranderen, op het lipidenmetabolisme te bestuderen.

In onze eerste studie werden de effecten van een éénmalige inname van plantaardige stanolesters op plantaardige sterol- en stanolconcentraties in serum, darm en lever onderzocht om inzicht te verkrijgen in de kinetiek van plantaardige stanolesters (hoofdstuk 3). Tegelijkertijd werd in de lever en de darm gekeken naar het expressieprofiel van genen betrokken bij het sterolmetabolisme. Om de invloed van plantaardige sterolen en stanolen, die reeds in het bloed en de weefsels aanwezig zijn, te verminderen, kregen de C57BL/6J muizen vanaf de geboorte een sterol- en stanol-arme voeding. Op de leeftijd van 8 weken kregen deze muizen een orale gavage. Hiervoor werd $0,25 \mathrm{mg}$ cholesterol samen met $50 \mathrm{mg}$ plantaardige stanolesters opgelost in $500 \mu \mathrm{l}$ plantaardig sterolarme olijfolie. Voorafgaande aan de gavage werden de muizen 2 uur gevast. Na de gavage werden zij op 7 verschillende tijdstippen opgeofferd. Vijftien minuten na toediening van de gavage nam de concentratie van plantaardige stanolen niet alleen in de darm toe, maar ook al in de lever. Deze laatste bevinding was onverwacht. Het betekent immers dat de absorptie van plantaardige stanolen in de enterocyten, gevolgd door de inbouw en secretie als chylomicronen in de lymfe, en tenslotte de opname ervan in de lever, slechts 15 minuten duurt. Bovendien was er geen duidelijke verandering in de serumconcentraties van plantaardige stanolen te zien op dit tijdstip. Het zou ook kunnen dat plantaardige stanolen of stanolesters de lever bereiken via de poortader, een route waarbij de vorming van chylomicronen niet vereist is. Daarom werd een tweede studie uitgevoerd. Voor deze studie werden C57BL/6J muizen vanaf de geboorte gevoed met hetzelfde plantaardige sterol en stanol arme voer. Op de leeftijd van 8 weken werden de muizen onder anesthesie gebracht en werd de ductus lymphaticus thoracicus gecanuleerd. De muizen in de controlegroep kregen een sham operatie, waarbij de lymfe-circulatie intact bleef. Ze kregen dezelfde orale gavage toegediend als de muizen in de eerste studie, met als enige wijziging dat nu deuterium-gelabelde plantaardige stanolesters en cholesterol werden gebruikt. Dit label maakte het mogelijkheid om de route te volgen, die de plantaardige stanolesters en cholesterol afkomstig uit de gavage, aflegden via de circulatie en de weefsels. De muizen bleven onder anesthesie totdat ze op 6 verschillende tijdstippen werden opgeofferd. Vijftien minuten na toediening was er geen toename 
van deuterium-gelabelde plantaardige stanolen in de lever van de lymfegecanuleerde muizen. Toch was de opname in de darm vergelijkbaar tussen de lymfe-gecanuleerde en de controle (sham-geopereerde) muizen. We concludeerden dan ook dat de opname van plantaardige stanolen in de lever via de lymfe verloopt. Het deuterium-gelabelde cholesterol kon niet aangetoond worden in de lever, hetgeen suggereert dat de snelle opname in de lever specifiek is voor plantaardige stanolen. Het is echter ook mogelijk dat de detectielimiet voor de bepaling van het gelabelde cholesterol in de lever te laag was. De vraag blijft dan ook hoe de vrije of de veresterde vorm van plantaardige stanolen de lever zo snel kunnen bereiken, zonder dat er grote veranderingen in serumconcentraties waarneembaar zijn.

Een andere bevinding was dat de expressie van genen betrokken bij het sterolmetabolisme tegenovergesteld was in de lever en de darm. Een daling van de cholesterolconcentratie in de darmcel kan aan de basis liggen van een toename in de expressie van SREBP2 en zijn targetgenen tot gevolg hebben. In de lever nam de expressie van ABCG5/ABCG8, twee LXR targetgenen, echter toe, terwijl hun expressie nauwelijks veranderde in de darm. Dit verschil kan mogelijk verklaard worden door verschillen in desmosterolconcentraties tussen de lever en de darm. In macrofagen is reeds eerder aangetoond dat desmosterol betrokken is bij de activatie van LXR. Tenslotte suggereert de sterke toename van de expressie van de LDLreceptor en PCSK9 in de darm een verhoogde klaring van cholesterol via de transintestinale cholesterolexcretie (TICE). Deze veronderstelling moet echter nader onderzocht worden.

Behalve in muizen, werden de effecten van een éénmalige inname van plantaardige stanolesters op het expressieprofiel van genen ook in de darm van mensen onderzocht (hoofdstuk 4). Hiervoor werden achttien gezonde deelnemers willekeurig verdeeld over twee groepen. 's Ochtends kregen ze in willekeurige volgorde een shake verrijkt met $4 \mathrm{~g}$ plantaardige stanolesters of een controle shake $(0 \mathrm{~g}$ plantaardige stanolesters). De deelnemers mochten een week voor deze postprandiale test geen producten eten, die rijk waren aan plantaardige sterolen en stanolen. Vijf uur na consumptie van de shake werden darmbiopten genomen in het duodenum (de twaalfvingerige darm) en het jejunum (de nuchtere darm). Het expressieprofiel van genen, die een rol spelen in het sterolmetabolisme, was vergelijkbaar na inname van de controle en de plantenstanolester verrijkte shake. Onverwachts was de bevinding dat er een downregulatie was van immuungerelateerde T-cell pathways in het jejunum. Reeds eerder is aangetoond bij mensen met een verstoorde immuunrespons, dat plantaardige stanolesters het immuunsysteem, in het bijzonder de T-helper cel response, kunnen activeren. In onze studie, met gezonde deelnemers leek de immuunrespons echter te zijn afgezwakt. Nader onderzoek zal moeten uitwijzen wat de functionele en fysiologische gevolgen zijn van deze mogelijke afname van de immuunrespons in de darm bij gezonde mensen.

In deze studie werd eveneens het effect op het postprandiale lipiden en lipoproteïnenprofiel bekeken (hoofdstuk 5). Bovendien onderzochten we of de resultaten van de postprandiale test gebruikt konden worden om te voorspellen hoe het lipidenprofiel van een individu zou veranderen na langdurige consumptie van plantaardige stanolesters. Hiervoor werd bloed afgenomen gedurende de eerste 4 uur na consumptie van de shake, die al niet dan verrijkt was met $4 \mathrm{~g}$ plantaardige 


\section{SAMENVATTING}

stanolesters. De deelnemers die tijdens de testdagen de shakes hadden gebruikt, kregen gedurende twee perioden van 3 weken eveneens een margarine al dan niet verrijkt met plantaardige stanolesters $(3 \mathrm{~g} / \mathrm{d})$. Er was een periode van 4 weken tussen beide interventies (controle en plantenstanolester conditie). Er werd een positieve correlatie gevonden tussen de postprandiale toename van glucose (iAUC) en de veranderingen in de concentraties van totaal cholesterol, LDL-cholesterol, apoB100, totaal VLDL, klein VLDL en IDL na het gebruik van een margarine verrijkt met plantaardige stanolesters gedurende 3 weken. Dit suggereert dat mensen met een verhoogde postprandiale glucoserespons minder gevoelig zijn voor het cholesterolverlagend effect van plantaardige stanolesters op langere termijn. Er is echter meer onderzoek nodig, waarbij gericht gekeken moet worden naar een verband tussen transcriptiefactoren die een rol spelen in het lipiden, het glucose en het insuline metabolisme. Enkele voorbeelden hiervan zijn SREBP2, SREBP-1c en chREBP.

Gedurende de postprandiaal test daalde de serumconcentratie van totaal cholesterol, terwijl die van de triglyceriden (TAG), glucose en insuline toenamen. Deze veranderingen waren vergelijkbaar na consumptie van de controle shake of de shake verrijkt met plantaardige stanolesters. De iAUCs van TAG, insuline en glucose waren eveneens vergelijkbaar op beide testdagen. Het lipoproteïnenprofiel veranderde niet na inname van de shakes.

Zoals verwacht, nam de serumconcentratie van totaal cholesterol, LDL-cholesterol en apolipoproteïne B100 (apoB100) af in deelnemers na inname van de margarine verrijkt met plantaardige stanolesters. De serumconcentraties van HDL-cholesterol, TAG en apoA1 veranderden niet. In vergelijking met de controle conditie verlaagde het totaal aantal VLDL-chylomicron, kleine VLDL en grootte LDL-deeltjes.

Dierstudies hebben aangetoond dat de samenstelling van de darmbacteriën (microbiota) geassocieerd is met het lipiden- en lipoproteïnenmetabolisme. Daarom onderzochten we het effect van een oraal toegediende amoxicilline kuur (7 dagen) op het lipiden- en glucosemetabolisme in deelnemers met een licht verhoogd cholesterolgehalte (hoofdstuk 6). Vierenzeventig deelnemers werden willekeuring verdeeld over 2 groepen. Een groep kreeg capsules met amoxicilline en de andere groep kreeg controle capsules (placebo) gedurende 1 week. De deelnemers kwamen op dag 1, 4, 8, 12 en 16 langs voor een nuchtere bloedafname. Dag 12 en dag 16 waren tijdstippen waarop de deelnemers geen capsules meer innamen. Inname van amoxicilline leidde niet tot veranderingen in de serumconcentratie van totaal cholesterol, LDL-cholesterol, TAG, C-reactief proteïne, glucose, insuline en de HOMA-index. Lichaamsgewicht en bloeddruk bleven ook ongewijzigd. Er werd echter een significante interactie gevonden tussen inname van amoxicilline en de startwaarde van het HDL-cholesterolgehalte, het TAG-gehalte, het glucosegehalte en de HOMA-index. Het gebruik van amoxicilline verlaagde de serumconcentratie van HDL-cholesterol in personen met een verhoogde startwaarde. De toename in de TAG-concentratie was verhoogd in deelnemers met verhoogde starwaarden. $\mathrm{Na}$ inname van amoxicilline verlaagde de glucose en de HOMA-index in de deelnemers met een hoge waarde bij aanvang van de proef. Het verschil in HDL-cholesterol en TAG-concentraties tussen de deelnemers met hoge startwaarde in de amoxicilline en de controlegroep leek af te nemen in de week volgend op de inname van de capsules. Veranderingen in het expressieprofiel van genen veroorzaakt door het antibioticum (dus onafhankelijk van een eventuele verandering in de samenstelling 
van de microbiota) kan een mogelijke verklaring zijn voor deze snelle terugkeer naar startwaarden. Vervolgstudies zijn echter nodig om het effect van antibiotica op het genexpressieprofiel te bestuderen. Ook is het noodzakelijk om na inname van amoxicilline de veranderingen in de samenstelling van de darmbacteriën na te gaan. Tenslotte is het ook de moeite waard om te onderzoeken of een bepaalde soort darmbacterie verantwoordelijk is voor deze bevindingen. 



\section{APPENDIX}

Dankwoord

Curriculum vitae

List of publications

Abbreviations 



\section{Dankwoord}

Hoewel mijn naam op de kaft van dit proefschrift staat, is dit uiteraard niet het resultaat van één persoon. Bij deze wil ik dan ook iedereen bedanken die er, op welke manier dan ook, een bijdrage aan geleverd heeft.

Beste Jogchum (prof. dr. J. Plat) en Ronald (prof. dr. ir. R.P. Mensink), jullie zou ik graag als eerste willen bedanken voor de gegeven kansen en de dagelijkse begeleiding. Ronald, bedankt voor je kritische blik op de manuscripten. Jogchum, je hebt me aan de ene kant heel veel vrijheid gegeven, maar tegelijkertijd heb je mij ook bij vele zaken betrokken en daardoor veel verantwoordelijkheid en vertrouwen gegeven. Je eeuwig optimisme en je enthousiasme werken aanstekelijk. Hartelijk dank voor alles!

De leden van de beoordelingscommissie, prof. dr. E.E. Blaak, dr. G.M. DallingaThie, prof. dr. E.C.M. Mariman, prof. dr. A.A.M. Masclee en prof. dr. E.A. Trautwein, wil ik bedanken voor het kritisch evalueren van mijn proefschrift.

Beste proefpersonen, jullie bijdrage aan mijn onderzoek was onmisbaar! Bedankt voor jullie inzet en interesse.

I would like to thank Raisio for making this project financially possible. Thanks a lot for providing the experimental products and the scientific support.

Dank aan alle collega's! Mijn kamergenootjes wil ik bedanken voor de gezellige sfeer. Florence, je hebt me wegwijs gemaakt in het celkweeklab. Ik vond het leuk om mee te werken aan de astma-studie en zal ons wekelijks bezoek aan de vriescontainer nooit vergeten. Je mag terecht fier zijn op het resultaat. Nadine, we hebben ongeveer 3 jaar samen op een kamer gezeten. Bedankt voor je helpende handen tijdens mijn humane studies en de nodige statistiekdiscussies. Lotte, onze tijd samen was veel te kort. Ik ken niemand met zoveel ambitieuze projecten als jij.

Verder wil ik de secretaressen, de analisten, de diëtisten en de computerspecialisten bedanken voor al hun hulp. Naast de collega's van Humane Biologie wil ik de mensen van de afdeling gastro-enterologie bedanken voor de afname van de darmbiopten. Ook zonder jullie was dit alles niet gelukt.

De mensen van het CPV, bedankt voor alle hulp tijdens de testdagen. Ook dank aan het Groningen-team: Gemma, Marleen en Rick. Zonder jullie was er geen canulatiestudie geweest. Het was een korte, maar intensieve en leerrijke periode.

Hoofdstuk 4 was er nooit geweest zonder de samenwerking met Wageningen voor het runnen van de micro-arrays. Mark, bedankt voor alle hulp en vooral voor de goede wetenschappelijke discussies.

Nico, bedankt voor de kleuringen en je geduld tijdens de zoektocht naar een foto voor de kaft. Zonder jou en Joris was de kaft nooit zo mooi geworden. Ontzettend bedankt voor alle tijd en energie die jullie erin hebben gestoken om tot dit resultaat te komen. 


\section{APPENDIX}

Mijn allerliefste paranimfen verdienen een speciaal plekje. Peter, je kwam halverwege mijn aio-periode het Belgenfront versterken. Ik vind het nog altijd dapper dat je proefpersoon bent geweest in mijn bioptenstudie. Het was fijn om onze eerste humane studie ongeveer gelijk op te starten. Ruimte 19 was toen een echt 'Belgenhok', ik denk met veel plezier terug aan die mooie tijd! Rudi, je kwam in mijn laatste jaar erbij en werd al snel mijn andere Belgenmakker. Ook jij wou je 'opofferen' voor de wetenschap, maar je was te gezond om deel te nemen aan de antibioticastudie. Als ik nood had aan afleiding, kon ik ook altijd bij jou terecht. Ik zal jullie origineel cadeautje op onze laatste werkdag samen nooit vergeten en ben dan ook heel blij dat jullie op deze dag achter me staan. Veel succes nog met het uitvoeren van de humane studies en het schrijven van jullie boekje.

Eline, we zijn ongeveer gelijk aan onze aio-periode gestart, waardoor we in hetzelfde schuitje zaten en altijd bij elkaar terecht konden. Het was niet altijd gemakkelijk om samen pauze te nemen, maar gelukkig waren er dan de weekends of de avonden om bij te praten. Bedankt voor alles!

Mariëlle, je had de antibioticastudie gekozen voor het schrijven van je bachelor thesis. Het moet een verrassing geweest zijn toen je merkte dat de bioptenstudie tegelijkertijd uitgevoerd werd. Ik kon me in ieder geval geen betere stagiaire wensen. Je was een grote hulp!

(Schoon)familie en vrienden, bedankt voor jullie onvoorwaardelijke steun, interesse en de nodige ontspannende feestjes, uitstapjes, activiteiten,...

Jolien, Katrien, Niels en Tom, het is niet altijd even gemakkelijk om af te spreken, maar het is wel iedere keer erg gezellig! Als goede vrienden zijn jullie een vaste waarde in tijden van ontspanning.

Papa en mama, bedankt om mij alle kansen te bieden om allereerst mijn studies en nadien dit doctoraat succesvol af te ronden. Bedankt om mij steeds te steunen in de richting die ik uitging. Mijn zussen en schoonbroers, Mireille en Johan, Veerle en Emeka, bedankt voor de luisterende oortjes en de morele steun. Céline en An-Sofie, veel succes met jullie studies. Amara, ik ben nog altijd super trots dat ik je meter mocht zijn. Samen met Tobenna zorg je voor de nodige afleiding en ontspanning. Nomso, als jongste supporter mag je hier zeker niet ontbreken.

Mijn schoonouders, Johan en Lut, ik voel me erg welkom in jullie gezin. Nele en Wim, Inne en Steven, Jitte en Ella, ook bij jullie voel ik mij 'thuis'. Bedankt hiervoor.

Last, but definitely not least, mijn grootste steun en toeverlaat. Lieve Joris, je bent geïnteresseerd in alles wat ik doe en steeds bereid om me te helpen. Dankjewel voor je eindeloze liefde en geduld. Dankjewel ook voor je persoonlijke touch aan dit werk. Ik kijk uit naar onze toekomst samen.

Bedankt,

Els 


\section{Curriculum Vitae}

Els De Smet was born on May 16, 1986, in Bilzen, Belgium. She completed secondary school at the Heilig-Hart college in Lanaken in 2004 (Latin-Mathematics). In 2009, she graduated as master of Biomedical Sciences at the Catholic University of Leuven (K.U.L). Her internship was spent at the department of Experimental Transplantation, Catholic University of Leuven. Under supervision of prof. dr. An Billiau and dr. Lien De Somer, she investigated immune mechanisms involved in graft-versus-leukemia after allogeneic bone marrow transplantation in mice. Since 2009, she has been working on her PhD thesis at the Department of Human Biology, Maastricht University. Her thesis describes several studies in relation to the role of plant stanol esters on intestinal lipoprotein metabolism. In 2013, she was nominated for the poster price at the European Atherosclerosis society in Lyon. 



\section{APPENDIX}

\section{List of publications}

De Smet E., Mensink R.P., Plat J. Effects of plant sterols and stanols on intestinal cholesterol metabolism: suggested mechanisms from past to present. Mol Nutr Food Res, 2012. 56(7): p. 1058-72.

De Smet E., Mensink R.P., Plat J. Acute effects of plant stanol esters on postprandial metabolism and its relation with changes in serum lipids after longer-term intake. Submitted

De Smet E., Mensink R.P., Konings M., Brufau G., Groen A.K., Havinga R., Schonewille M., Kerksiek A., Lütjohann D., Plat J. Acute effects of plant stanol esters on hepatic and intestinal lipid and lipoprotein metabolism in mice. Submitted

De Smet E., Mensink R.P., Boekschoten M.V., Wolfs T.G., Germeraad W.T., Plat J. An acute intake of plant stanol esters changes immune-related pathways in the jejunum of healthy volunteers. Submitted

De Smet E., Plat J., Mensink R.P. The effects of oral amoxicillin on serum lipids and glucose concentrations in slightly hypercholesterolemic subjects. Submitted

Plat J., Hendrikx T., Bieghs V., Jeurissen M.L.J., Walenbergh S.M.A., Gorp P.J., De Smet E., Konings M., Vreugdenhil A.C.E., Lütjohann D., Mensink R.P., Sverdlov R. Protective effects of plant sterol and stanol esters in diet-induced non-alcoholic steatohepatitis in hyperlipidemic mice. Submitted

Brüll F., De Smet E., Mensink R.P., Vreugdenhil A., Kerksiek A., Luetjohann D., Wesseling G.J., Plat J. Dietary plant stanol ester consumption improves immune function in asthma patients; results of a randomized double-blind clinical trial. Submitted 



\section{Abbreviations}

$\begin{array}{ll}\text { ABC } & \text { ATP-binding cassette transporter } \\ \text { ABCA1 } & \text { ATP-binding cassette transporter A1 } \\ \text { ABCG1 } & \text { ATP-Binding cassette transporter G1 } \\ \text { ABCG5 } & \text { ATP-binding cassette transporter G5 } \\ \text { ABCG8 } & \text { ATP-binding cassette transporter G8 } \\ \text { ACAT2 } & \text { acetyl-coenzyme A acetyltransferase } \\ \text { ACC1 } & \text { acetyl-coenzyme A carboxylase 1 } \\ \text { AMPK } & \text { AMP-activated protein kinase } \\ \text { apo } & \text { apolipoprotein } \\ \text { ATP } & \text { adenosine triphosphate } \\ \text { BMI } & \text { body mass index } \\ \text { Caco2 } & \text { colon carcinoma cell line } \\ \text { CD3 } & \text { cluster of differentiation number 3 } \\ \text { CD4 } & \text { cluster of differentiation number 4 } \\ \text { CD14 } & \text { cluster of differentiation 14 } \\ \text { CETP } & \text { cholesteryl transfer protein } \\ \text { chREBP } & \text { carbohydrate responsive element binding protein } \\ \text { CM } & \text { chylomicron } \\ \text { CVD } & \text { cardiovascular disease } \\ \text { EC50 } & \text { half maximal effective concentration } \\ \text { FAS } & \text { fatty acid synthase } \\ \text { FFA } & \text { free fatty acid } \\ \text { FFQ } & \text { food frequency questionnaire } \\ \text { FIAF } & \text { fasting induced adipose factor } \\ \text { Foxp3 } & \text { forkhead box P3 } \\ \text { GC-MS } & \text { gas-liquid chromatography-mass spectroscopy } \\ \text { GSEA } & \text { gene set enrichment analysis } \\ \text { HDL } & \text { high-density lipoprotein } \\ \text { HepG2 } & \text { human hepatocellular liver carcinoma cell line } \\ \text { HMG-CoA } & \text { 3-hydroxy-3-methyl-glutaryl-CoA } \\ \text { HPRT1 } & \text { hypoxanthine-guanine phosphoribosyltransferase } \\ \text { hsCRP } & \text { high sensitive C reactive protein } \\ \text { iACC } & \text { incremental area under the curve } \\ \text { IBMT } & \text { intensity-based moderated T-statistics } \\ \text { IDL } & \text { intermediate-density lipoprotein } \\ \text { IPA } & \text { ingenuity pathway analysis } \\ \text { LAS } & \text { leica application suite } \\ \text { LDL-C } & \text { low-density lipoprotein cholesterol } \\ \text { LDLr } & \text { low-density lipoprotein receptor } \\ \text { LPS } & \text { lipopolysaccharide } \\ \text { LXR } & \text { liver X receptor } \\ \text { MRP1/ABCC1 } & \text { multidrug resistance protein 1 } \\ \text { MTTP } & \text { microsomal triglyceride transfer protein } \\ \text { NiDAB } & \text { nickel sulfate-diaminobenzidine } \\ \text { NMR } & \text { nuclear magnetic resonance } \\ \text { NPC1L1 } & \text { niemann-Pick C1-Like 1 } \\ \text { PBMC } & \text { peripheral blood mononuclear cells } \\ & \end{array}$




\section{APPENDIX}

PCSK9 proprotein convertase subtilisin/kexin type 9

PGC-1a peroxisomal proliferator-activated receptor coactivator

RIA

RNA

SCFA

radioimmunoassay

ribonucleic acid

SREBP-1C

SREBP2

SULT2B1

TAG

TC

TCR

Th1

short-chain fatty acids

sterol regulatory element binding protein- $1 \mathrm{c}$

sterol regulatory element binding protein 2

sulfotransferase family cytosolic 2B member 1

triacylglycerol

total cholesterol

T-cell receptor

T-helper-1 cell

T-helper-2 cell

Th2

transintestinal cholesterol excretion

TLR4

toll-like receptor 4

TNFa

Treg

VLDL

VILL

tumor necrosis factor $\alpha$

regulatory $\mathrm{T}$-cell

very low-density lipoprotein

villin 1-like protein 